\title{
Insecticide-treated bednets (ITNs) for malaria control : factors relevant for utilization in a western Kenyan community
}

Citation for published version (APA):

Alaii, J. A. (2003). Insecticide-treated bednets (ITNs) for malaria control : factors relevant for utilization in a western Kenyan community. [Doctoral Thesis, Maastricht University]. Universiteit Maastricht. https://doi.org/10.26481/dis.20030625ja

Document status and date:

Published: 01/01/2003

DOI:

10.26481/dis.20030625ja

Document Version:

Publisher's PDF, also known as Version of record

\section{Please check the document version of this publication:}

- A submitted manuscript is the version of the article upon submission and before peer-review. There can be important differences between the submitted version and the official published version of record. People interested in the research are advised to contact the author for the final version of the publication, or visit the DOI to the publisher's website.

- The final author version and the galley proof are versions of the publication after peer review.

- The final published version features the final layout of the paper including the volume, issue and page numbers.

Link to publication

\footnotetext{
General rights rights.

- You may freely distribute the URL identifying the publication in the public portal. please follow below link for the End User Agreement:

www.umlib.nl/taverne-license

Take down policy

If you believe that this document breaches copyright please contact us at:

repository@maastrichtuniversity.nl

providing details and we will investigate your claim.
}

Copyright and moral rights for the publications made accessible in the public portal are retained by the authors and/or other copyright owners and it is a condition of accessing publications that users recognise and abide by the legal requirements associated with these

- Users may download and print one copy of any publication from the public portal for the purpose of private study or research.

- You may not further distribute the material or use it for any profit-making activity or commercial gain

If the publication is distributed under the terms of Article $25 \mathrm{fa}$ of the Dutch Copyright Act, indicated by the "Taverne" license above, 
Insecticide-treated bednets (ITNs) for malaria control

Factors relevant for utilization in a western Kenyan community

Jane A. Alaii 

Insecticide-treated bednets (ITNs) for malaria control

Factors relevant for utilization in a western Kenyan community

PROEFSCHRIFT

ter verkijging van de graad van doctor aan de Universiteit Maastricht,

op gezag van de Rector Magnificus,

Prof. Dr.A. C. Nieuwenhuizen Kruseman,

volgens het besluit van het College van Decanen,

in het openbaar te verdedigen

op woensdag 25 juni 2003 om I 2.00 uur

door

Alaii, Jane Adhiambo 


\title{
Promotors
}

Prof. Dr. H.W. van den Borne

Prof. Dr. S. van der Geest - Universiteit van Amsterdam

\section{Co-Promotor}

Dr. Penelope A. Phillips-Howard - CDC/KEMRI

\author{
Beoordelingscommissie \\ Prof. Dr. N.K. de Vries (voorzitter) \\ Prof. Dr. G.J. Dinant \\ Prof. Dr. P. Reddy (Medical Research Council, South Africa) \\ Prof. Dr. P. Streefland (Universiteit van Amsterdam) \\ Dr.A.Verbon
}

ISBN: 90-568I-| 70-3

\section{Lay out and cover design}

Nora Oosting \& Leo Zander, Maastricht

\section{Printed by}

Unigraphic Maastricht

\section{(C) Copyright Jane Alaii \& CDC/KEMRI}

All rights reserved. Illustrations and brief excerpts from this work may be used for scientific and educational purposes provided that the source is acknowledged. 


\section{Funding and support}

Fieldwork for these studies was supported by the United States Agency for International Development (USAID). Student support towards this thesis was received from the Netherlands Foundation for the Advancement of Tropical Research (WOTRO [grantWB52853]). Other support towards health education to improve child adherence with bednets was received from the Fund for Good Causes (Loon op Zand, NL). The Kenya Medical Research Institute (KEMRI), and the Centers for Disease Control and Prevention (CDC), Kenya Field station, provided the infrastructure and logistical support necessary for the studies. The study presented in this thesis was included in the research programme of the Care and Public Health Research Institute (CAPHRI), which participates in the Netherlands School of Primary Care Research (accredited by the Royal Dutch Academy of Sciences (KNAW).

\section{Disclaimer}

The material presented in this thesis must not be construed as reflecting the views whatsoever of the Kenya Medical Research Institute (KEMRI), the Centers for Disease Control and Prevention (CDC), or the Research Institute, CAPHRI, Maastricht University. Care has been taken to ensure the accuracy of the information presented, and the author alone is responsible for the views and any omissions herein. Any use of trade names is for identification purposes only and does not imply endorsement by the author. 


\section{DEDICATION}

To all deserving individuals who strived for the same, but never quite got the opportunity. 


\section{CONTENTS}

Chapter 1 General Overview 9

Chapter 2 Sleeping arrangements in a rural community in western Kenya: Relevance for bednet utilization

Chapter 3 Care seeking for childhood malaria in western Kenya: knowledge, attitudes, perceptions and behaviour (KAPB) before and after a trial of insecticide-treated bednets

Chapter 4 Malaria knowledge and prevention: people's perceptions before and after a randomised controlled trial of bednets in western Kenya

Chapter 5 Community reactions to the introduction of permethrin-treated bednets during a randomised controlled trial in western Kenya

Chapter 6 Factors affecting use of permethrin-treated bednets during a randomised-controlled trial in western Kenya

Chapter 7 Insecticide-treated bednets in western Kenya: social and cultural variables in relation to adherence during and after a randomised-controlled trial

Chapter 8 Effect of child training in bednet mounting skills on child adherence with bednet use in western Kenya

Summary

Samenvatting

Appendices Principal components analysis, and staging guide

Acronyms

Acknowledgements 



\section{CHAPTER I}

\section{GENERAL OVERVIEW}

The studies reported in this thesis formed part of a multi-disciplinary investigation into malaria control during a two-year trial of insecticide-treated bednets in rural western Kenya (Phillips-Howard et al., 2003[a]) and thereafter for two more years, March 1996 - January 1999 and May 1999 - May 2001 respectively. This chapter presents a general overview of malaria as a major public health problem, outlining the magnitude of its burden globally and in Africa, attempts to tackle the disease, including the use of insecticide-treated bednets. The rationale and conceptual framework for the studies making up the thesis are also presented. In the outline of the thesis we present a summary of the designs and conclusions drawn for each individual study. The chapter closes with general conclusions and recommendations pooled from all the studies included in this thesis. 


\section{WHAT IS MALARIA?}

Malaria is a potentially fatal parasitic disease caused by protozoan Plasmodium, and mainly transmitted to humans through the bite of an infected female mosquito genus Anopheles. Malaria may also be transmitted through transfusions of infected blood, and from an infected pregnant woman to her unborn child (NIAID, 2000). The disease is characterised by cyclical bouts of fever, headache, muscle and joint pains, nausea, and general malaise. Untreated malaria can result in anaemia, kidney failure, coma, and death. All vertebrates, both human and animal can be infected with malaria parasites. Humans are generally host to four types of malaria including P. falciparum, P. vivax, P. ovale, and P. malariae (Gilles \& de Meillon, 1968). P. Falciparum is most common and virulent. It multiplies most rapidly and can clog small blood vessels, resulting in dangerous complications such as cerebral malaria (Lankinen et al., 1994). Due to repeated attacks of malaria, many semi-immune people in high-risk areas of the tropics may carry disease parasites without being ill. However, because they are yet to develop immunity for malaria, children below five years of age are particularly vulnerable to disease. Malaria in pregnancy contributes to neonatal and maternal mortality, and causes low birth weight infants (WHO, 1996).

\section{MALARIA AS A GLOBAL PRIORITY}

Malaria remains a leading health problem in the tropics and sub-tropics, affecting populations in Asia, Africa, and South and Central America. Although once thought eradicable ${ }^{1}$, and simple and effective treatments for malaria exist, morbidity and mortality from the disease is on the rise, with an estimated 300-500 million clinical cases, and over one million deaths globally annually (WHO, 1996a). Poor populations particularly in rural areas carry the overwhelming burden of disease - they often cannot access effective treatment due to inadequate infrastructure and limited resources. By itself, malaria impoverishes soci-

\footnotetext{
I In 1955, the World Health Assembly adopted Global Malaria Eradication based on DDT and anti-malaria drugs, resulting in the eradication of malaria by 1967, mainly in developed countries. The campaign was not considered feasible for much of tropical Africa, thus the continent barely benefited from it (Nchinda, 1998; Trigg \& Kondrachine, 1998). Malaria has virtually been wiped out in temperate climates (NIAD, 2000). Elsewhere, the achievements of the eradication campaign proved unsustainable; hence the shift from eradication to control marked by the endorsement of the Global Malaria Control Strategy at a Ministerial Conference on Malaria Control in 1992 (Trigg \& Kondrachine, 1998).
} 
eties, undermining development as it reduces the productivity of sick people and their caretakers (Sachs \& Malaney, 2002).

The marked increase in malaria in the last two decades has been linked mainly to the continued rapid spread of parasite and vector resistance to drugs and insecticides respectively (WHO, 1997; Lengeler et al., 1996). The resurgence of malaria in some regions may be linked to expansion of breeding grounds resulting from global changes in the environment and habitat (Lindsay \& Birley, 1996; RBM/WHO 2001). Deteriorating health systems and population displacement are also linked to increased disease in areas endemic for vector-borne diseases including malaria (NIAID 2000; Nchinda, 1998). Searches for a malaria vaccine remain elusive (Graves \& Gelband, 2003), and alternative drugs are not only increasingly toxic (Marsh \& Snow, 1997), but also unaffordable for most affected populations in the developing world (Phillips \& Phillips-Howard, 1996).

\section{MALARIA IN SUB-SAHARAN AFRICA}

Africa bears the brunt of the malaria burden, accounting for $90 \%$ of global malaria morbidity and mortality (RBM/WHO, 2001). It is estimated that one in every twenty (20) children dies from malaria before the age of five years (WHO, 1993). In Africa, mortality risks have increased significantly over the past decades, coupled with the spread of drug resistance, particularly of chloroquine $^{2}$ (Snow et al., 1999). The incidence of malaria continues to grow, with an estimated 40 percent increase between 1970 and 1997 in sub-Saharan Africa (WHO, 1999). Overall, malaria is responsible for 15\% loss in all disabilityadjusted life-years (DALYs) ${ }^{3}$ in Africa (World Bank, 1993). The disease accounts for at least $1.3 \%$ reduction in Africa's economic growth annually with approximately US\$ 12 billion annual losses both as a direct and indirect cost of disease (Gallup \& Sachs, 2001).

2 Chloroquine, introduced in the mid-1940s, has been the most widely used therapeutic anti-malarial. It was for a long time the drug of choice for first-line treatment of malaria infections for its low cost, low toxicity, and until recently, its effectiveness against all forms of malaria. It appears that no other anti-malarial has offered so many positive properties and so few contradictions to its use (Foster, 1995).

3 The DALY (Disability-Adjusted Life Year) is a quality of life measurement that quantifies the burden of disease in a population, combining both morbidity and mortality effects. It is an estimate of total years of healthy life lost due to premature death and loss to healthy life due to disability or handicap, adjusting for severity of disability. One DALY lost is equivalent to one year of healthy life lost (World Bank, 1993). 
The extremely high burden of the disease in Africa is attributed to two main factors. Firstly, both P.falciparum, the most dangerous type of malaria, and Anopheles Gambiae, the most efficient vector of malaria transmission predominate most climatic zones of Africa, with high transmission rates in vast areas.

Secondly, areas endemic for malaria are often also the poorest. Poor people, as in much of Africa, tend to be physically marginalized, living in less developed areas, where control tools may not be easily accessible (WHO, 1997; WHO, 1999). With the increasing spread of parasite and vector resistance to old and new drugs and insecticides, coinciding with the resurgence of malaria linked to war, climatic change, and inadequate health systems, no quick victory is anticipated (WHO, 1999).

\section{COMBATING MALARIA}

While the development of new control tools is essential, it is equally recognized that much of the morbidity and mortality associated with malaria could be reduced, provided that existing tools are made accessible and are effectively used (RBM, 2000). Preventing mortality and reducing illness through improved access to prompt diagnosis and effective treatment remain key targets of the current global malaria control strategy (WHO, 1993; WHO, 1993[a]).

However, since the resurgence of malaria is compounded by the spread of drug resistance, prevention and selective vector control have become quite significant (WHO, 1993). Among these, insecticide-treated bednets ${ }^{4}$ (ITNs) and curtains have emerged in recent years as the most practical (Lengeler, et al., 1996). The health impact of insecticide-treated bednets was determined in research trials in The Gambia (Alonso et al., 1991), Ghana (Binka et al., 1996), the Kenyan coast (Nevill et al., 1996), and Burkina Faso (Hablutetzel et al., 1997). It is estimated that 6 lives could be saved for every 1,000 children protected under bednets translating to approximately 336,000 malaria deaths averted if every child slept under ITNs (Lengeler, 2003). Successful malaria prevention using ITNs could also decrease demand for new drugs and slow down the spread of resistance

\footnotetext{
4 The term bednets is used to refer to mosquito nets and all netting material used as barriers to mosquito biting. Bednets have long been used as a form of personal protection against malaria. The only less familiar aspect of bednet use is the combination of insecticide and netting material (Lengeler et al., 1996), although it has a long history (Lindsay \& Gibson, 1988) dating back to the World War II (Harper et al., 1947). Insecticide-treated materials have an added advantage of repelling and/or killing mosquitoes, thus offer protection even with torn nets, or when body parts are in contact with netting (Lengeler et al., 1996).
} 
(WHO, 1999). In a concerted effort towards achieving their widespread application, the World Health Organization (WHO), through its Roll Back Malaria (RBM) movement ${ }^{5}$, has pledged that by the year 2005 , up to $60 \%$ of children and pregnant women in endemic areas will have access to insecticide treated bednets (Nabarro, 1998; WHO, 1999).

\section{INSECTICIDE-TREATED BEDNETS (ITNS)}

Effective application of insecticide-treated bednets for malaria control comprises three main components including bednet acquisition or ownership, regular retreatment of bednets with insecticide, and using bednets correctly and/or consistently. The successes achieved in efficacy trials have been associated with strict research conditions to maintain regular use of bednets and bednet re-treatment. The realities of bednet use, however, differ to that in a controlled environment. In areas of low bednet use and where bednets are used mainly for reasons other than disease prevention, optimal adherence ${ }^{6}$ is often not easily achievable. People primarily use bednets to avoid nuisance biting, rather than for malaria prevention (Zimicki, 1996), hence irregular use. In Ghana, a 97\% adherence rate recorded at the beginning dropped to $50 \%$ after two years, and further to $20 \%$ in the hot dry season (Binka \& Adongo, 1997). In coastal Kenya, informal post-intervention observations estimate a fall from $80 \%$ to $7 \%$ coverage of treated bednets (Snow, RW; personal communication July 1998). Differentials in coverage during the Gambian trial (Alonso et al., 1991) and an evaluation of a national programme in the same country (D'Alessandro et al., $1995)$ illustrate the dilemmas of going to scale outside of ideal research conditions (Lengeler, 2003). The introduction of bednet re-impregnation charges

\footnotetext{
5 Roll Back Malaria (RBM), is a global partnership to reduce by half the global malaria burden by the year 2010, and halving it again by the year 2015. It was founded in 1998 by the governments of countries affected by malaria, the WHO, the UN Development Programme (UNDP), the UN Children's Fund (UNICEF), and the World Bank. RBM aims to build on the currently standing WHO global malaria control strategy endorsed in Amsterdam, 1992, (WHO, 1993) and using past experience, develop a new health sector-wide approach to combat malaria, with communities and country priorities at the centre of the movement (WHO, 1999).

6 Adherence or compliance is the extent to which a person's behaviour (in terms of taking medications, or executing lifestyle changes) coincides with recommended advice. However, the term compliance is perceived suggestive of coercion, while adherence suggests dialogue and compromise. Throughout this thesis we use the terms interchangeably within the context of the main definition.
} 
resulted in a marked drop in coverage (from $>70 \%$ to $25 \%$ ), resulting in a return in child mortality to pre-intervention levels (D’Alessandro et al., 1995). The implication is that it does not matter how efficacious an intervention is, rather, if compliance with use is low, the effectiveness will be poor. If ITNs are to be successful against malaria, their effective implementation, promotion and sustainability over time will require appropriate behavioural changes, not just providing bednets to increase coverage.

\section{THE SOCIAL CONTEXT OF MALARIA}

As with any tool designed for disease control, it is important to identify behavioural and social risk factors for disease, and other constructs within the array of human behaviour and social functioning that may impede or enhance the intervention (Green \& Kreuter, 2001). Most health communication interventions for infectious diseases in African countries portray behaviour change as a simple knowledge and action issue - suggestive that awareness attainment should automatically result in enactment of required behaviours. For these interventions, uniform and rather static messages are typically designed often focusing on how to recognize and treat individual symptoms of disease, with the expectation that this should promote a "simple action". While health education is an essential basis for making informed decisions, post-ITN trial observations concur that knowledge on its own is not enough and does not guarantee required action. Appropriate bednet use will require an approach going beyond simply raising awareness. Success rests largely on sustained behaviour change that people are willing to make night after night even when they are healthy and may not perceive a significant risk of disease - making bednet use a nightly year round tradition.

Behavioural theory distinguishes between knowledge and action, that even after the acquisition of relevant knowledge and skills, other important intervening factors exist. Thus, even when benefits seem obvious, the adoption of new behaviours may still fail to take place (Rogers, 1995). While it may seem that individuals make independent decisions, these tend to be situated within a myriad of interacting factors including people's intention and readiness for change - in turn influenced by the attributes of the innovation, the required behaviour, the individual, and his social environment (Prochaska et al., 1992; Bandura, 1986; Rogers, 1995). In other words, the adoption of new ideas, if and when people adopt them, and how they deploy them will depend on a mix of factors including perceived risk, perceived benefits of the intervention, the perceived subjective norm, and the skills necessary for effective deployment of the intervention (Janz \& Becker, 1984; Fishbein \& Ajzen, 1975; Bandura, 1986; 
Rogers, 1995; Prochaska et al., 1992). Bandura (1986) suggests that even in the event that all the conditions have been met, one's perceived self-efficacy - confidence in their ability to undertake and persist in the required action - remains an important determining factor for action (Bandura, 1986). The implication is that when planning programmes that require changes in behaviour, it is essential to understand people's perceptions of disease and attitudes toward a proposed intervention, the influence of the social or subjective norm on that behaviour, and people's readiness for change. Interventions are then tailored around this knowledge to maximise acceptability and sustainability.

\section{CONCEPTUAL FRAMEWORK}

Theories of behaviour change have been used successfully in retrospective, cross-sectional and longitudinal studies of problem behaviours related to smoking, dietary, and physical exercise habits (Glanz et al., 1997). However, there seems to be minimal application of theory-based approaches to infectious disease control programmes. In the context of malaria control using insecticidetreated bednets, we applied these theories, some implicitly, others directly, to study environmental and structural factors that might impact on correct bednet use. A theoretical approach goes beyond describing behaviours in specific situations, by providing a basis for generalisations to other situations. We used theory to guide systematic interpretation of research already undertaken, and planning of research yet to be undertaken, and to describe variables relevant for effective bednet utilization.

Building upon experiences from previous bednet studies (MacCormack \& Snow, 1986; Brieger et al., 1996; Winch et al., 1996; Marsh et al., 1996; Binka \& Adongo, 1997), and on cognitive processes that suggest that one will perform an action that maximises positive outcomes or that which minimises negative outcomes (Fishbein \& Ajzen, 1975; Prochaska et al., 1992; Rogers, 1995;

Bandura, 1997), we assessed factors affecting bednet use with an emphasis on identification of predisposing factors for positive and/or negative behaviour. During assessments we focussed on understanding the malaria problem in the community, including community knowledge of the disease, the value attached to bednets, and the implications for promoting adherence with insecticidetreated bednets as a malaria control intervention. Core questions included sociocultural and environmental motivations and/or constraints to malaria control using bednets, particularly factors influencing children's coverage and adherence with bednet use. The theories implicit in our study include the theory of planned behaviour (Ajzen, 1991) and diffusion of innovations theory (Rogers, 1995). Theories applied explicitly in the study included the stages of change 
construct from the Trans-theoretical Model (Prochaska et al., 1992) and the Social Cognitive Theory (Bandura, 1986). A common assumption underlying these theories is the importance of motivation to undertake a specific behaviour.

\section{The theory of planned behaviour}

The theory of planned behaviour [TPB] (Ajzen, 1991), an extension of the theory of reasoned action [TRA] (Fishbein \& Ajzen, 1975), defines the relationship between beliefs, attitudes and behaviour, stipulating that intention is the primary determinant of behaviour. Intention is influenced by three factors including attitudes toward performing the behaviour, the perceived subjective norm on that behaviour, and perceived behavioural control. One's attitudes toward performing the behaviour are dependent on their evaluation of the perceived benefits of the behaviour, whether one's peers approve of the behaviour (Fishbein \& Ajzen, 1975), and whether one feels in volitional control of performing the behaviour that is required (Ajzen, 1991). This theory is implicit in knowledge, attitudes, and practices (KAP) surveys that have become a standard approach to examining people's beliefs and practices in relation to disease and community receptiveness of disease control interventions. We applied the same to study people's malaria knowledge and attitudes, and how these shape their care seeking and perceptions of interventions such as insecticide-treated bednets.

\section{The diffusion theory}

Defining diffusion as the communication of a new idea, Rogers (1995) draws attention to the perceived newness of the idea as affecting a target groups' decision to either adopt or reject it, adding that regardless of advantages, getting new ideas adopted is often very difficult. Some key issues to address in the diffusion process include understanding the characteristics of adopters at different stages of social change, how the perceived attributes of the innovation might affect its adoption rate, and the influence of interpersonal networks.

Characteristics of the innovation are particularly important in understanding adoption rates. These include its perceived advantage, its compatibility with existing norms, the ease with understanding and applying it, the extent to which people might be able to try it out before making a decision about it, and the extent to which the positive results associated with it are visible to the user. Concepts from the diffusion theory were used to interpret early operational research findings, and to suggest a course of action. 


\section{The stages of change model}

The stages-of-change is one of four constructs of the trans-theoretical model (TTM) (Prochaska \& Di Clemente, 1983). Two critical assumptions of the TTM are that change is not a discrete event, and that no single theory can effectively address behaviour change. It provides, therefore, based on its stages of change construct an integrative framework for pooling processes and principles across major theories to address change - hence the name trans-theoretical (Prochaska et al., 1992). The stage of change construct represents a temporal dimension of change, involving progress through a series of five main stages expressed in terms of intent to act, or actual action undertaken, and expressed in terms of duration. The stages include pre-contemplation, contemplation, preparation, action, and maintenance. Relapse, an additional stage, can occur at any point in the change continuum (Prochaska \& Di Clemente, 1983). Termination (abstinence), a sixth stage mainly applicable to addictive behaviours such as smoking, and possible for other behaviours such as multiple sex partners, has recently been identified. The implication is that not all modifications of behaviour count as action. A key principle is that each stage has its own peculiar characteristics and needs, thus interventions will be more efficacious and cost-effective when they are matched to individual stages.

\section{Social cognitive theory (SCT)}

The social cognitive theory (SCT) distinguishes between knowledge and action; that besides knowledge, there may be other intervening factors that finally influence the course of action people take (Bandura, 1986). Like the Health Belief Model (Becker, 1974), SCT emphasizes the importance of perceived benefits - that the person must perceive the benefits of performing a given behaviour as outweighing the costs (Bandura, 1986). Also, the person must have a sense of self-efficacy regarding performing a required behaviour. Self-efficacy, a concept fairly equivalent to perceived behavioural control (Ajzen, 1991), refers to ones belief to be capable (have the skills and abilities) of performing a given behaviour (Bandura, 1997). The Social Cognitive Theory therefore emphasizes the need to address cognitive and environmental factors that are more likely to influence the adoption, implementation and sustained use of an intervention (Bandura, 1986). Principles from the social cognitve theory and the stages of change theory were integrated in quasi-experimental studies targeting caregivers and school age children, aimed at determining factors governing child bednet use in individual households. 


\section{GOAL AND OBJECTIVES}

The overall goal was to investigate acceptability of bednets and factors impacting on insecticide-treated bednet (ITNs) use in western Kenya, and the implications for the design of health education and promotional interventions for sustained long-term malaria control using ITNs.

The specific objectives were,

1 To assess local sleeping arrangements including existing bednet use practices, and their relevance for bednet utilization.

2 To determine community malaria knowledge and beliefs as well as care seeking for malarial diseases, and the implications for implementing strategies to reduce morbidity and mortality due to malaria.

3 To determine the perceived effectiveness of insecticide-treated bednets, their acceptability, and the implications for promoting ITNs for malaria control.

4 To determine environmental and structural variables impacting on adherence with bednet use and the implications for health promotion design to promote ITNs.

5 To assess the effectiveness of a pilot training programme for school aged children in mounting bednets, and the implications for involving children in achieving public health outcomes.

\section{DESIGN AND METHODS}

\section{Background and rationale}

A randomised-controlled trial of the efficacy of insecticide-treated bednets was conducted in a rural population in western Kenya between March 1996 and January 1999 (Phillips-Howard et al., 2003 [a]). This was followed immediately by a follow-up study to investigate the effect of long-term exposure to ITNs on immune response to malaria (May 1999 - May 2001). Both studies were multidisciplinary (Figure 1.1), including the social science studies from which this thesis draws. While randomised controlled trials are designed to study the efficacy $^{7}$ of an intervention, it was our premise that bednets differ from most other controlled interventions in that they require continued active participation by

\footnotetext{
7 Efficacy refers to the potential impact of an intervention, when applied in almost ideal conditions such as in carefully controlled research trials. Effectiveness refers to the extent to which the same intervention, when deployed in real life conditions, could achieve results similar to those observed in a controlled environment.
} 


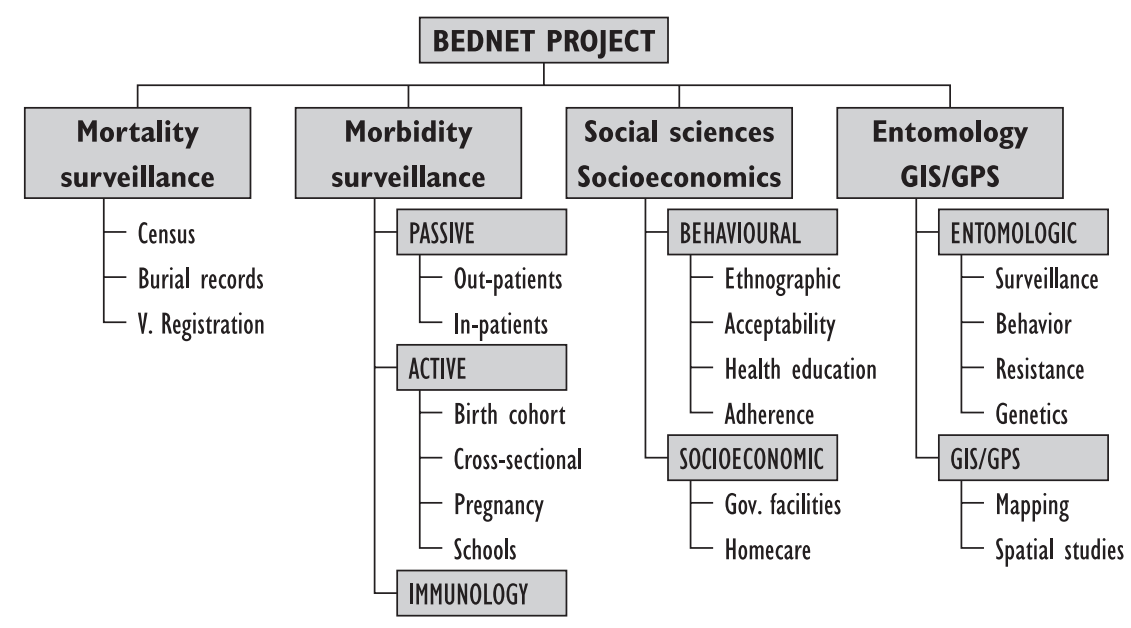

Figure I.I Summary of scientific disciplines within the western Kenya bednet project (I996-200 I)

the study population, to adhere each night with bednet use. This provides an opportunity to learn about behavioral traits that might impact on effectiveness, thus generating relevant information for national programmes

Prior to the bednet study, meetings were held with government officials (Division Officers, Chiefs, and Assistant Chiefs) to explain the purpose of the ITN trial. Open community meetings (baraza) were conducted to solicit the support and participation of the villagers and to answer questions about the proposed study and its multi-disciplinary components. Local language (Dholuo) and English leaflets describing the project were distributed as a reinforcement of issues of interest, and for sharing with families back home. Messages were mainly conveyed by word of mouth - using folk songs, poetry, and community meetings as media. Key messages emphasized the need for child adherence, addressing questions why children were the main targets for malaria prevention. Other messages reminded participants that bednets were only as effective as they were used, hence the importance of seeking prompt treatment for children showing malaria symptoms.

\section{Study area and population characteristics}

The study site is situated in Bondo District, Western Kenya. The climate is typically tropical and has a bimodal rainfall pattern averaging $1000-1800 \mathrm{~mm}$ per year. Asembo, administratively referred to as Rarieda Division, covers $200 \mathrm{~km}^{2}$ 


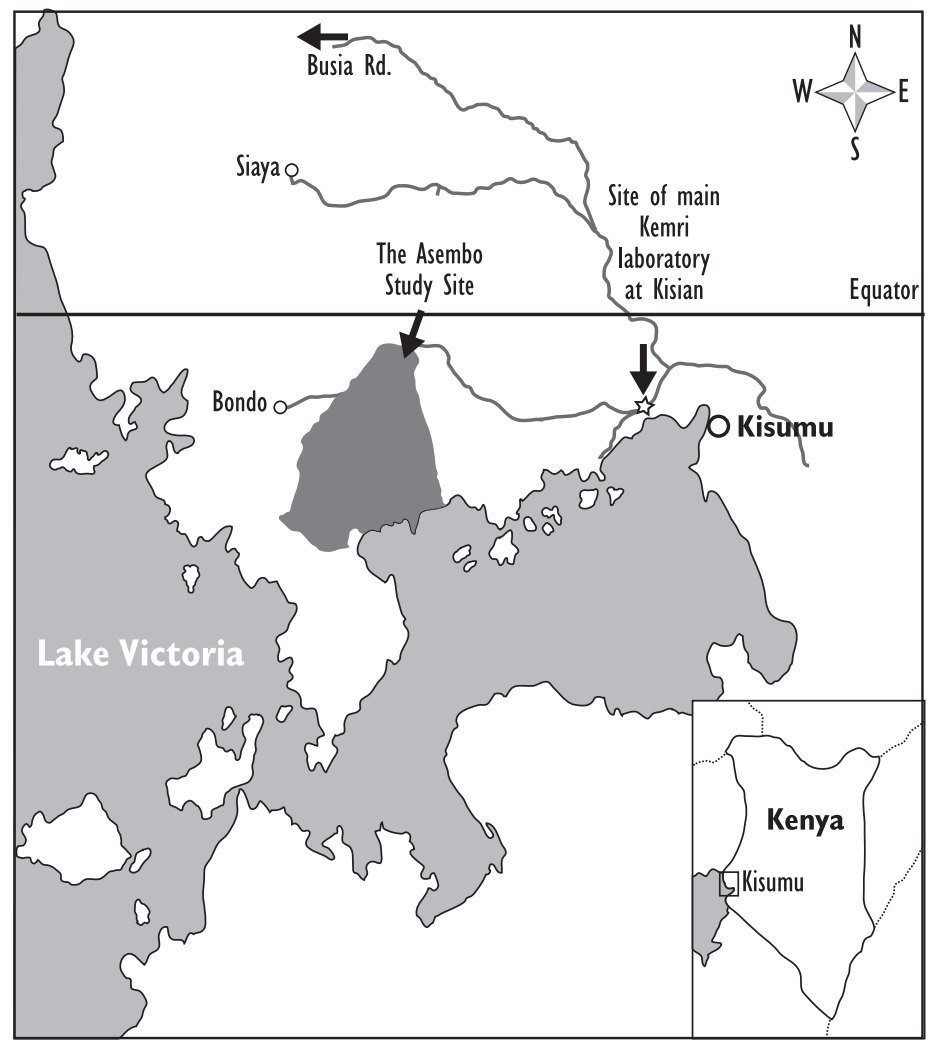

Figure 1.2 The study location, showing the field site, Asembo, and the research station, Centre for Vector Biology and Control Research (CVBCR), KEMRI

on the north-eastern shores of Lake Victoria (Figure 1.2), and has a population estimate of 55,000 people $-15 \%$ children under 5 years of age (PhillipsHoward et al., 2003 [b]). Ninety-six percent of the study population are members of the Luo ethnic group. Except for market centres, the population is highly dispersed, and the inhabitants live in family homesteads (dala/mier) surrounded by their agricultural fields. Homesteads within each village consist of one or more (average of four) households (Phillips-Howard et al., 2003[b]). The most common type of house is the two-roomed traditional Luo hut, which has a stick framework, plastered with mud, a grass-thatch roof, and one door. It is not uncommon for houses to lack windows, but eaves are open, allowing easy entrance and exit for mosquitoes. Bednet coverage before the ITN trial was below 5\% (Alaii, 1997). 
Asembo has a subsistent peasant economy comprising cultivation and limited animal farming made up either of a few heads of cattle, goats, or chicken. Off farm activities include fishing, an important component of the economy of lakeside ethnic communities (Cohen and Atieno-Odhiambo, 1989) and retail outlets. Men mostly migrate to seek jobs in towns, returning home once a month or once a year depending on distance - women and children are often left in the village home both to cut down on expenditure costs of living in towns, and to oversee family property in the rural home.

Malaria transmission in the study area occurs throughout the year with two seasonal peaks reflecting the bimodal rainfall pattern. The main malaria vectors in the study area are An. gambiae and An.funestus, with some transmission attributed to An. arabiensis. Entomologic inoculation rates are estimated to range from an average of 60 to 300 infective bites per person per year in Asembo (Sexton et al., 1990; Beach et al., 1993; Beier et al., 1994). Studies in the course of the bednet trial estimated under-five mortality at 275/1000 live births. A detailed description of the study site and population may be found in Phillips-Howard et al., 2003 [b].

\section{Target populations}

Research questions mainly targeted factors affecting bednet use, particularly with regards to children, the primary target of malaria control interventions. Interviews targeted mainly mothers or child caregivers, and school-age children. Mothers and caregivers in their traditional role as the immediate household managers and first source of care of children played an important role in helping identify the factors that influence equity and coverage issues in the home. Assessments comprised complementary qualitative and quantitative research conducted in three components including formative research, studies evaluating changes in community knowledge of malaria and perceptions of bednets, and studies to monitor adherence with bednet use.

\section{Data management}

Qualitative research was used to gain an in-depth understanding and a general representation of contextual issues regarding malaria and use of insecticidetreated bednets. Field notes were transcribed and typed into word-processors as it was collected. Expanded notes were explored manually, checking for emerging themes and summarizing into quantifiable information (counts) and/or incorporated into verbatim reports that were used as vignettes to quantitative studies. Quantitative data were coded and entered using Clarion ${ }^{\circledR}$, Rel. 2.1 (Clarion Software Corp.) into data screens with automatic range and consistency checks. As per standard practise at the field station, data were further checked 
for consistency using SAS ${ }^{\circledR}$, Rel. 8.1 (SAS Institute Inc., Cary, NC, USA). Analyses were mainly performed using SPSS ${ }^{\circledR}$, Rel. 9.0 - 11.0 (SPSS Inc., Chicago, IL, USA), and in some instances, SUDAAN (Research Triangle Park, NC, USA) and SAS software packages.

\section{Ethical considerations}

All research in the different disciplines of the study on insecticide-treated bednets underwent relevant institutional review processes under the umbrella of the larger bednet project. Clearance was given under the Kenya Medical Research Institute (KEMRI), Nairobi, Kenya, and the Centers for Disease Control and Prevention (CDC), Atlanta, USA ethical review boards. Study participants were informed that participation in all the studies was voluntary, and informed written (in Dholuo, the local language) consent to participate obtained as appropriate. All data, including tape-recorded discussions were stored out of the reach of unauthorized persons and used for research purposes only. Also, to ensure anonymity, identifiers such as participants' names were not included in reports. Age and sex homogeneity during group interviews and/or discussions were applied as appropriate.

Where consent was denied, we did not persist but substituted homes as appropriate. In addition, for security assurance during night spot-checks, the spot-check team was accompanied by a well-known villager held in high esteem.

\section{Design, thesis outline, and main findings}

This section presents an overview of the design, methods, and main findings. Specific methodological details and discussion of findings are presented in individual chapters of the thesis as appropriate. Evaluation of community malaria knowledge overlapped time frames between formative research and the end of the bednet trial, thus chapter presentation in the outline below does not necessarily follow a linear sequence.

\section{Formative and early operational research}

Formative and operational research conducted prior to and immediately after the distribution of insecticide-treated bednets included descriptions of sleeping arrangements and community reaction to ITNs respectively. These aimed to gauge community acceptability of bednets, and the relevance for bednet utilization and health education design. These studies did not involve explicit use of behavioural theory, although theoretical concepts are implicit in the methodologies applied.

Purposive sampling - deliberate inclusion of participants based on researcher expectations that they might provide relevant answers - was used to draw 
mothers for the sleeping arrangements study, presented in chapter 2 . The study describes a general representation of local sleeping arrangements, especially for children, and malaria-related knowledge and practices, including existing bednet use. Caregivers for children $<5$ years of age were interviewed using focus group discussions, in-depth interviews, and a household questionnaire. Important findings indicated participants perceived bednets to prevent mosquitoes that cause malaria, and not malaria per se - thus bednet use was seasonal, and the preserve of adults, rather than children. Pending behaviour change, a programme targeting children would have to issue bednets to cover all sleeping spaces to ensure coverage for children. The complexity of malaria transmission implies that explaining that bednets prevent mosquito biting, which is the sole cause of malaria, may be more effective than simply stating that bednets prevent malaria.

After distributing insecticide-treated bednets free of charge, an array of social and cultural issues associated with the ITN project became apparent (Chapter 5). Random inclusion (by lottery method) of villages, followed by self-inclusion of participants (mainly targeted at child caregivers) was applied for a participatory study into immediate community reticence to use bednets.

Explorations with 323 participants indicated a combination of misconceptions about the use of insecticide in bednets, lack of congruity between preventing nuisance biting versus disease prevention, and concepts of multiple causation of malaria collectively prevented people from immediately perceiving the potential benefits of ITNs for malaria control. The findings highlighted what Rogers (1995) terms the innovation decision stage during which people require information to reduce uncertainty about an intervention, prompting us to revisit health education on the project - moving on from awareness creation to more practical issues including providing correct information designed specifically to address people's concerns and fears about the intervention. Our experience raises caution for programmes not to place too much emphasis on positive results while failing to recognize that change is a gradual process evolving in stages, with different needs arising at each stage.

\section{Evaluation of community malaria knowledge}

Formative and early operational studies were validated through quantitative studies presented in chapters 3 and 4. A standardised questionnaire was used prior to and at the end of the bednet trial to assess changes in people's knowledge of malaria, including care seeking and perceptions of bednets. Independent random samples of caregivers of children $<5$ years of age $(\mathrm{N}=1189)$ participated. Knowledge that mosquitoes cause malaria increased post-intervention, with reduced citation of fever among illnesses commonly affecting children. However, concepts of multiple causes of malaria remained.

Chapter 3 describes the study assessing changes in caregivers' knowledge and perceptions of childhood illnesses and resorts to care as a consequence of the bednet project. The findings concur with other studies that the diagnosis and 
treatment for childhood malaria begins in the home, depending on a myriad of factors including the interpretation of illness symptoms, previous experience with perceived symptoms, and advice of significant others. Self-medication is common - shops are within easy reach and one can purchase drugs depending on the amount of money at their disposal. We surmise that improvement in shopkeeper training, education to caregivers on homecare, and inclusion of informal and traditional sources when training peripheral health care workers, should continue in parallel with bednet programmes.

The study component presented in chapter 4 explored recall of key health messages at the end of the bednet trial, and whether experience with use of ITNs would increase likelihood to purchase bednets and pay for bednet re-treatment with insecticide in the future. Only $1 \%$ of mothers indicated (nonprompted) that ITNs protected children against malaria. Bednets ranked low among household expenditure priorities, regardless of intervention status. Most respondents envisaged paying nearly the current market price for a regular size bednet, but not that of an insecticide sachet. The problem seems less of costs, and more of the value attached to use of insecticide in bednets, perhaps due to the difficulty of perceiving direct benefits of the insecticide. Despite indication from epidemiological studies that ITNs impacted most positively on children's health (ter Kuile et al., 2003; Phillips-Howard et al., 2003 [c]), our study offers no evidence to suggest they would be purchased as a household priority, especially in the face of many competing financial needs and limited financial capacity (Meltzer et al., 2003).

\section{Studies monitoring adherence}

Theoretical principles of behaviour change were explicitly applied in studies presented in chapters $6-8$, to determine environmental and structural variables affecting adherence. The main focus was on adherence with ITN use among the local population, particularly with children's coverage and pattern of ITN use. Both qualitative and quantitative methods were applied.

Actual adherence was assessed every quarter of the year, through direct predawn observations in computer generated random lists of households. The results, presented in chapters 6 and 7 indicate adherence with bednet use was better following long-term use (May 1999-May 2001) than during the trial (March 1997-Jan. 1999), 80\% versus 73\% ( $\mathrm{P}<0.01$ ). Bednet coverage in households and perceived heat under bednets were statistically associated with adherence. Bednet use was seasonal, most likely in cooler months. The more people in the household relative to the number of bednets available, the less likely family members were adherent with children least likely to benefit from limited availability. It is of concern that bednet programmes may distribute bednets freely to pregnant mothers and infants only. We surmise, based on our data that unless bednets are issued to cover all sleeping spaces available bednets will be transferred over to adults and males, soon after acquisition into the household. 
Lastly, our studies indicate that saturating households with bednets is not the only antecedent to child adherence with bednet use. Chapter 8 outlines a quasiexperimental pilot study involving training of children 6-10 years of age in bednet mounting skills assessed to explore the potential to include them as mother's helpers in ensuring daily bednet use. Elicitation motivational interviews (Miller \& Rollnick, 1991) were conducted with caretakers, to explore specific contextual factors governing child bednet use in households. Secondly, children from the same households were trained in bednet mounting skills. Thirdly, effectiveness of training was evaluated through spot-checks to observe bednet use in May 2001. Significantly more children appeared to have adequate skills post-training than before; $\mathrm{P}<0.001$, but high mounting points and inadequate adult support hindered children's effective applications of acquired skills. In order to reduce wear and tear, caregivers decide if and when children might sleep under bednets. Child training and motivational interviews appeared to achieve better adherence, but this was only significant for the latter $(\mathrm{P}<0.05)$. MI results concur that an approach based on dialogue rather than on passive information dissemination improves caregiver appreciation of the importance of child bednet use. We conclude that children are promising helpers in ensuring bednets are mounted, but are barred by a mix of technical and social barriers from effectively contributing to the achievement of public health goals.

\section{STUDY LIMITATIONS AND CONCLUSIONS}

Our studies indicated high levels of acceptability of bednets, and adherence with using the disease control tool. This is indeed very promising for future implementation. The studies concur, however, with economic studies during the bednet trial (Meltzer et al., 2003) that in the absence of any perceived immediate financial rewards of ITNs, particularly with regards to insecticide, coverage might not be sustained if the financial burden falls upon this impoverished rural community. African countries are currently targeting reduction and/or elimination of taxes and tariffs on mosquito nets, netting materials and insecticides as a means of stimulating and maintaining high levels of bednet coverage in households (WHO/RBM, 2000). While ensuring high coverage, both of bednets and bednet re-treatment must remain the primary objective of malaria control programmes using bednets, protection is only ensured if people use and re-treat bednets regularly, thus questions of adherence remain equally important. In addition to promoting coverage, creating and maintaining a culture of ITN use must include the promotion of correct bednet use for maximal public health outcomes. Our qualitative and quantitative studies illustrated that ITNs remain valued for avoiding nuisance biting, and are not considered a pri- 
ority (Alaii, 1997; Alaii et al., 2003 [a], [b]), least of all as a public health item. As with questions of affordability (Meltzer et al., 2003), correct use of ITNs will be largely determined by the perceived need to use a bednet in the first place. It remains to be seen whether the population will value ITNs because of perceived health or subsidiary benefits, and whether bednets and insecticide will be ranked as a household priority.

A major limitation is that our studies were conducted in an environment in which people were issued bednets free of charge, distributed in all identified sleeping spaces. Insecticide-treatment of bednets was done free of charge, using paid staff drawn from the community. In addition, an intensive health education campaign targeting the whole study area was undertaken to encourage adherence with bednet use. Due to the ideal conditions of the research our results might not offer conclusive evidence about the viability of insecticide-treated bednets as a malaria control tool in this population in the absence of mechanisms to maintain high coverage and adherence levels. However, as we alluded to in the rationale for the study, bednet use, even in a research trial, requires active application of the intervention, facilitating a glimpse into what people's actions might be in real life conditions. We discuss our findings in the different papers presented herein in the light of the limitations of the study, but concur with Rogers (1995) that an intervention that offers people the opportunity of triability is able to draw better conclusions about the likelihood that they will adopt the intervention, the nature of the adoption, and who might benefit from it. The lessons drawn, though not conclusive, provide useful insights for scaling up insecticidetreated bednets and other malaria interventions in this community.

Future operational research after the withdrawal of project-supported activities relating to bednet use in the study area should target differentials in bednet coverage and patterns of bednet use to be able to advise national programmes adequately. Questions of whether people might purchase bednets to replace worn ones, who finally accesses bednets when there are not enough to cover all sleeping spaces in a household, and whether bednets will be re-treated with insecticide remain important. Previous failure to ensure bednet re-treatment with insecticide following the closure of a bednet project in a neighbouring community suggests it would be pointless, however, to make such assessments in the absence of necessary physical support systems to make bednets and insecticide easily accessible (Kachur et al., 1999). It is imperative that people know where to get insecticide, and specifically what insecticide to use. Also, since questions of wear and tear, including fire safety concerns make it prohibitive for children to deploy bednets independently, research must target the development of as longer-lasting (and less flammable?) bednets as possible if this age group is to benefit. Lastly, the indication that bednets might only be used seasonally has serious implications for their effectiveness. In addition to health promotion to maintain awareness and to facilitate appropriate attitude and behavioural changes, sector-wide improvements in health delivery systems should continue in parallel with bednet programmes. 


\section{REFERENCES}

Ajzen, I. (199I). The theory of planned behaviour. Organizational Behaviour and Human Decision Processes, 13, I79-2II.

Alaii, J.A., van den Borne, H.W., Kachur, S.P., Mwenesi, H., Vulule, J.M., Hawley,W.A., Meltzer, M.I., Nahlen, B.L., \& Phillips-Howard, P.A. (2003 [a]). Perceptions of bednets and malaria prevention before and after a randomised controlled trial of bednets in western Kenya. American Journal of Tropical Medicine and Hygiene, 68, Suppl. 4.

Alaii, J.A. (1997). The relevance of sleeping arrangements and bedtime mobility patterns for implementing insecticide-treated bednets in Asembo, western Kenya. Master of Science Dissertation, Faculty of Health Sciences, London, South Bank University.

Alaii, J.A., van den Borne, H.W., Kachur, S.P., Shelley, K., Mwenesi, H., Vulule, J., Hawley,W.A., Nahlen, B.L., \& Phillips-Howard, P.A. (2003 [b]). Community reactions to the introduction of permethrin-treated bednets for malaria control during a randomised controlled trial in western Kenya. American Journal of Tropical Medicine and Hygiene, 68, Suppl. 4.

Alonso P.L., Lindsay S.W., Armstrong J.R.M., Conteh M., Hill A.G., David P.H., Fegan G., de Francisco A, Hall A.J., Shenton FC, Cham K, \& BM, G. (199I). The effect of insecticidetreated bednets on mortality of Gambian children. Lancet, 337, I449-I 502.

Alonso, P., Lindsay, S., Armstrong, J., Keita, K., Gomez, P., Shenton, F., Konteh, M., Keita, K., Marshall, C., Phillips, A., Cham, K., \& Greenwood, B. (1993).A malaria control trial using insecticide-treated bed nets and targeted chemoprophylaxis in a rural area of The Gambia, west Africa: the impact of the interventions on mortality and morbidity from malaria. Transactions of the Royal Society of Tropical Medicine and Hygiene, 87 (Suppl 2: S37S44).

Bandura, A. (1986) Social foundations of thought and action:A social cognitive theory New Jersey: Prentice-Hall

Bandura, A. ( 1 997) Self-efficacy:The exercise of control New York: Freeman

Bartholomew, L.K., Parcel, G.S., Kok, G., \& Gottlieb, N.H. (200I). Intervention Mapping: Designing theory and evidence-based health promotion programmes. Mountain View, CA: Mayfield Publishing Company.

Beach, R.F., Ruebush, T.K., Sexton, J.D., Bright, P.L., Hightower,A.W., Breman, J.G., Mount, D.L., \& Oloo,A.J. (1993). Effectiveness of permethrin-impregnated bed nets and curtains for malaria control in a holoendemic area of western Kenya. American Journal of Tropical Medicine and Hygiene, 49, 290-300.

Becker, M. (1974). The health belief model and personal health behavior. Health Education Monographs, 2.

Beier, J.C., Oster, C.N., Onyango, F.K., Bales, J.D., Sherwood, J.A., Perkins, P.V., Chumo, D.K., Koech, D.V.,Whitmire, R.E., Roberts, C.R., Diggs, C.L., \& Hoffman, S.L. (1994). Plasmodium falciparum incidence relative to entomological inoculation rates at a site proposed for testing malaria vaccines in western Kenya. Am J Trop Med Hyg, 50, 529-536.

Binka, F.N., Kubaje,A., Adjuik, M.,Williams, L.A., Lengeler, C., Maude, G.H.,Armah, G.E., Kajihara, B., Adiamah, J.H., \& Smith, P.G. (1996). Impact of permethrin-impregnated bednets on child mortality in Kassens-Nankana District, Ghana:A randomized-controlled trial. Trop Med Int HIth, I, I47-I54. 
Binka, F.N., \& Adongo, P. (1997). Acceptability and use of insecticide impregnated bednets in northern Ghana. Trop Med Int HIth, 2(5), 499-507.

Bloland, P.B., Ruebush,T.K., McCormick, J.B., Ayisi, J., Boriga, D.A., Oloo,A.J., Beach, R., Hawley, W.A., Lal, A., Nahlen, B., Udhayakumar,V., \& Campbell, C.C. (1999). Longitudinal cohort study of the epidemiology of malaria infections in an area of intense malaria transmission. II. Descriptive epidemiology of malaria infection and disease among children. Am J Trop Med Hyg, 60, 64I-648.

Brieger,W.R., Onyido,A.E., Sexton, J.D., Ezike,V.I., Breman, J.G., \& Ekanem, O.J. ( 1996). Monitoring community response to malaria control using insecticide-impregnated bednets, curtains and residual spray at Nsukka, Nigeria. Health Education Research., I I (2), I33-I 45.

Cohen, D.W., \& Atieno-Odhiambo, E.S. (1989). Siaya:The historical anthropology of an African landscape. London: James Currey Ltd.

D'Alessandro U, Olaleye B, Langerock P et al, The Gambian National Impregnated Bed Net Program: evaluation of effectiveness by means of case-control studies Transactions of the Royal Society of Tropical Medicine and Hygiene I:638-642

D'Alessandro, U., Olaleye, B.O., McGuire,W., Langerock, P., Bennett, S., Aikins, M.K., Thompson, M.C., Cham, M.K., \& Greenwood, B.M. (1995). Mortality and morbidity from malaria in Gambian children after introduction of an impregnated bednet programme. Lancet, 345, 479-483.

Fishbein, M., \& Ajzen, I. (1975). Belief, attitude, intention and behaviour:An introduction to theory and research. Reading, Massachusetts:Addison-Wesley.

Foster, S. (1994). Economic prospects for a new anti-malarial drug. Transactions of the Royal Society for Tropical Medicine and Hygiene, 88 (Suppl I), 55-56

Gallup, J.L., \& Sachs, J.D. (200I).The economic burden of malaria. American Journal of Tropical Medicine and Hygiene, 64, 85-96.

Gilles, M.T., \& de Meillon, B. (1968). The Anophelinae of Africa south of the Sahara. 54, I-343.

Glanz, K., Lewis, F.M., \& Rimer, B.K. (Eds.). (1997). Health behaviour and health education:Theory, research, and practice (2nd ed.). San Francisco: Jossey-Bass.

Government of Kenya. (1994). Siaya District Development Plan, 1994-1996. Nairobi: Government printers.

Graves, P., \& Gelband, H. (2003). Vaccines for preventing malaria (Cochrane review). In the Cochrane Library (I) CD000I 29.

Green, L.W., \& Kreuter, M.W. (Eds.). (1999). Health promotion planning:An educational and ecological approach (3rd ed.). Mountain View: Mayfield.

Habluetzel, A., Diallo, D.A., Esposito, F., Lamizana, L., Pagnoni, F., Lengeler, C., Traoré, C., \& Cousens, S.N. (1997). Do insecticide-treated curtains reduce all-cause mortality in Burkina Faso? Trop Med Int Hlth, 2, 855-862.

Harper, P.A., Lisansky, E.T., \& Sasse, B.E. (1947). Malaria and other insect-borne diseases in the South Pacific campaign. American Journal of Tropical Medicine and Hygiene, 27 (Suppl)(3I-68).

Janz, N., \& Becker, M. (1984). The Health Belief Model:A decade later. Health Education Quarterly, II, I-47.

Kaseje, D.C.O., Spencer, H.C., \& Sempebwa, E.K.N. (1987). Usage of community-based chloroquine treatment for malaria in Saradidi, Kenya. Annals of Medicine and Parasitology, 8 I (suppl I), SIII-SII5. 
Lankinen, K.S., Bergström, S., Måkelå, P.H., \& Peltomaa, M. (1994). Health and disease in developing countries. London: Macmillan.

Lengeler, C., de Savigny, D., \& Cattani, J. (Eds.). (1996). Net Gain:A New Method of Preventing Malaria Deaths. Geneva \& Ottawa:WHO/IDRC.

Lengeler, C. (2003) Insecticide-treated bednets and curtains for preventing malaria (Cochrane Review) The Cochrane Library (Issue I, 2003, Oxford: Update Software)

Lindsay, S.W., \& Birley, M.H. (1996). Climate change and malaria. Annals of Medicine and Parasitology, 90(6), 573-88.

Lindsay, S.W., \& Gibson, M.E. (1988). Bednets revisited- an old idea, new angle. Parasitology Today, 4(I0), 270-272

Marsh, K., \& Snow, R.W. ((1997)). 30 Years of Science and Technology:The Example of Malaria. Lancet, 349(Suppl III), I-3.

Marsh,V.M., Mutemi,W., Some, E.S., Haaland,A., \& Snow, R.W. (1996). Evaluating the Community Education Programme of an Insecticide-treated Bednet Trial on the Kenyan Coast. Health Policy Plan, I I (3), 280-29I.

Meltzer, M.I., Terlouw, D.J., Kolczak, M.S., Odhacha,A., ter Kuile, F.O., Vulule, J.M.,Alaii, J.A., Nahlen, B.L., Hawley,W.A., \& Phillips-Howard, P.A. (2003). The household-level economics of using permethrin-treated bednets to prevent malaria in children under 5 years of age. American Journal of Tropical Medicine and Hygiene, 68, Suppl. 4.

Miller,W.R., \& Rollnick, S. (199I). Motivational Interviewing: Preparing people for change. New York: Guilford Press.

Miller,W.R. (1996). Motivational Interviewing: Research, practice, and puzzles. Addictive Behaviours, 2 I(6), 835-842.

Nabarro, D.N. (1998). The "roll back malaria" campaign. Science, 280, 2067-8.

Nchinda, T.C. (1998). Malaria:A re-emerging disease in Africa. Emerging Infectious Diseases, Special Issue 4(3) July-Sept.

NIAID. (2000). Malaria. NIH Publication (00-47I5, April 2000).

Nevill, C.G., Some, E.S., Mung'ala,V.O., Mutemi,W., New, L., Marsh, K., Lengeler, C., \& Snow, R.W. (1996). Insecticide treated bednets reduce mortality and severe morbidity from malaria among children on the Kenyan coast. Tropical Medicine and International Health, I, 139-46.

Phillips, M., \& Phillips-Howard, P.A. (1996). Economic Implications of Resistance to Anti Malarial Drugs. Pharmacoeconomics, 10, 225-238.

Phillips-Howard, P.A., ter Kuile, F.O., Nahlen, B.L., Alaii, J.A., Gimnig, J.E., Kolczak, M.S., Terlouw, D.J., Kariuki, S., Shi,Y.P., Kachur, S.P., Hightower,A.W., Vulule, J.M., \& Hawley,W.A. (2003 [a]). The efficacy of permethrin-treated bednets on child mortality and morbidity in western Kenya. II: Design and methods. American Journal of Tropical Medicine and Hygiene, 68, Suppl. 4.

Phillips-Howard, P.A., Nahlen, B.L., Alaii, J.A., ter Kuile, F.O., Gimnig, J.E., Terlouw, D.J., Kachur, S.P., Hightower,A.W., Lal,A.A., Schoute, E., Oloo, J.A., \& Hawley,W.A. (2003 [b]). The efficacy of permethrin-treated bednets on child mortality and morbidity in western Kenya. I: development of infrastructure and description of study site. American Journal of Tropical Medicine and Hygiene, 68, Suppl. 4. 
Phillips-Howard, P.A., Nahlen, B.L., Kolczak, M.S., ter Kuile, F.O.,Alaii, J.A., Hightower,A.W., Gimnig, J., Arudo, J.A.,Vulule, J., Schoute, E., Kachur, S.P., Oloo, A.J., \& Hawley,W.A. (2003 [c]). Efficacy of permethrin-treated bednets in the prevention of mortality in young children in an area of high perennial malaria transmission in western Kenya American Journal of Tropical Medicine and Hygiene, 68, Suppl. 4.

Prochaska, J.O., DiClemente, C.C., \& Norcross, J.C. (1992). In search of how people change: Applications to the addictive behaviours. American Psychologist, 47(9), I I02-I I I 4.

Prochaska, J.O., \& DiClemente, C.C. (1983). Stages and processes of self-change of smoking: Toward an integrative an integrative model of change. Journal of Consulting and Clinical Psychology, 5 I, 390-395.

Roll Back Malaria (RMB). (2000). Potential for Progress. Roll Back Malaria website: http://www.rbm.who.int (May 2000).

RBM/WHO. (200I). Malaria at a glance. Roll Back Malaria website: http://www.rbm.who.int (March 200I).

Rogers, E.M. (Ed.). (1995). Diffusion of innovations (4th ed.). New York:The Free Press.

Sachs, J., \& Malaney, P. (2002). The economic and social burden of malaria. Nature, 4I 5, 680-5.

Sexton, J., Ruebush,T.K., Brandling-Bennett, A.D., Breman, J.D., Roberts, J.M., Odera, J.S., \& Were, O.B.J. (1990). Permethrin-impregnated curtains and bed nets prevent malaria in western Kenya. American Journal of Tropical Medicine and Hygiene, 43, I I-I8.

Snow, R.W., Lindsay, S.W., Hayes, R.J., \& Greenwood, B.M. (1988). Permethrin-treated Bednets Prevent Malaria in Gambian Children. Transactions of the Royal Society for Tropical Medicine and Hygiene, 82, 838-842.

Snow, R.W., McCabe, E., Mbogo, C.N.M., Molyneux, C.S., Some, E.S., Mung'ala,V.O., \& Nevill, C.G. (1999). The effect of delivery mechanisms on the uptake of bed net re-impregnation in Kilifi District, Kenya Health Policy Plan, I4(I), I8-25

ter Kuile, F.O., Terlouw, A.J., Phillips-Howard, P.A., Hawley,W.A., Friedman, J.F., Kolczak, M.S., Kariuki, S.K., Shi,Y.P., Kwena, A.M.,Vulule, J.M., \& B.L., N. (2003). Impact of permethrintreated bednets on malaria and all cause morbidity in young children in an area of intense perennial malaria transmission in western Kenya: cross-sectional survey. American Journal of Tropical Medicine and Hygiene, Malaria Supplement.

Trigg, P.I., \& Kondrachine,A.V. (1998). Commentary: Malaria control in the 1990s. Bulletin of the World Health Organization, 76(I), II-16.

WHO (1993). Global Malaria Control. Bulletin of the World Health Organization, 7I, 28I-284.

WHO (I993 [a]). Implementation of the global malaria control strategy Report of a VMO study group on the implementation of the global plan of action for malaria control 1993-2000 (WHO Technical Report No. Series No. 839). World Health Organization

WHO (1996). Tropical diseases control: Malaria in the world. Geneva: Division of control of tropical diseases (CTD/TDT/96.I2),WHO.

WHO (1996 [a]). Investing in research for development: Report of the ad hoc committee on health research relating to future intervention options (TDR/Gen/96I). The World Health Organization.

WHO (1997).World malaria situation. Weekly Epidemiological Record, 72, 269-290.

WHO (1999). The World Health Report 1999: making a difference. Geneva,World Health Organization. 
WHO/RBM (2000). African Summit on Roll Back Malaria, Abuja, Nigeria, April 25, 2000. WHO/CDS/RBM/2000. 17.

Winch, P.J., Makemba, A.M., Makame,V.R., Mfaume, M., Lynch, M.C., Premji, Z., Minjas, J.N., \& Shiff, C.J. (1996). Social and cultural factors affecting rates of regular retreatment of mosquito nets with insecticide in Bagamoyo District, Tanzania. Tropical Medicine and International Health, 2(8), 760-770.

World Bank (1993). World development report 1993 - Investing in Health. Oxford: Oxford University Press.

Zimicki, S. (1996). Net Gain: Promotion in Sub-Saharan Africa. In Lengeler, C., de Savigny, D., \& Cattani, J. (Eds.). Net Gain:A New Method of Preventing Malaria Deaths. Geneva \& Ottawa: WHO/IDRC. 



\title{
CHAPTER 2
}

\author{
SLEEPING ARRANGEMENTS \\ IN A RURAL COMMUNITY IN WESTERN KENYA: \\ RELEVANCE FOR BEDNET UTILIZATION I
}

ITo be submitted as:

Jane A. Alaii, H.W. van den Borne, S. Patrick Kachur, Halima Mwenesi, John Vulule, William A. Hawley, S. van der Geest, Penelope A. Phillips-Howard.

Sleeping arrangements in a rural community in western Kenya: Relevance for bednet utilization 


\begin{abstract}
A study of sleeping patterns and malaria-related knowledge and practices was conducted in western Kenya, prior to a trial of insecticide-treated bednets (ITNs). The study aimed to describe a general representation of local sleeping arrangements, especially for children, and malaria-related knowledge and practices, including existing bednet use. Caregivers for children $<5$ years of age were interviewed using complementary qualitative research methods. Sleeping spaces were determined by a combination of space, age, and customary beliefs, not solely based on household membership. Weaned children $>2$ years are relocated to sleep with siblings or alone. Children mostly slept in kitchens and living rooms. Bednet coverage was low $(<5 \%)$, due to perceived costs, heat and daily re-hanging. Net maintenance was poor; the majority were old and torn. Two-thirds of 26 households lacking bednets knew of no disadvantages. Those perceiving disadvantages cited heat, fire risk, and detergent needs for washing nets. Bednets were valued for avoidance of nuisance biting for adults. Malaria was perceived to be from multiple causes. While ITNs prevented mosquito biting they were thus not perceived to affect other causes of malaria, and the risk of malaria. To maximize ITN use, information on the role of mosquitoes as the sole cause of malaria, and prevention of biting through ITNs will need to be disseminated. ITN success would require coverage of all sleeping spaces to ensure children also benefit from the intervention.
\end{abstract}




\section{INTRODUCTION}

Malaria affects approximately $40 \%$ of the world's population - with most at risk populations found in the world's poorest countries. Africa accounts for ninety per cent of an estimated 300-500 million acute illnesses and 1.5-2.7 million deaths globally annually (WHO, 2000 [a]). Children below five years of age and pregnant women are most at risk. Efforts to control the disease in recent decades continue to be hampered by the rapid spread of parasite and vector resistance to both new and long established drugs, and insecticides respectively (WHO, 1999a; Snow, 1997; Lengeler et al., 1996). With increasing treatment costs, sustainable global initiatives to prevent malaria are sought. Current policy options for malaria control include disease prevention using insecticide-treated bednets (ITNs) (Nabarro, 1998; WHO, 2000[b]). A review of results of efficacy trials of ITNs in sub-Saharan Africa concluded that their correct use could save up to 6 lives for every 1000 protected children $<5$ years of age (Lengeler, 2003). A recently completed trial of ITNs in western Kenya reports even better results, indicating 34.5 (95\% confidence interval [CI] 16.4-49.9) lives saved per 1,000 infants protected (Phillips-Howard et al., 2003 [a]). The WHO Roll Back Malaria initiative has pledged that by the year 2005, up to $60 \%$ of children and pregnant women will have access to insecticide treated nets (WHO, $2000[\mathrm{~b}])$. Outside of controlled trials, programmatic bednet interventions must take into account social-cultural, behavior and economic effects (Winch et al., 1994). As with any tool for disease control, the introduction of ITNs requires a prior understanding of community perceptions of disease prevention and control, and of factors that could mitigate or support the adoption of the intervention. In this study we explore sleeping patterns of children prior to the introduction of insecticide-treated bednets in a randomized controlled trial in an area of intense perennial malaria transmission in western Kenya.

\section{METHODS}

\section{Study objective}

1 To clarify Luo behavior regarding local sleeping arrangements and any conflicts between where people live (eat) and where they sleep;

2 To determine bednet use prior to the introduction of ITNs, and community perceptions of bednets role in malaria prevention;

3 To explore the acceptability of bednets, factors governing bednet ownership and use, and cultural practices that might impact on coverage and adherence. 
Particular emphasis was placed on exploring the position of children with regard to access to household items such as bednets. The study findings were compiled into a working report, used to inform the planning and implementation of the randomized controlled trial.

\section{Study design}

The study was conducted in Asembo Bay, western Kenya, on the shores of Lake Victoria, in a population targeted for a randomised controlled trial of ITNs. Description of the study site and population are presented in the introduction to this thesis, and elsewhere (Phillips-Howard et al., 2003 [b]). The sleeping patterns study was conducted prior to introduction of ITNs, over 8 weeks between April 1996 and June 1996 by one full-time social scientist and one field assistant. The study was conducted using three complementary qualitative methods; in-depth interviews, focus group discussions, and semi-structured household questionnaire.

\section{In-depth interviews}

Twenty-four in-depth interviews were held with caregivers of children $<5$ years of age, to gather information from a representative group of caregivers on local knowledge of childhood illnesses including malaria, on local family sleeping arrangements, and on use of mosquito avoidance measures. The interviews started with a general question about common childhood illnesses and their perceived seriousness. Caregivers were probed on local terms used for malaria, and their interpretation. They were also asked what causes malaria, whether they thought malaria was preventable, how it might be prevented, and if they perceived any role for bednets in preventing malaria. Other questions included local sleeping arrangements including community and household bednet ownership, what bednets were used for locally, who used bednets, and perceived advantages and disadvantages of bednets. Interviews were conducted in Dholuo, by the social scientist and research assistant, usually in the morning hours at the participant's homes. Exceptionally, interviews were conducted in other venues.

\section{Focus group discussions}

Three focus group discussions (FGD) were used to check responses of individual caregivers generated from the in-depth interviews. FGD were held in Dholuo, and took place mid-afternoon, in central locations identified as convenient by the caregivers. Focus group participants were identified with the help of three local nyamrerwas (village health workers). Four days prior to the discussion, a request for the participation of caregivers to attend a FGD was sent to 16 homes neighboring the nyamrewa. This provided a turnout of up to 12 mothers per FGD. Non-participation of caregivers related to work in the shamba or a market visit. Age homogeneity was important for focus group discussions. Participants 
were identified based on three age categories; (a) mainly young women [<30years], (b) young to lower middle age [30-40 years], and (c) upper middle age to old [ $>40$ years]. This was done to facilitate free discussion particularly for the mainly young age group [just as Luo norms tend to suggest women should not speak where men speak, it is expected that young girls should not air their opinion in a gathering with women of an older age group].

\section{Structured questionnaires}

Semi-structured interviews were conducted in 38 households; using household as the sampling unit. The information generated from the in-depth interviews and FGD was used to design a structured questionnaire, translated into Dholuo. The questionnaire was pre-tested with the assistance of a trained field assistant. Interviews were mainly conducted mid-morning in the participant's home, or occasionally elsewhere for the convenience of the participant. The questionnaire documented individual household sleeping arrangements, net ownership, and use, as well as observational data including household type, condition of sleeping spaces, and bednets (if any). The questionnaire was divided into two parts. The first part assessed general household membership, household sleeping arrangements including factors governing bed space allocation, and current bednet ownership. The second section categorized respondents by their current (pre-intervention) bednet status. Those with at least one bednet were questioned about their bednet use patterns including children's access to the bednets. Those without a bednet were interviewed on their current mosquito avoidance practices including their apparent effectiveness, and perceived advantages or disadvantages of bednets. The household questionnaire was a representation of the in-depth interviews, only that all questions were specific to the household being interviewed. The questionnaire did not attempt to statistically quantify in-depth interviews and focus group discussions. Rather, the aim was to get true representations of individual household sleeping arrangements and bednet use.

Purposive sampling was used for all research questions and phases of data collection. Purposive sampling simply means that samples are deliberately selected based on the research need. Since we wanted to measure cultural practices regarding sleeping arrangements, and existing bednet use, our samples were chosen based on whom we expected to be able to tell us about these issues. We included caregivers based on the family status; identifying them as a young family comprising mainly small children, or a relatively older family having both small and adult children. The addition criterion used for in-depth interviews was based on researcher judgment of whether preceding interviews generated adequate information and/or new information that needed clarification. For questionnaire interviews we deliberately identified households having at least one bednet and asked for their consent to be interviewed. 


\section{RESULTS}

\section{In-depth interviews and focus group discussions}

Twenty-four caregivers (mean age $38.5(\mathrm{SD}=16.1)$ completed in-depth interviews. Two-thirds of the informants had formal schooling (mean $=7.3$ years, S.D. 1.8). Informants reportedly had on average 4-5 children. Three informants reported having a bednet; this was unrelated to family income. One informant had three bednets, one of which was used by her children. A total of 30 women [overall mean age 36.6 years] contributed to the three focus group discussions. Group participants were reluctant to provide information on schooling or number of children so this was not pursued further.

\section{Malaria terminology}

Discussions with caregivers generated terms used interchangeably to mean malaria, and correspond to biomedical definitions of malaria-related illness including maleria, midhusi, wich-bar, and fudha (Table 2.1). Notably, fudha is a condition defined as serious malaria, and perceived to precede the onset of remomatin (literally low blood and corresponding to the biomedical definition of anemia). Early in the bednet trial (Phillips-Howard et al., 2003 [c]) people did not connect remo-matin with malaria despite the fact that they perceived it as a condition following fudha. As the trial progressed, however, it was not uncommon to hear mothers remarking; "malaria has eaten his blood." A study of illness perception and care seeking is presented elsewhere in this thesis (Chapter 3).

\section{Malaria knowledge}

Two major childhood illnesses were listed in all in-depth interviews and focus group discussions: malaria (midhusi, or wichbar), and cough. Others mentioned diarrhoea and angiew (measles), listed by over two-thirds of in-depth interviewees, and in two focus group discussions. There was general consensus that malaria was most serious as it appeared difficult to treat [no herbal cure], and could result from multiple causes. While all suggested mosquito bites caused malaria, they all likewise perceived other causes for malaria. Commonly encountered remarks were, "... if mosquitoes bite a child, or if he gets rained on he will get malaria." A focus group participant adding to group discussion indicated variability in illness interpretation; “... also (suggesting in addition to mosquito biting and being rained on), if the child drinks dirty water he will have fever and stomach ache - and that is malaria." An elderly lady during in-depth interviews indicated a general lack of association of conditions fitting biomedical definitions of malaria, citing them as discrete illness conditions; "Before (in the past), we knew of okulbat (condition characterized by difficulty breathing), fudha (defined locally as stage preceding condition termed as low blood [anemia]), and even malaria as dangerous, but now, there are so many diseases. When a child died we said he had strong malaria [fudha], but now...." 
Table 2.I Disease terms used interchangeably for malaria (Restricted to terms generated during study)

\begin{tabular}{|c|c|c|c|c|}
\hline Disease term & $\begin{array}{l}\text { Main user } \\
\text { of term }\end{array}$ & $\begin{array}{l}\text { Definition } \\
\text { and comments }\end{array}$ & $\begin{array}{l}\text { Perceived } \\
\text { cause }\end{array}$ & $\begin{array}{l}\text { Commonly } \\
\text { perceived signs }\end{array}$ \\
\hline Malaria & $\begin{array}{l}\text { Common term among } \\
\text { young caregivers, but } \\
\text { also used by older } \\
\text { people. }\end{array}$ & $\begin{array}{l}\text { Pronounced maleria is the local } \\
\text { adaptation of the biomedical } \\
\text { term malaria. }\end{array}$ & $\begin{array}{l}\text { Getting cold and/or } \\
\text { being rained on, and } \\
\text { [because researchers } \\
\text { say] mosquitoes. }\end{array}$ & $\begin{array}{l}\text { Fever, vomiting, diarrhea, } \\
\text { and joint pains. }\end{array}$ \\
\hline Midhusi & $\begin{array}{l}\text { Common among the } \\
\text { older community } \\
\text { members - does not } \\
\text { appear understood well } \\
\text { among the young. }\end{array}$ & $\begin{array}{l}\text { Indigenous term used before } \\
\text { "malaria" was introduced. } \\
\text { (General cover term for malaria } \\
\text { symptoms, including chills, fever } \\
\text { and general malaise.) }\end{array}$ & $\begin{array}{l}\text { Getting cold and/or } \\
\text { being rained on. }\end{array}$ & $\begin{array}{l}\text { As above for malaria, but } \\
\text { more specific to fever/ } \\
\text { chills, and vomiting. }\end{array}$ \\
\hline Wich-bar & $\begin{array}{l}\text { Same as midhusi; } \\
\text { young people may use } \\
\text { when speaking to the } \\
\text { elderly. }\end{array}$ & $\begin{array}{l}\text { Interchangeable for malaria } \\
\text { or headache. Mostly used in } \\
\text { reference to malaria in adults. } \\
\text { Caregivers (depending on age) } \\
\text { may say the child has wich-bar } \\
\text { (meaning malaria). People seek } \\
\text { clarification; literally "You have } \\
\text { malaria?" }\end{array}$ & $\begin{array}{l}\text { Getting cold and/or } \\
\text { being rained on - in } \\
\text { reference to malaria. }\end{array}$ & $\begin{array}{l}\text { If referring to malaria, } \\
\text { mostly accompanied } \\
\text { with expressions about } \\
\text { fever, chills, and general } \\
\text { malaise. }\end{array}$ \\
\hline Fudha & $\begin{array}{l}\text { Common among the } \\
\text { elderly. }\end{array}$ & $\begin{array}{l}\text { Serious malaria, or identified } \\
\text { as an illness stage before remo } \\
\text { matin or ndulume**. }\end{array}$ & Not specified. & $\begin{array}{l}\text { Hot body, joint pains, } \\
\text { diarrhea, chills, often } \\
\text { clinically diagnosed as } \\
\text { malaria. }\end{array}$ \\
\hline
\end{tabular}

** Remo-matin (low blood) corresponds to biomedical description of anemia, and is perceived to become evident after fudha. Untreated fudha is perceived to lead to ndulume (condition characterized by fits, convulsions, and loss of consciousness). Despite their association with fudha, which is apparently linked to malaria, the two illness conditions do not appear connected with malaria.

Participants said that malaria was most common in the main rainy season (March-May) when there was a lot of cold and wetness, and mosquitoes seemed to be in abundance. Some mentioned that they perceived malaria to be increasingly prevalent and difficult to manage; "There are no days when malaria is a lot or less intense. Long ago malaria could come when people started eating early maize (first harvest of the season), but these days malaria is just everywhere (occurring frequently)." (In-depth interview informant). 
"When we were married there were mosquitoes but no malaria, and we would use herbs for bathing and drinking to treat midhusi. But malaria is everywhere nowadays, and even there are new mosquitoes... people do not respond to herbal treatments." (Participants in focus group comprising elderly women).

One-third of in-depth interviewees and a half of all focus group participants suggested malaria could only be effectively prevented through the use of prophylactic drugs and/or injections. The main drugs cited were chloroquine-based (chloroquine, Malaraquine ${ }^{\circledR}$ ), and paracetamol (Panadol ${ }^{\circledR}$ ). Notably, people often used drugs like Panadol ${ }^{\circledR}$ alone to self-treat for malaria, indicating local self-treatment practices focusing on malaria symptoms including fever (in children) and headache (in adults) rather than on clearing the parasite. Older participants generally suggested that malaria was not preventable.

“...You cannot prevent malaria. Only God can prevent it - if he refuses to let it rain, then there will be no malaria." (Elderly woman during an in-depth interview).

"Malaria cannot be prevented, but it can be treated if taken to the doctor (medical facility)..." (Participants in focus group comprising elderly women).

Half of the participants in one focus group, (mainly from a community that had taken part in a previous malaria research study) agreed that malaria was preventable using bednets; "Yes malaria can be prevented... like if you have a bednet, but you find that in other homes only the father and mother uses the net, and the children sleeping down are left and mosquitoes bite them all over." The extent to which they believed this was true or whether they were simply repeating health communication messages from the previous study was not explored.

\section{Existing bednet use}

All participants in the two studies said bednets were a rare household item because of cost implications, including firstly, cost of the bednets themselves; "...If somebody can afford (a net) they buy it...there is something they gain from the net, that is why they buy it." Secondly, cost in terms of the contribution of large family sizes as a factor for low bednet coverage was indicated; “... If you buy a net you buy for the children also. You cannot buy one and leave the children - You (rather) leave everybody to be bitten. The children do not all sleep in one bed. Two focus group participants who had just one bednet in their households added; “... Buying three nets can be hard. If I have just one net I just cover myself and leave the children - children are many and sleep in different places so the net cannot fit them." Lastly, cost in the aspect of competing needs for constrained family budgets was indicated; “... very few people have a net because it is expensive. The land here is dry, not fertile. When someone gets money he buys something to eat first, then school requirements for the children ..."

Asked what kinds of families owned bednets, participants generally remarked that wealth was not the only factor; “...it depends - even if you are not wealthy and you think you have money you can buy it ..." with some claiming that “... other people buy a net so that they may appear wealthy ..." 


\section{Value of bednets}

All participants in in-depth interviews and focus group discussions agreed that the effectiveness of mosquito nets was limited to a specific area, particularly as they perceived multiple causes for malaria; “... Nets can prevent the bite of mosquitoes that cause malaria, but they are not so effective - children will play in the rain and drink dirty water. So you must clear the bushes, remove stagnant water, and stop children playing in the rain." This line of thought was punctuated by a common remark in focus groups thus; “...You see, even those who have nets always still have malaria. Nets can prevent mosquitoes but not malaria because you cannot walk with a net throughout. During the wet seasons someone can get malaria - it is cold, and you cannot avoid the wetness." Participants commonly remarked that the main function of nets was to avoid nuisance biting and 'anything that might fall on you'; "When mosquitoes are many you use it, otherwise you just fold it away at other times." Related to this, a large number of participants explained one reason why children rarely had access to nets even in households that owned one; "...Me if I have one net I will use it because children sleep a lot, and they may not feel if they are bitten by mosquitoes." (Common remark in all focus group discussions and in over a half of in-depth interviews).

\section{Common mosquito avoidance measures}

Asked about the common means of protection from mosquito biting in their households, all participants, including those with nets, stated a range of methods including traditional methods (either by smoking or just by their natural smell alone), and mosquito coils; "If you have KES. 2.00 (US\$ 0.05) [to spare] you can get a mosquito coil which affords the whole household protection. It burns the whole night so mosquitoes do not disturb you in the middle of the night unlike the case with traditional plant products."

(Participant during focus groups). Two to three participants said they did nothing but flap off mosquitoes when disturbed in the night. There appeared a general agreement that prevention by smoking the house using cow-dung, herbs, or mosquito coils, was common but not practiced all the time. The methods were described as quite inconvenient and unpleasant, making houses and clothes smell of smoke; "...they (burning herbs or mosquito coils) can embarrass you when you have to go on a journey and your clothes are smelling of smoke" (Elderly woman during focus groups).

Elderly women reported concerns about the health risk from using traditional methods as they caused chest congestion, and difficulty breathing. Overall, they were also widely described as quite ineffective as they go off in the night, only for mosquitoes to return with renewed vigour. Many mothers suggested preference for mieny (a strong smelling shrub), which they placed by the head of the bed to protect their exposed faces. All the same, they argued in general, it is tiresome getting the herbs daily, so covering the whole body and head under a blanket, or flapping off mosquitoes in the night were more likely practices. For these reasons, some participants recognized the potential cost-effectiveness and health value of bednets saying; "With a bednet you do not waste money buying mosquito coils every day, or expose your health to the dangers of heat and smoke caused by burning herbs to repel mosquitoes from the house". 


\section{Perceived advantages and disadvantages of bednets}

At least a quarter of in-depth interviewees described perceived advantages of a bednet as making the bedroom neat, thus a white colour bednet was thought ideal. However, there were general concerns that white nets would be particularly difficult to maintain in one-roomed households where everything took place, including cooking - since people cooked using firewood, causing a lot of smoke and soot in houses. The potential of bednets to provide a barrier against foreign bodies like other insects, snakes and things that might fall on one was described by all participants and informants. Also, there was consensus that nets could provide warmth, though one-quarter of the informants perceived this as a potential disadvantage. One elderly woman, however, suggested that nets could still be used effectively even on a warm night; "I do not think that heat should be a problem. Most people have worn out blankets and would welcome the warmth a bednet could give. Besides, if there is heat I would simply kick away my blanket and remain warm and protected under my bednet!"

The rest of the informants and all focus group participants were mostly noncommittal about any disadvantages, saying only those with nets could describe their disadvantages, if any; "I do not have a net, I cannot tell you that it is good or bad you can only talk about something you have had an experience with." (Common remark during in-depth interviews).

"All I can tell you is that I feel bad without a net, like last night I was slapping my face trying to flap off mosquitoes." (Participant in a focus group discussion).

"We are waiting for the day you will give us the nets, and after that come and ask if someone has seen anything bad." (Participants during focus group discussions).

We took this opportunity to ask about when best the project staff might visit homes once the nets were provided, to monitor adherence with ITN use. Participants expressed a general reluctance to have strangers coming into the sleeping areas of their homes. Also, Luo fertility beliefs prohibit certain kinship relations from crossing into each other's sleeping spaces. Mothers expressed concern that such visits would result in breaking local taboos; especially since field staff were recruited from the study communities. Their concerns were punctuated by remarks including; "You cannot go to into someone's bedroom to see if the net is there..." and "a net (always in the singular) is used at night only, so you cannot go and ask if somebody is using it."

\section{Semi-structured questionnaire}

\section{Respondent characteristics}

Thirty-eight (38) caregivers with a mean age of 31 years, and 6.9 years of schooling were interviewed on household sleeping arrangements using the structured questionnaire. Respondents had an average of four children. Tworoomed (1 living room and 1 bedroom) traditional thatch houses with grass roofs predominated the homesteads visited, making up about two-thirds (25) of households interviewed. Just about a quarter of respondents reported owning 
at least one net. Generally, respondents were apprehensive about strangers going into their sleeping quarters, so observations of sleeping areas were limited to the living rooms and kitchens only, invariably where most interviews took place. Only three thatched houses had a window. The eaves in all houses were large, the doors loosely fitting with gaps either at the bottom, top, or sides and quite a number of roofs had gaps which could allow rain leakage. The kitchens were in the worst condition, with doors literally hanging loose and poorly constructed wall thatching. All household rooms observed, including kitchens, had open ceiling beams used to hang clothes and other things.

Households appeared equally likely to be composed of the two spouses and their children (17), or of mothers and children only (15). It is not unusual for men to leave home and stay in major towns where they work, returning home on weekends or month ends depending on distance. In six households relatives mostly count as family members in their capacity as child caregivers.

\section{Sleeping arrangements}

All rooms in the house are potential sleeping areas. Children did not necessarily sleep in the same household in which they qualified as members. In about twothirds (22) of the households interviewed, all members including an adult boy and two adult girls slept in the same household. Infants slept in the same room as their mothers, often sharing the same bed space. Young children mainly slept in the living room (30), though occasionally space constraints made them sleep in the kitchen (4) or in the simba (young man's hut)(3). Adult girls mainly slept at the granny's (7) or in the kitchen (6), while boys were more likely to sleep in the simba (7), and if he has not built a simba, at his uncles' place (4).

Sleeping areas were governed by a combination of factors including space (20) for young children, and by customary beliefs and practices related to age and family relations (15), particularly for adult boys and girls. Luo customs governing fertility concerns prohibit children attaining puberty from sleeping under the same roof. Consequently, these age groups seek sleeping space in several other houses in the homestead as described above; a practice locally termed lawo nindo.

It is not unusual for a child to be displaced from the mother's bed before attaining two years of age. At least one child $<5$ years of age was displaced from the mother's bed in about one-half (22) of the households interviewed. A newborn child caused displacement half of the time, while parental privacy explained displacement a third of the time. Occasionally (4), a child would desire to sleep with their older siblings elsewhere, and mothers allowed it if she felt it was safe to do so. Of 22 displaced children, about one half (13) slept with their not somuch-older siblings, one-quarter (6) slept alone, and the remaining one-third slept with another adult elsewhere in the family homestead.

Most households had only one bed and the parents occupied it. Only 8 households had at least one additional bed that was used by children, mainly the older boys of the family. Traditionally, people slept on papyrus reed mats, thus beds have remained a luxury, invested in mainly for parental use. 
Customary relations governed sleeping arrangements for visitors in over twothirds of the households that were interviewed. Unshared sleeping spaces for visitors appeared equally likely to be available in one of the other houses in the homestead (19), or in their hosts' house (15). Occasionally, owing to space implications, visitors shared sleeping spaces (8) with children or displaced them altogether (4).

\section{Family bedtimes and waking up times}

Family bedtimes ranged from $1900 \mathrm{hrs}$ when an infant was put to sleep, to 2300-2400hrs when adult female and male household members went to bed. Since family bedtimes tended to revolve around the time the mother was done with her household chores, the average family went to bed anytime between 2100-2200hrs. Family bedtimes varied frequently (21) or occasionally (17), mostly depending on when dinner was served. The family arose between 5.00am and 8.00am, depending on their daily commitments (22), a late night (9), or due to illness (3). Again, family rising time centred on the mother, and it is not unusual to find mothers without child caregivers taking with them an infant to the lakeside (for business) or to the farm as early as 5.00am.

\section{Existing bednet ownership and use}

Of the 38 households participating in semi-structured questionnaire interviews, 14 had owned at least a bednet, of which 12 had a bednet at the time of the interviews. Results on bednet use are restricted to the 12 households. Almost all (10) households with a bednet had purchased their nets, while the remaining two had received them as gifts. Two thirds of the households had just one bednet, used by the parents and an infant. All households used their nets to prevent nuisance biting, while half mentioned they were also used for malaria prevention. Only 2 respondents said they used the bednet to prevent "anything that might fall on me", while one perceived the bednet to make her room neat.

About one-half (7) of the caregivers said that a child had access to the net(s) in the house. Overall, two-thirds said the parents and their child who shared a bed with them often used a net. The remaining one-third said parents used one net, while their children shared another. One caretaker noted, however, that she and her husband had separate beds so the children could not use the net anytime their father was home.

Answering questions on any perceived problems with using their nets, twothirds of the respondents lamented they were old and torn. We observed that most nets were worn, one beyond repair (thus excluded from households categorized as having a bednet). Other commonly perceived problems included heat listed by about two-thirds (7), and the inconvenience of daily mounting for children, cited by one-third (4) of respondents. Two respondents reported that nets trapped children, causing them not to use nets when they knew they would arise early and leave the child in bed. One mother, who had experience using a treated bednet given as a gift lamented difficulties with re-treating her 
net, both due to cost limitations (when insecticide was available), and nonavailability (because the insecticide finally became unavailable locally).

\section{Households without bednets}

Two-thirds (26) of respondents selected had no bednet. When asked to hypothetically rank-order how they would spend a gift of a large sum of money, just onefifth (5) listed bednets as the first item they would invest their money in. Others included business ventures, household needs including renovation and purchase of items, and purchasing cattle or goats, each listed by about one-quarter of the respondents. Less than one-fifth (3) listed clothes for the family as a priority. Food was not listed in the first category. Overall matrix scores of the ranks indicated the household was of most concern (25 of 77), followed by starting a business of some sorts (18 of 77). Bednets, sharing equal concerns as the need for clothes and livestock, came third, each scoring 10 of 77. Food appeared to be of least concern with regards to this hypothetical question.

Explaining their ranking of nets, the six who ranked nets first claimed nets were the most important of their needs. Two-thirds (14) of 20 respondents not listing nets first, or at all, claimed they had just forgotten it, and they would otherwise rank it second. The rest said either business would bring money to buy nets later or that while they acknowledged the importance of bednets, other perceived needs were more important.

Almost all (22) respondents in households without bednets stated they mainly burned mosquito coils for protection against mosquito biting. One-seventh (3) said they mainly used traditional means including mieny that they placed at the head of the bed. One participant said she did nothing but flap off mosquitoes in the night. Individual ranking of the perceived common means of protection against mosquito biting in Asembo homes indicated mosquito coils and traditional means in the first rank. The same methods dominated the second rank, where only two mothers listed bednets. Overall, bednets were generally ranked third, by half of the respondents. More expensive commercial methods including repellent jelly and aerosol sprays appeared least commonly used, ranked by one and two respondents respectively. Clearing bushes, appearing in the second, third, and fourth ranks were listed by 4 mothers only. Explaining their ranking of bednets, almost all (23) respondents said local people could barely afford one bednet, while one claimed bednet coverage in her neighbourhood was low because there were not that many mosquitoes. About a half (11) of the respondents thought nets cost something in the range of KES 250-400 (US\$ 4-6.6), while one-quarter thought nets cost over KES 400 (US\$ 6.6+). One eighth of the respondents perceived nets to be just very expensive, while the remaining one-quarter had no idea what nets cost and would not, therefore, make any estimate.

Asked to list perceived advantages of bednets, most (18) said nets protect against malaria. About a half (12) hypothesized that nets provided good sleep by preventing nuisance biting, while one-quarter (6) thought nets could protect 
one from anything that might fall on them. Other perceived advantages included privacy, listed by an eighth of the respondents, and making the room neat, or generating warmth on cold nights, listed by two respondents. About two-thirds (16) were non-committal about any perceived disadvantages. However, the rest (9) listed perceived disadvantages including heat (7), and risk of fires and detergent concerns for washing, each cited by one respondent.

\section{Bednet adherence monitoring}

Though generally apprehensive about bednet monitoring, almost all (37) respondents suggested the best times would be when they were at home, and mainly (26) in the daytime hours between mid-morning to afternoon hours. About one-quarter (10) thought monitoring could be done in the early morning hours. A negligible two respondents thought the best times would be in the late evening and early night respectively, when sleeping arrangements were likely to be in progress. Overall, the general indication was that monitoring must not interfere with daily household routine, particularly the mother's domestic chores.

\section{DISCUSSION}

In this paper we report findings from a rural community on their perceptions on malaria disease and bednet use. These findings contributed towards the design of our health communications, prior to the bednet trial. Our messages focused on improving local understanding of malaria, and persuading people that ITNs could help reduce morbidity and mortality associated with the disease. Sometime after the implementation of bednets, the focus shifted to practical issues; providing correct information aimed at addressing identified concerns and fears about the insecticide-treated bednets.

One important limitation with our study relates to the household questionnaire sample that was (deliberately) not representative of the entire community. The sampling technique applied in the overall study was purposive. We deliberately chose participants whom we expected to be able to tell us about the issues of interest, including experience with bednet use. Thus, although within the community from which the participants were sampled approximately $5 \%$ had bednets, we selected for our in-depth survey a higher proportion to better represent the views of those using bednets. This is a valid and useful technique in qualitative research when the aim is not to generalize, but to gain in-depth understanding of an existing phenomenon. Our findings were later validated in subsequent quantitative studies during the bednet trial. A study on knowledge, attitudes and practices with regards to malaria and bednets (Alaii et al, 2003 [a]) 
showed that while people's knowledge that mosquitoes cause malaria increased, the concept of multiple causes including getting cold through rain remained. Our study of adherence with bednet use in the short-term (Alaii et al, 2003 [b]) showed that the leading reasons for low adherence in children include perceived heat under bednets, disruption of sleeping arrangements, and technical issues such a low motivation to mount bednets in children's sleeping spaces.

A striking finding in our study was participants' perceptions that bednets prevent mosquitoes that cause malaria, and not malaria per se. It has been noted that the failure of programme participants to see the utility of their efforts is often linked to the complexity of locally held notions about malaria transmission (Helitzer-Allen et al., 1993). Disseminating information in locally relevant terms increases chances of improving understanding. Notably, explaining that nets prevent mosquito biting, which is the sole cause of malaria, may achieve better results than simply stating that bednets prevent malaria.

The findings revealed high likelihood of acceptability of bednets. However, the results also indicated equal likelihood that bednet use may be seasonal, and, in the absence of provision of nets for adults too, age dependent - with children losing out. While children's sleeping spaces appeared well defined, with bedtime movements revolving around age and customary beliefs, once in a while visitors spending the night may displace children. It appears that children's relative inferior status with regards to bednet access is aggravated by the general lack of congruity in preventing nuisance biting versus preventing disease, a result of widespread local association of malaria with factors other than mosquitoes. Also, socioeconomic activities in the home (mothers taking children with them to 'work' as early as 5:00 a.m.) may hamper a family's ability to notice benefits of bednets if children are re-exposed during peak Anopheles vector feeding time. The findings generally indicate a need for a concerted health education and information campaign, targeting the man-vector link in malaria transmission including how it is possible that malaria poses a health risk even when mosquitoes appear to be absent. Winch et al., (1994), suggest that while awareness creation is important, some motivational factors not necessarily directly related to health or climatic changes could be explored to maximize bed net usage. Although privacy was found to be a motivating factor for bednet usage in studies in The Gambia (MacCormack, 1989), it did not feature prominently in this study area, and may not be a good promotional indicator for this population. This could be attributed to the fact that in a polygamous household in rural Asembo, co-wives have separate houses. Also only small children share bedrooms with their parents, and they are relocated to new sleeping areas as soon as they are perceived old enough to infringe on parental privacy - all the more reason why coverage must ideally target all sleeping spaces identified in a household.

Concerns over the daily mounting and opening of bednets, bears important implications for adherence with bednet use as well. Bednets in sleeping spaces including the living rooms and kitchens will definitely have to be put up and 
taken down again daily, both for safety against theft, and study participants' concerns about neatness in the living rooms or net cleanliness and fire safety concerns in the kitchens. While mothers appear enthusiastic about getting bednets, daily mounting could soon become drudgery rather than a blessing. Also, the suggested fear of fire could front as a legitimate reason not to mount bednets at some times and in some places. Since these are the places children are likely to sleep in, the chances of low adherence for children, despite high coverage overall, may become a major factor to contend with. Overall, a core objective of an intervention targeting children would include addressing the emphasis on them, explaining and improving understanding on why they will need preferential coverage, and how other household members can benefit from this. 


\section{REFERENCES}

Alaii, J.A., van den Borne, H.W., Kachur, S.P., Shelley, K., Mwenesi, H., Vulule, J., Hawley,W.A., Nahlen, B.L., \& Phillips-Howard, P.A. (2003 [a]). Community reactions to the introduction of permethrin-treated bednets for malaria control during a randomised controlled trial in western Kenya. American Journal of Tropical Medicine \& Hygiene, 68, Suppl. 4.

Alaii, J.A., van den Borne, H.W., Kachur, S.P., Mwenesi, H.,Vulule, J.M., Hawley,W.A., Meltzer, M.I., Nahlen, B.L., \& Phillips-Howard, P.A. (2003 [b]). Perceptions of bednets and malaria prevention before and after a randomised controlled trial of bednets in western Kenya. American Journal of Tropical Medicine \& Hygiene, 68, Suppl. 4.

Lengeler, C., de Savigny, D., \& Cattani, J. (Eds.). (1996). Net Gain: A New Method of Preventing Malaria Deaths. Geneva \& Ottawa:WHO/IDRC.

Lengeler, C. (2003). Insecticide-treated bednets and curtains for preventing malaria (Cochrane Review) In The Cochrane Library. Oxford: Update software (Issue I, 2003).

Helitzer-Allen, D.L., Kendall, C., \& Wirima, J.J. (1993). The Role of Ethnographic Research in Malaria Control:An Example from Malawi. Research in the Sociology of Health Care, 10, 269 286.

MacCormack, C.P. (1989). People's attitudes. (WHO informal consultation on the use of impregnated bednets and other materials for vector-borne disease control). Geneva, Salle, 1989, Agenda Item 8.2

Phillips-Howard, P.A., ter Kuile, F.O., Nahlen, B.L., Alaii, J.A., Gimnig, J.E., Kolczak, M.S., Terlouw, D.J., Kariuki, S., Shi,Y.P., Kachur, S.P., Hightower,A.W.,Vulule, J.M., \& Hawley, W.A. (2003 [a]). The efficacy of permethrin-treated bednets on child mortality and morbidity in western Kenya. II: Design and methods. American Journal of Tropical Medicine \& Hygiene, 68, Suppl. 4.

Phillips-Howard, P.A., Nahlen, B.L., Alaii, J.A., ter Kuile, F.O., Gimnig, J.E., Terlouw, D.J., Kachur, S.P., Hightower, A.W., Lal,A.A., Schoute, E., Oloo, J.A., \& Hawley,W.A. (2003 [b]). The efficacy of permethrin-treated bednets on child mortality and morbidity in western Kenya. I: development of infrastructure and description of study site. American Journal of Tropical Medicine and Hygiene, 68, Suppl. 4.

Phillips-Howard, P.A., Nahlen, B.L., Wannemuehler, K.A., Kolczak, M.s., ter Kuile, F.O., Gimnig, J.E., Olson, K., Alaii, J.A., Odhacha, A., Vulule, J.M., \& Hawley,W.A. (2003 [c]). Impact of permethrintreated bednets on the incidence of sick child visits to peripheral health facilities. American Journal of Tropical Medicine and Hygiene, 68, Suppl. 4.

Winch, P.J., Makemba, A.M., Kamazima, S.R., Lwihula, G.K., Lubega, P., Minjas, J.N., \& Shiff, C.J. (1994). Seasonal variation in the perceived risk of malaria: Implications for the promotion of insecticide-treated bed nets. Social Science and Medicine, 39(63-75).

Winch, P.J., Makemba, A.M., Kamazima, S.R., Lurie, M., Lwihula, G.K., Premji, Z., \& Shiff, C.J. (1996). Local terminology for febrile illnesses in Bagamayo District, Tanzania, and its impact on the design of a community-based malaria control programme. Social Science and Medicine, 42, I057-67.

WHO (1996). Tropical diseases control: Malaria in the world. Geneva: Division of control of tropical diseases (CTD/TDT/96.12), WHO. 
WHO (2000[a]). WHO Expert Committee on Malaria:Twentieth Report. Geneva, World Health Organization

WHO (2000[b]). The African Summit on Roll Back Malaria, Abuja, Nigeria,April 25, 2000, Geneva, World Health Organization 


\section{CHAPTER 3}

CARE SEEKING FOR CHILDHOOD MALARIA

IN WESTERN KENYA: KNOWLEDGE, ATTITUDES, PERCEPTIONS AND BEHAVIOUR (KAPB)

BEFORE AND AFTER A TRIAL

OF INSECTICIDE-TREATED BEDNETS I

ITo be submitted as:

Jane A. Alaii, S. Patrick Kachur, H.W. van den Borne, Halima Mwenesi, John Vulule, William A. Hawley, S. van der Geest, Penelope A. Phillips-Howard. Care seeking for childhood malaria in western Kenya: Results of knowledge, attitudes, perceptions and behaviour (KAPB) surveys before and after a trial of insecticide-treated bednets. 


\begin{abstract}
We conducted knowledge, attitudes, perceptions, and behaviour (KAPB) surveys with independent random samples of caregivers of children $<5$ years of age to explore knowledge and care seeking practices for childhood malaria before and after a trial of insecticide-treated bednets in western Kenya. Knowledge that mosquitoes cause malaria increased post-intervention, with former control villages appearing better informed than former experimental villages ( $44.4 \% \mathrm{vs}$. $27.9 \% ; \mathrm{P}<0.001)$. Analyses suggested 3 distinct domains of illnesses - those perceived best managed using traditional medicine, pharmaceutical medicine, or a combination of both. Nearly three quarters $(70.7 \%)$ of households reported that at least one child in their home was ill around the time of interview. Malaria associated illness categories were perceived to occur more frequently pre-intervention than post intervention $(\mathrm{OR}=0.476$; $95 \%$ CI $0.278-0.811$; $\mathrm{P}<0.01$ ). Of 347 households with a recent child malaria history, $96.3 \%$ administered home treatment as first care. Self-medication was mostly used (60.2\%); over half of which were obtained from local shops. The second resort to care was use of traditional remedies $(21.1 \%)$. Use of medicines significantly decreased post-intervention, with a concurrent increased use of folk remedies $(\mathrm{OR}=0.48,95 \%$ CI $0.30-0.78 ; \mathrm{P}<0.01)$. Overall, $42.7 \%$ of the caregivers visited a medical facility at some point. The leading deterrents to health facility use were cost (35.7\%) and distance (27.6\%). It appeared that medical care at formal health facilities would be sought as an additional resort, mainly after other care such as self-medication, had been tried without success $\left(\mathrm{X}^{2}\right.$, $\mathrm{P}<0.001)$. There appeared no association between caregivers' education and resorts to care. The advice of significant others appeared important for deciding care seeking $\left(\mathrm{X}^{2}, \mathrm{P}<0.001\right)$. Implications for scaling up home based malaria interventions are discussed.
\end{abstract}




\section{INTRODUCTION}

Early diagnosis and access to prompt treatment using effective anti-malarial drugs is a key component of current global malaria control strategies. For Africa, where the malaria mortality burden is highest (WHO, 1996), and health services are not within easy reach, the goal is to ensure that quality drugs are easily obtained and distributed everywhere, including in the home (Marsh et at., 1999; TDRnews, 2002). Ultimately, the application of strategies for malaria control lies in the hands of their end users (WHO, 1993; World Bank, 1993)understanding contextual aspects of the disease and its management is crucial for choosing and tailoring interventions (Agyepong et al., 1995; Mwenesi et al., 1995; Winch et al., 1996; Tanner \& Vlassof, 1998). Prior to and after a trial of insecticide-treated bednets (ITNs) and concurrent health education in western Kenya, we conducted surveys to examine changes in people's malaria knowledge and practices relating to childhood malaria including, care seeking, prevention, and the role of bednets. Such comparative analysis might provide useful information for programmatic decisions, particularly those affecting health education and promotion. Typical of most societies, women in our study area are de facto household managers and the main caregivers. Since the deployment of malaria control measures lies with those responsible for health in their families, targeting mothers is key for developing effective malaria preventive interventions. In this paper we describe findings in relation to caregivers' knowledge and practice regarding childhood malaria including care seeking. An analysis of the predictors of practices (behaviours) with regard to protection from malaria, including the value attached to bednets, motivation for use, and their implications for sustained bednet use is presented elsewhere (Alaii et al., 2003 [a]). The specific objectives of this study were to document any changes pre- vs. post-intervention with regards to 1) mother's perceptions of malaria, 2) care seeking for a recent childhood malarial illness, including the use of drugs, and 3) decision-making about resorts to care.

\section{METHODS}

\section{Study site and population}

This paper forms part of a multi-disciplinary investigation into malaria control during a trial of insecticide-treated bednets (ITNs) in rural western Kenya. Detail of the study site and population is presented elsewhere (Phillips-Howard et al., 2003 [a]). The study site, Asembo, covering $200 \mathrm{~km}^{2}$ on the shores of Lake Victoria, is situated $50 \mathrm{~km}$ from Kisumu, the regional headquarters. The 
population is predominantly Luo, living in highly dispersed villages. The economy is mainly subsistent, based on small family farms, fishing, and marketing food and grain. Baseline studies revealed low bednet coverage $(<5 \%)$, with preference given to adults and visitors. People perceived bednets primarily as a way to avoid mosquito nuisance rather than an important tool for child health (Alaii, 1997).

Rainfall occurs year-round, heaviest in March-April, with a second peak in November-December. Total annual rainfall averages over 1,000 mm (PhillipsHoward et al., 2003 [a]). Malaria is holoendemic, with entomologic inoculation rates between 60-300 infective bites per person per year (Beier et al., 1994). The primary vectors are Anopheles gambiae and Anopheles funestus, with Plasmodium falciparum being the principal species of human malaria in the region. Prior to the trial, parasite prevalence studies indicated that 70-80 percent of children under five were infected at any time, with little seasonal variation (Bloland et al., 1999).

From the outset and during the trial an intensive educational campaign delivered messages by word of mouth and other techniques (participatory educational theatre, calendars, community meetings, information sheets, song) throughout the study area. While the project focused on the role of ITNs in reducing child morbidity and mortality due to malaria, key messages emphasised that children presenting with illness including fever should be taken to health facilities for proper diagnosis and treatment, regardless of ITN status.

\section{Study design}

The data were generated from pre- and post-intervention household surveys conducted in March 1996 and January 1999, respectively. Independent random samples of respondents from 600 of 8,707 compounds were used in each survey. Logistical constraints related to infrastructural difficulties in the study area (Phillips-Howard et al., 2003 [a]), and constant mobility and home relocations characteristic of the Luo people (Mboya, 1938; Mboya, 1967), made it impractical to conduct a matched samples study. Multi-stage sampling was used to ensure a cross-section of respondents. Firstly, a list of all homesteads with at least one child $<5$ years of age was drawn from project census records, followed by random selection of homesteads. Finally, one household with a child $<5$ years of age was randomly selected. One additional criterion was used postintervention - after listing all homesteads with a child $<5$ years the sampling frame was divided into former control and former experimental villages, followed by random selection of 300 homesteads each to facilitate comparisons between the 2 groups of homesteads post-intervention.

A pre-tested, pre-coded questionnaire translated into Dholuo was used, targeting caregivers of children $<5$ years of age. To minimise social desirability bias, respondents gave spontaneous answers that interviewers marked on a structured checklist. The questionnaire was designed following baseline ethnographic stud- 
ies (Shelley K., Unpublished report; Alaii, 1997) - designed to document more contextual information on the social aspects of malaria and factors relevant for bednet implementation. Questions used post-intervention were adapted from the pre-intervention questionnaire. Both surveys assessed caregivers' knowledge of the perceived causes of malaria, and resorts to care for childhood illness; including questions to assess local domains of illness and care seeking, and specific household care seeking for a child $<5$ years recently (in the past week) presenting with malaria. Questions assessing domains of illness included asking caregivers whether they used herbal remedies for specific listed illnesses including malaria and folk illnesses bio-medically associated with malaria, and asking sequentially if they used medicines purchased from shops to treat these illnesses. Lastly, they were asked [for the same list of illnesses] if they would seek care from a local dispensary, and again if they would at a hospital. Questions on care seeking for recent childhood malaria episode included the type of care action taken when the child first presented with illness, if any additional care was sought, whether the caregiver consulted someone, whether medicines were given, and the type of medicines used.

\section{Data collection}

Thirteen field surveillance supervisors administered questionnaires, using free flowing questions. All had experience in survey research, and were fluent in Dholuo, the language of interview. At both surveys they were trained on the use of the questionnaire, and conducted at least 3 field trials each. During data collection the researcher and assistants checked all forms in the field office for consistency and completeness. Field workers revisited households wherever gaps on the questionnaire were identified. Data coding and entry were done at a central location in Kisumu, the research institute's base station.

\section{Definitions}

In this paper we interchangeably use the terms herbal, traditional, and folk remedies to refer to all components of traditional therapy. During interviews we used the term "yadh nyaluo" which is a general term for various folk therapies found in the community. The terms experimental and control villages are used in comparisons between villages that had previously been assigned experimental or control status during the randomised-controlled trial of insecticide-treated bednets (ITNs). Also, the terms pre-intervention and post-intervention are used here to mean before and after the trial of ITNs respectively. 


\section{Statistical methods}

Data were entered into Clarion ${ }^{\circledR}$, Rel. 2.1 (Clarion Software Corp.) using data screens with automatic range and consistency checks. Data were further checked for consistency using SAS ${ }^{\circledR}$, Rel. 8.1 (SAS Institute Inc., Cary, NC, USA).

Analysis was done using SPSS ${ }^{\circledR}$, Rel. 11.0 (SPSS Inc., Chicago, IL, USA).

Analyses on local classification of illness and how it may impact on general care seeking included all respondents in the study sample. For the analysis of care seeking for a child with recent malaria, a categorical variable was derived from the data, including several illness concepts whose local defining symptoms approximate clinical malaria (Alaii et al., in preparation). These included diseases caregivers attributed to malaria, including del maore (fever), midhusi (early stages before malaria symptoms become obvious), liet (high fever), and fudha (illness stage preceding the onset of anaemia). Of 439 (36.9\%) households stating a child had been ill in the past week, 347 (79\%) fitted this category, and are the focus of analyses relating to care seeking for a recently ill child.

Statistically significant differences in responses were not identified during analyses comparing control and intervention villages in the post-intervention survey. Thus, these data were pooled to represent the post-intervention sample, to increase sample size and precision.

Principal Components Analysis (PCA) was used to assess how responses cluster for items in questions that assess illness classification, and to illustrate underlying dimensions of resort to care. Basic procedures used in PCA were applied (Kaiser, 1960; Cattell, 1966; Field 2000). Items included in the analysis were considered to correlate well if the correlation matrix (R-matrix value) was significant at the $\mathrm{P}<0.05$ level. A Kaiser-Meyer-Olkin (KMO) value of 0.7 , and a Bartlett's test of sphericity value $\mathrm{P}<0.05$ meant the data were robust and delivered statistically reliable results. A Cronbach alpha coefficient $(\alpha=0.7)$ was used to check the internal consistency of factors extracted in the PCA analyses. Chi-square tests $(\mathrm{P}<0.05)$ signified independence in cross-tabulations of variables, and compatibility of the distribution of values in a single variable.

\section{RESULTS}

\section{Illness classification and general trends in resort to care}

\section{Underlying structure of resorts to care}

Principal Components Analyses (PCA) to identify the dimensions in likelihood use of herbal remedies to treat illnesses commonly affecting children had a KMO 0.757, and Bartlett's test of sphericity $(\mathrm{P}<0.001)$. Three factors with 
eigenvalues $>1$, explaining $62.467 \%$ of the total variance in responses were extracted. Appendix 3.1 shows three distinct categories evident in the clustering of items in the three factors; illnesses definitely defined as malaria-related (malaria and midhusi) [factor 1], diarrhoeal diseases [factor 2], and illnesses manifesting with convulsions (talarieya, and ndulume) [factor 3]. There appeared an overlap of diarrhoeal diseases between factors 1 and 2 - suggesting two underlying dimensions and thus two different interpretations of these diseases.

The analyses for likely use of pharmaceutical medicines purchased from local shops, or dispensed at local dispensaries or at hospitals all revealed R-matrix values $\mathrm{P}<0.05$, KMO above 0.8 , and Bartlett's tests of sphericity $\mathrm{P}<0.001$. For each care type, two factors with eigenvalues $>1$ were extracted - appendix 3.2 shows results for likely use of medicines purchased in local shops. Mild malaria illness and fever, and diarrhoeal diseases with the exception of orianyanja [childhood diarrhoea] appeared to cluster in factor 1. Orianyanja and folk illnesses (including those manifesting with convulsions and identified locally as fudha, talarieya, ndulume) bio-medically associated with malaria but often less understood among the lay population clustered in factor 2 .

\section{Care seeking for a recently ill child}

\section{Recent childhood illnesses}

Overall, 841 (70.7\%) respondents stated their child had been recently ill. Of these, 439 (52.2\%) indicated that a child within their household was ill [any illness] within the range of the past week, of which 317 (71.5\%) were said to be ill at the time of interview. Of the 439 , only $25.9 \%$ were sick in the range of the past week pre-intervention, compared to $45.1 \%$ post-intervention in villages issued bednets eralier; $\mathrm{P}<0.001$. Notably, however, the frequency of perceived child fever decreased from $72.7 \%$ pre-intervention, to $62.0 \%(\mathrm{P}<0.05)$. Significant differences were noted in comparisons between pre-intervention households and former control households, $25.9 \%$ versus $50.8 \%, \mathrm{P}<0.001$. There were no significant differences between former control and former experimental villages.

Combined, the study sample shows the two most commonly named recent childhood illnesses were del maore (65.8\%), and malaria (32\%), (Table 3.1). While del maore was listed more frequently pre-intervention, all other illnesses appeared listed significantly more frequently post-intervention. Notably, ndulume and talarieya, conditions that can be ascribed to severe malarial disease were rarely recorded and were not significantly different pre- and post-intervention. Comparisons post intervention between former control and former intervention villages yielded no significant differences, except for ich kach (stomach upsets) $(\mathrm{OR}=0.432,95 \% \mathrm{CI} 0.223-0.838, \mathrm{P}=0.011)$, and angiew (measles) $(\mathrm{OR}=$ $0.319,95 \%$ CI $0.111-0.919, \mathrm{P}=0.027)$, which appeared to occur approximately twice as frequently in control villages than intervention villages. 
Table 3.I IIlness presentation in children falling ill the past week $(N=439)$

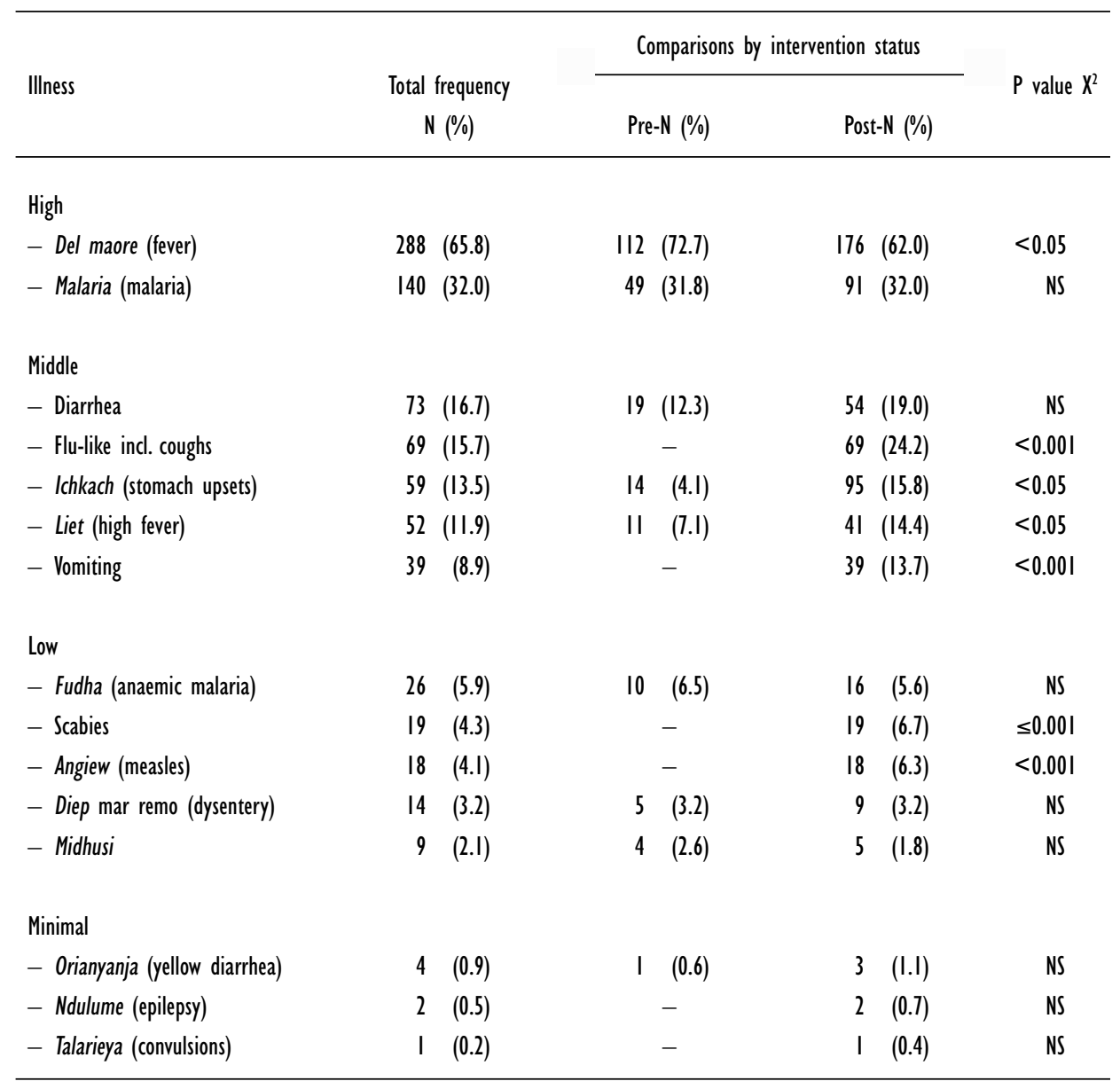

Children in 347 (79\%) households reportedly presented with at least one illness symptom whose local description fit biomedical definitions of malaria related illness, including malaria, del maore, midhusi, liet, and fudha. Table 3.2 summarizes these grouped illness categories derived from the data, and likely to be malaria. These illness categories were perceived to occur more frequently pre-intervention than post intervention $(\mathrm{OR}=0.476 ; 95 \%$ CI $0.278-0.811 ; \mathrm{P}<0.01$. No significant differences were noted post intervention, comparing control and intervention villages. The remainder of the results presented on care seeking for a recently ill child is restricted to this group.

Decision making for care seeking

Of the 347 households where a child was reported to have recently experienced 
Table 3.2 Derived proportions of malaria related illnesses by presence of fever and intervention status

\begin{tabular}{|c|c|c|c|c|c|c|c|}
\hline \multirow{2}{*}{ Illness } & \multirow{2}{*}{$\begin{array}{c}\text { Total } \\
\text { frequency } \\
\text { N (\%) }\end{array}$} & \multicolumn{2}{|c|}{ Comparisons by intervention status } & \multirow{2}{*}{$\begin{array}{c}P \\
\text { value } \\
X^{2}\end{array}$} & \multirow{2}{*}{$O R$} & \multicolumn{2}{|c|}{$95 \% \mathrm{Cl}$} \\
\hline & & Pre-N (\%) & Post-N (\%) & & & Low & High \\
\hline $\begin{array}{l}\text { One of malaria related } \\
\text { illnesses* }\end{array}$ & $347(79.0)$ & $133 \quad(86.4)$ & $214 \quad(75.1)$ & $<.01$ & 0.476 & 0.278 & 0.811 \\
\hline Fever (-malaria) & $197(44.9)$ & 80 (51.9) & II7 (4I.I) & $<.05$ & 0.644 & 0.434 & 0.956 \\
\hline Fever (+malaria) & $91 \quad(20.7)$ & $32(20.8)$ & $59 \quad(20.7)$ & NS & 0.995 & 0.614 & 1.614 \\
\hline Malaria (-fever) & 49 (II.2) & I7 (II.0) & $32 \quad(I I .2)$ & NS & 1.019 & 0.546 & 1.902 \\
\hline
\end{tabular}

Including malaria, del maore, liet, midhusi, and fudha, while excluding all other illnesses not locally defined as a manifestation of malaria.

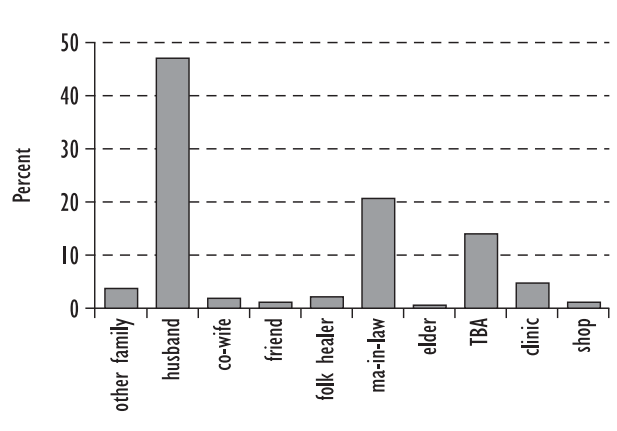

Figure 3.I First person consulted at onset of child's illness

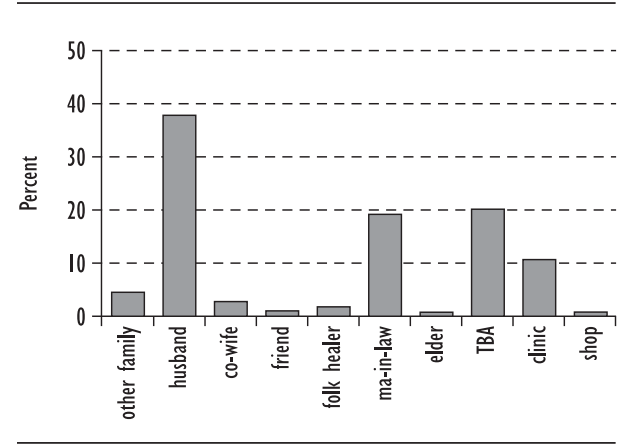

Figure 3.2 Person perceived to have given best advice

one of the malaria-like illnesses, $242(69.7 \%)$ caregivers consulted someone else when their child became sick (Figure 3.1). The child's biological father was most commonly (47.5\%) consulted, followed by mothers-in-law $(21.1 \%)$, and local traditional birth attendants (TBAs), (14.5\%). Others included clinic personnel $(9.1 \%)$ and other family members $(4.1 \%)$. Of 241 (99.6\%) mothers rating quality of advice received (Figure 3.2), the majority listed the child's biological father's advice as best (37.8\%), followed by TBAs (19.9\%), and mothers-in-law (19.1\%). At least 10.8\% caregivers perceived clinical personnel advise as best. While the advise of fathers and mothers-in-law was commonly sought at onset of illness, their rating in relation to perceived quality of advice appeared to drop while those of others such as TBAs and clinic staff rose. Generally, there appeared little favour for the advise of co-wives and friends. 
Table 3.3 Types and distribution of care pre vs. post intervention

\begin{tabular}{|c|c|c|c|c|c|c|c|c|}
\hline & \multirow{2}{*}{\multicolumn{2}{|c|}{$\begin{array}{l}\text { Total frequency } \\
\text { N }(\%)\end{array}$}} & \multicolumn{2}{|c|}{ Comparisons by intervention status } & \multirow{2}{*}{$\begin{array}{c}P \\
\text { value } \\
X^{2}\end{array}$} & \multirow{2}{*}{ OR } & \multicolumn{2}{|c|}{$95 \% \mathrm{Cl}$} \\
\hline & & & Pre-N (\%) & Post-N (\%) & & & Low & High \\
\hline Home treatment $(\mathrm{HT})$ given & 334 & $(96.3)$ & $121 \quad(91.0)$ & 213 & $<0.001$ & 21.1 & 2.7 & 164.4 \\
\hline Medicine & & $(60.4)$ & $86 \quad(71 . I)$ & $115 \quad(54.2)$ & $<0.01$ & 0.48 & 0.30 & 0.78 \\
\hline Traditional folk (+others) & 132 & $(39.6)$ & $35 \quad(28.9)$ & $97 \quad(45.8)$ & & & & \\
\hline $\begin{array}{l}\text { Additional care sought } \\
\text { after HT }\end{array}$ & 284 & $(81.8)$ & $74 \quad(55.6)$ & 210 & $<0.001$ & 41.9 & 14.7 & 119.2 \\
\hline Recognized medical facility & 145 & $(41.8)$ & $66 \quad(49.6)$ & $79 \quad(36.9)$ & $<0.05$ & 0.59 & 0.38 & 0.92 \\
\hline Shop/chemist & 72 & $(25.4)$ & II (14.9) & $61 \quad(29.0)$ & $<0.05$ & 2.35 & 1.16 & 4.75 \\
\hline Traditional healer & 50 & $(17.6)$ & $17 \quad(23.0)$ & $33 \quad(15.7)$ & NS & 0.63 & 0.32 & 1.21 \\
\hline CHW/CBD & 21 & $(7.4)$ & $3 \quad(4.1)$ & $18 \quad(8.6)$ & NS & 2.22 & 0.63 & 7.76 \\
\hline Some private clinic & 24 & $(8.5)$ & $3 \quad(4.1)$ & $21 \quad(10.0)$ & NS & 2.63 & 0.76 & 9.11 \\
\hline Medicine given (ever) & 318 & $(96.4)$ & $116(100.0)$ & $202 \quad(94.4)$ & NS & 1.06 & 1.03 & I.II \\
\hline Chloroquine & 166 & $(47.8)$ & $63 \quad(47.4)$ & 103 & NS & 1.03 & 0.67 & 1.60 \\
\hline $\begin{array}{l}\text { Sulphadoxine Pyremithamine } \\
\text { (SP) }\end{array}$ & 40 & $(I I .5)$ & $27 \quad(20.3)$ & $13 \quad(6.1)$ & $<0.001$ & 0.25 & 0.13 & 0.51 \\
\hline Antipyretics & 208 & $(59.9)$ & $65 \quad(48.9)$ & $143 \quad(66.8)$ & 0.001 & 2.11 & 1.35 & 3.28 \\
\hline Amodiaquine & & $(2.0)$ & $3 \quad(2.3)$ & $4 \quad(1.9)$ & NS & 0.83 & 0.18 & 3.75 \\
\hline
\end{tabular}

\section{Tracing care seeking patterns}

Almost all (96.3\%) caregivers stated their recently ill child received some form of home care at the onset of illness. The majority $(60.4 \%)$ received pharmaceutical medicines, while the rest received traditional folk remedies (21\%), and other care $(18.6 \%)$, including sponging and rest $\left(\mathrm{X}^{2}=108.545\right.$, df $\left.2, \mathrm{P}<0.001\right)$. Most pharmaceutical medicines used at home were obtained from local retail shops $(51.6 \%)$, while others were retained from a previous visit to a local health centre $(5.2 \%)$ or hospital $(0.5 \%)\left(\mathrm{X}^{2}=176.545, \mathrm{df} 1, \mathrm{P}<0.01\right)$. A comparison of pre-intervention with post intervention (Table 3.3), suggested a decline in the use of medicines for home treatment at the onset of illness, and an increase in the use of folk therapy post intervention $\left(\mathrm{X}^{2}=13.008\right.$, df $2, \mathrm{P}<0.01$ [OR $=$ $0.48,95 \%$ CI $0.30-0.78]$ ). No significant differences were noted in comparisons post-intervention, except that the use of traditional healers appeared to be higher in the former control than the former experimental group (20.7\% vs. $10.1 \%$, $[\mathrm{P}<0.05])$. Analyses of use of specific medicines yielded no change in the use of 
chloroquine. Due to the discontinuation of a cohort study in Asembo Bay, there was a three-fold decrease in the availability of suphadoxine-pyrimethamine (SP) drugs post-intervention $(\mathrm{OR}=0.25,95 \%$ CI $0.13-0.51, \mathrm{P}<0.001)$.

One hundred forty-eight (42.7\%) caregivers stated that they had taken their child to a formal health facility at some point during the illness. The leading deterrents to formal health facility use were cited as financial constraints (35.7\%), and distance (27.6\%). It appeared also that facility-based care, as an additional resort, might have been sought only after other preceding care had failed $(14.6 \%)$, and/or the condition generally did not improve $(17.9 \%)\left(\mathrm{X}^{2}=\right.$ 48.694 , df $4, \mathrm{P}<0.001)$. Six percent of caregivers overall indicated failure to visit a formal health facility was a result of previous failure to provide positive results. No significant differences were noted between mother's education and resort to care, though frequency data suggested that the more education a mother had, the more likely she was to use medicines either bought over-thecounter (OTC) or from a formal health facility.

\section{DISCUSSION}

In this study we attempt to determine whether caregivers knowledge and perceptions of childhood illnesses and resorts to care changed as a consequence to the introduction of insecticide-treated bednets in a randomised controlled trial. Data were generated suggesting that the perceived frequency of malaria-like illness, and use of self-medication appeared to decrease while traditional medicines increased. Importantly, however, illness in general, reported in nearly three quarters of households, was not perceived to decrease significantly over the course of the trial. Malaria-like illnesses were thus replaced, as perceived by caregivers, by other illnesses. Similarly, shop-bought medications appeared to be replaced by a concurrent increase in the use of informal care providers such as traditional healers. It is unclear whether these findings partly reflect an increased awareness of the population about malaria and its symptoms, consequent to our educational activities associated with the trial. It may also reflect that less severe illnesses replaced malaria-like illnesses. Our questionnaire surveys were unable to differentiate adequately to confirm this. However, clinical studies conducted before and during the trial confirm that malaria-associated indices fell significantly, consequent to bednet use (ter Kuile et al., 2003).

Our results concur with and support other studies indicating that the diagnosis and treatment for childhood malaria begins in the home (Gomes et al., 1994; Tanner and Vlassof, 1998), often involving soliciting for the opinion of significant others. Self-medication is common in western Kenya (Ruebush et al., 1995; Geissler et al., 2000) and in other parts of the country (Mwenesi et al., 
1995; Marsh et al., 1996). Shops, known locally as duka, are within easy reach, and caregivers can purchase at least some proportion of the required drug and/or dosage even if they do not have enough money. During the course of this trial, however, only chloroquine was available at local retailers. Studies on rational drug use have illustrated that compliance with prescribed regimens is poor and people freely share medication with others, even when people visit formal health facilities (Ruebush et al., 1995). Decisions about care seeking are made depending on a myriad of factors including the interpretation of illness symptoms, previous experience with perceived symptoms, and advice given. Immediate additional care was not necessarily sought from a formal health facility, although many caregivers eventually visited a health service. Only $2.3 \%$ of 347 mothers appeared to have visited a formal health facility from the outset.

Knowledge, attitudes, and practices (KAP) surveys have become a standard approach to examining people's beliefs and practices in relation to disease and community receptiveness of disease control interventions. A major limitation with our study is that unlike studies elsewhere (Mwenesi et al., 1995; Winch et al., 1996) it did not seek to obtain an in-depth description of lay terminology and perceptions of malaria, and its care seeking. These questions had been addressed in formative studies (Shelley K., unpublished report) and the aim with this paper was to describe the effect of the bednet study and its health education components on peoples perceptions of malaria. It is no doubt that the study does not generate any new knowledge into malaria and care seeking research, however, it generates contextual information critical for malaria control in this population.

Our analyses indicate distinct classifications of illness influencing care seeking revolving around perceptions of the type of illness. Therefore some conditions are perceived best suited to pharmaceuticals, others to traditional remedies, and yet others to a combination of both pharmaceutical and folk medicine. The pattern of factor loadings suggested mothers perceived malaria illness to be in a different category from other folk illnesses they would normally treat using herbal remedies. Frequency distributions of the data reflect the factor loadings, indicating that caregivers readily treat fever using biomedical resources but preferred traditional therapy for its related folk illnesses presenting with convulsions. Ethnographic assessment in the study area (Shelley K., unpublished report) and in a coastal Kenyan community (Mwenesi et al., 1995) observed that interpretation of illness is not necessarily based solely on a set of indicators, but as well on a consideration of the social and cultural environment at the time of illness, and caretaker's appraisal of physical symptoms. Formative research indicated that while caregivers recognized disease conditions presenting with convulsions as serious, they did not appear to link them with malaria, neither did they necessarily perceive them as treatable using pharmaceuticals. Because these conditions are perceived caused by evil spirits (jochiende) cast on the sufferer through witchcraft, it is a widely held belief in lakeside communities in western Kenya that they cannot be treated until the offending spirit has 
been dispelled - perceived possible only through prayer or strong traditional healing involving "communication with the spirits". Thus biomedical care is perceived a waste of time, and while mothers may eventually seek medical care, they first must seek alternative therapy. This has implications for early diagnosis and appropriate treatment for serious conditions such as talarieya (convulsions) and fudha (stage before anaemia becomes obvious), which do not appear to be linked in peoples' perceptions to malaria.

Failure to visit a formal health facility by caregivers was reportedly due to practical issues including distance, cost, and perceived past quality. While it may appear that people do not attend formal health services for some conditions, health facility use is often regarded as an alternative (mostly a last resort) after some preferred care has been tried, or when an illness is interpreted as potentially fatal, in which case people may seek formal health care from the outset (Alaii et al., 2003 [b]). Indeed, self-treatment is common for conditions perceived related to malaria, and people often use multiple sources of care (McCombie, 1996; Saradamma et al., 2000), switching from self-treatment to alternative care depending on availability and their interpretation of the patient's condition (Tanner \& Vlassof, 1998; Nyamongo, 2002). As elsewhere (Mwenesi et al., 1995; Winch et al., 1996) intervention design for this population may benefit from cognizance of the interplay between economics, personal beliefs, and/or culture on health behaviours and outcomes. A key component of current global malaria control strategies relates to reducing illness and death in young children through prompt appropriate treatment (WHO, 2001). This requires improving either the promptness with facility-based treatment, or the appropriateness of home treatments. The former is not easily attainable considering infrastructural and resource limitations characteristic of countries endemic for malaria, particularly in remote communities. Attempts at facility-based solutions must first address geographic and economical constraints in target areas. Improving home treatment, on the other hand is more readily achievable - by making the right drugs more widely available and educating caregivers and drug sellers about appropriate use and complete dosing (Pagnoni et al., 1997; Marsh et al., 1999; Kidane \& Morrow, 2000).

A role for health education and/or promotion in this population is indicated in two aspects. Firstly, caregivers' perception that malaria is best treated using pharmaceutical medicines (Alaii et al., 2003 [b]) could be exploited to improve care seeking for related serious conditions such as talarieya, fudha, and remo-matin (anaemia). Mwenesi et al., (1995) have suggested before that one way to do this is by improving local understanding and recognition of the linkages between such illness conditions and malaria through carefully planned health education and promotion. Secondly, the ease with accessing anti-malarial drugs over-the-counter in the region (Geissler et al., 2000) indicates not only the need to improve treatment through rational use of drugs, but also a ready existing framework for scaling up malaria treatment. With appropriate training, drug sellers and community health workers can help improve local self-prescribing 
practices (Pagnoni et al., 1997; Marsh et al., 1999; Kidane \& Morrow, 2000). Shopkeeper training is currently a major vehicle for scaling up prompt effective malaria home treatment (WHO, 2001). How far this goes with efforts to minimize the evolution of drug resistance is debatable, but it is a good start towards addressing the malaria problem where it is felt most.

Since people tend to move freely from one care strategy to another, identifying potential partners is essential. In our study, we identify five distinct subgroups of resourceful partners and/or targets for programme design; 1) lay providers including traditional healers, 2) household-level care givers including mothers and/or child caregivers, 3) the commercial sector including shopkeepers and market vendors, 4) community health workers including traditional birth attendants and community-based drug distributors, and 5) the formal health sector. Conveying the subjective meaning of a health problem and its antecedents is key for success (Bartholomew et al., 2001) - the participation of these groups, particularly the lay providers and household care givers offers the advantage of being able to explain health conditions in a culturally meaningful manner. The community health worker level is also valuable, providing ready linkages between caregivers, and the informal and formal health sectors.

While our study population has had the advantage of trying bednets and is better placed to decide on health benefits associated with bednet use, the survey suggests that the presence of ITN did not necessarily influence the perception of caregivers that childhood illnesses in general were impacted by the presence of bednets. While malaria-like illness did appear to be reduced, and the use of self-treatment with shop bought medication dropped, treatment with traditional medications rose. This suggests that during bednet delivery programmes, public health staff need to be aware that community perceptions of disease, and their consequent actions and resorts to care, may not tally with expected 'formal' health seeking. Improvement in shopkeeper training, education to caregivers on homecare, and inclusion of informal and traditional sources when training peripheral health care workers, should continue in parallel with bednet programmes. 


\section{REFERENCES}

Agyepong, I.A.,Aryee, B., Dzikunu, H., \& Manderson, L. (1995). The malaria manual: Guidelines for the rapid assessment of social, economic and cultural aspects of malaria. (TDR/SERMSR/95-I).

Alaii JA, (1997). The relevance of sleeping arrangements and bedtime mobility patterns for implementing insecticide-treated bednets in Asembo, western Kenya. M.Sc. Dissertation, London, School of Education, Politics and Social Sciences, Faculty of Health Sciences, South Bank University, UK.

Alaii, J.A., van den Borne, H.W., Kachur, S.P., Mwenesi, H.,Vulule, J.M., Hawley,W.A., Meltzer, M.I., Nahlen, B.L., \& Phillips-Howard, P.A. (2003 [a]). Perceptions of bednets and malaria prevention before and after a randomised controlled trial of bednets in western Kenya. American Journal of Tropical Medicine \& Hygiene, 68, Suppl.4.

Alaii, J.A., van den Borne, H.W., Kachur, S.P., Shelley, K., Mwenesi, H., Vulule, J., Hawley,W.A., Nahlen, B.L., \& Phillips-Howard, P.A. (2003 [b]). Community reactions to the introduction of permethrin-treated bednets for malaria control during a randomised controlled trial in western Kenya. American Journal of Tropical Medicine \& Hygiene, 68, Suppl. 4.

Alaii, J.A., van den Borne, H.W., Kachur, S.P., Mwenesi, H., Vulule, J., Hawley, W.A., Nahlen, B.L., \& Phillips-Howard, P.A. (in preparation/Chapter 2). Sleeping arrangements in a rural community in western Kenya: Relevance for bednet utilization.

Bartholomew, L.K., Parcel, G.S., Kok, G., \& Gottlieb, N.H. (200I). Intervention Mapping: Designing theory and evidence-based health promotion programs. Mountain View, CA: Mayfield Publishing Company.

Beier, J.C., Oster, C.N., Onyango, F.K., Bales, J.D., Sherwood, J.A., Perkins, P.V., Chumo, D.K., Koech, D.V.,Whitmire, R.E., Roberts, C.R., Diggs, C.L., \& Hoffman, S.L. (1994). Plasmodium falciparum incidence relative to entomological inoculation rates at a site proposed for testing malaria vaccines in western Kenya. American Journal of Tropical Medicine \& Hygiene, 50, 529--536.

Bloland, P.B., Ruebush, T.K., McCormick, J.B., Ayisi, J., Boriga, D.A., Oloo,A.J., Beach, R., Hawley, W.A., Lal, A., Nahlen, B., Udhayakumar,V., \& Campbell, C.C. (1999). Longitudinal cohort study of the epidemiology of malaria infections in an area of intense malaria transmission. II. Descriptive epidemiology of malaria infection and disease among children. American Journal of Tropical Medicine \& Hygiene 60, 64I-648.

Cattel, R.B. (1966) The scree test for the number of factors. Multivariate Behavioural Research, I, 245-443. In Field,A. (2000). Discovering statistics using SPSS for windows: Advanced techniques for the beginner. (I ed.). London: SAGE Publications Ltd.

Field,A. (2000). Discovering statistics using SPSS for windows:Advanced techniques for the beginner. (I ed.). London: SAGE Publications Ltd.Gomes, M., Espino, F., Abaquin, J., Realon, C., \& Salazar, N.P. (1994). Symptomatic identification of malaria in the home and in the primary health care clinic. Bull.WHO, 72, 383-390.

Geissler, P.W., Nokes, K., Prince, R.J., Odhiambo, R.A.,Aagaard-Hansen, J., \& Ouma, J.H. (2000). Children and medicines: self treatment of common illnesses among Luo school children in western Kenya. Social Science and Medicine, 50, I77I-I 783. 
Kaiser, H.F. (1960). The application of electronic computers to factor analysis. Educational and Psychological Measurement. In Andy Field (2000) Discovering statistics using SPSS for windows:Advanced techniques for the beginner, London, SAGE Publications Ltd. 20, I4II5I.

Kidane, G. \& R.H. Morrow (2000). Teaching mothers to provide home treatment of malaria in Tigray, Ethiopia: a randomised trial. Lancet 356(9229): p. 550-5

McCombie, S. C. (1996). "Treatment seeking for malaria:A review of recent research." Social Science and Medicine 43(6): 933-945

Marsh, V.M., Mutemi,W.M., Muturi, J., Haaland,A.,Watkins,W.M., Otieno, G., \& Marsh, K. (1999). Changing home treatment of childhood fevers by training shopkeepers in rural Kenya. Tropical Medicine and International Health, 4(5), 383-389.

Mboya, P. (1938). “Luo Kitgi gi Timbegi”. Kisumu, Anyange Press, Kenya.

Mboya, P. ( 1967). Luo Kitgi Gi Timbegi:A Handbook of Luo Customs. Nairobi: Equatorial Publishers.

Mwenesi, H., Harpham, T., \& Snow, R.W. (1995). Child Malaria Treatment Practices among Mothers in Kenya. Social Science and Medicine, 40(9), I27I - 1277.

Nyamongo, I. K. (2002). "Health care switching behaviour of malaria patients in a Kenyan rural community." Social Science and Medicine 54: 377-386

Pagnoni, F., et al. (1997). A community-based programme to provide prompt and adequate treatment of presumptive malaria in children. Transactions of the Royal Society of Tropical Medicine and Hygiene 9I(5): p. 5I 2-7

Phillips-Howard, P.A., Nahlen, B.L.,Alaii, J.A., ter Kuile, F.O., Gimnig, J.E., Terlouw, D.J., Kachur, S.P., Hightower, A.W., Lal,A.A., Schoute, E., Oloo, J.A., \& Hawley,W.A. (2003 [a]). The efficacy of permethrin-treated bednets on child mortality and morbidity in western Kenya. I: development of infrastructure and description of study site. American Journal of Tropical Medicine and Hygiene, 68, Suppl.4.

Phillips-Howard, P.A., Nahlen, B.L., Kolczak, M.S., ter Kuile, F.O.,Alaii, J.A., Hightower,A.W., Gimnig, J., Arudo, J.A., Vulule, J., Schoute, E., Kachur, S.P., Oloo, A.J., \& Hawley, W.A. (2003 [b]). Efficacy of permethrin-treated bednets in the prevention of mortality in young children in an area of high perennial malaria transmission in western Kenya. American Journal of Tropical Medicine and Hygiene, 68, Suppl. 4.

Ruebush, T.K., Kern, M.K., Campbell, C.C., \& Oloo, A.J. (1995). Self-treatment of malaria in a rural area of western Kenya. Bulletin of the WHO, 73, 229-236.

Saradamma, R.D., Higginbotham, N., \& Nichter, M. (2000). Social factors influencing the acquisition of antibiotics without prescription in Kerala State, south India. Social Science and Medicine, 50, 891-903.

Tanner, M., \& Vlassof, C. (1998). Treatment-seeking behaviour for malaria:A typology based on endemicity and gender. Social Science and Medicine, 46, 523-532.

ter Kuile, F.O., Terlouw, A.J., Phillips-Howard, P.A., Hawley,W.A., Friedman, J.F., Kolczak, M.S., Kariuki, S.K., Shi, Y.P., Kwena, A.M.,Vulule, J.M., \& B.L., N. (2003). Impact of permethrintreated bednets on malaria and all cause morbidity in young children in an area of intense perennial malaria transmission in western Kenya: cross-sectional survey. American Journal of Tropical Medicine and Hygiene, Malaria Supplement.

TDRnews (2002). Scaling up home management of malaria. TDR News 67: I-2. 
Winch P. J., Makemba A. M., Kamazima S. R., Lurie M., Lwihula G. K., Premji Z., Minjas J. N., Shiff C. J., (1996) Local terminology for febrile illnesses in Bagamoyo District, Tanzania and its impact on the design of a community-based malaria control programme. Social Science and Medicine 42: 1057-1067.WHO (1993) A global strategy for malaria control. Geneva

WHO (1996) Tropical diseases control: Malaria in the world. Geneva, Division of control of tropical diseases (CTD/TDT/96.12),WHO

WHO (200I) The use of antimalarial drugs: Report of a WHO informal consultation, I 3- I 7 November 2002.WHO/CDS/RBM/200I.33. Geneva

World Bank (1993). "World development report 1993 - Investing in Health.” Oxford, Oxford University Press 



\title{
CHAPTER 4
}

\author{
MALARIA KNOWLEDGE AND PREVENTION: \\ PEOPLE'S PERCEPTIONS BEFORE AND AFTER \\ A RANDOMISED CONTROLLED TRIAL \\ OF BEDNETS IN WESTERN KENYAI
}

I Published as:

Jane A. Alaii, H.W. van den Borne, S. Patrick Kachur, Halima Mwenesi, John M. Vulule, William A. Hawley, Martin I. Meltzer, Bernard L. Nahlen And Penelope A. Phillips-Howard (2003) Perceptions of bednets and malaria prevention before and after a randomised controlled trial of bednets in western Kenya. American Journal of Tropical Medicine and Hygiene, 68, Suppl.4. 


\begin{abstract}
A study of mothers' perceptions regarding bednets and malaria was conducted before and after a randomized controlled trial of insecticide treated bednets (ITNs) in western Kenya. Awareness of the study and rationale for bednet use increased, by the end of the trial. Knowledge that mosquitoes caused malaria also increased, however, a higher proportion of mothers from control, rather than intervention villages, cited this $(44.4 \%$ vs. $27.9 \%$; $<0.001)$. Mothers from intervention villages were more knowledgeable about the use and maintenance of bednets, and insecticide re-treatment. Both groups specified advantages of ITNs. Mothers from intervention villages noted practical advantages such as protection against bedbugs and falling roof debris. Few $(<1 \%)$ mothers indicated that ITNs protected children against malaria. Intervention homes used significantly fewer mosquito coils, insect spray, medicines, and burned cow dung less often compared with those in control villages. Mothers were willing to pay approximately US $\$ 4.5$ for a regular bednet, but only US cents 10.5 (intervention) and 0.036 (control) for retreating a bednet. This study suggests that, despite two years of experience of use, bednets and insecticides would not be purchased as a household priority in this impoverished rural community.
\end{abstract}




\section{INTRODUCTION}

Current policy options for malaria control include prompt and effective disease treatment, and disease prevention through use of insecticide-impregnated bednets (ITNs) (WHO, 2000). A review of results of efficacy trials of ITNs in subSaharan Africa concluded that their correct use could save up to 6 lives for every 1000 protected children $<5$ years of age (Lengeler, 2002). In the mortality trial in western Kenya, an estimated 34.5 lives would be saved per 1000 infants protected with bednets, if retreated biannually with permethrin (Phillips-Howard et al., 2003 [a]). Whether malaria control programmes could attain similar impressive results remains to be seen (Lengeler et al., 1996; D’Alessandro, 2001). Nonetheless, ITNs are potentially a valuable component of African malaria control programs. In most malaria-endemic communities, ITN coverage remains below $10 \%$ and insecticide re-treatment rates decline dramatically with the introduction of cost-recovery systems (Kachur et al., 1999; D’Alessandro et al., 1995). However, a social marketing programme in Tanzania increased ITN coverage from $10 \%$ to $60 \%$, with a concomitant significant improvement in child survival (Schellenberg et al., 2001). It is not known whether the success achieved in such programmes will be sustained, particularly on a national scale. Of major concern is whether people are willing to purchase bednets and insecticide routinely to protect their children against malaria disease. Better understanding of people's perceptions of malaria and its perceived cause, preventive action, and value attached to ITNs is needed for planning bednet programmes (MacCormack et al., 1984; Winch et al., 1997; Binka \& Adongo, 1997). In this paper we report on the perceptions of mothers of malaria, malaria prevention, and ITNs before and after a two-year randomised controlled trial of ITNs. We explore whether information disseminated for the trial was recalled at trial's end, and whether experience with use of ITNs would influence their decision to purchase bednets and re-treatment with insecticide in the future.

\section{METHODS}

\section{Study site and population}

This paper forms part of a multi-disciplinary trial of the efficacy of permethrintreated bednets on child morbidity and mortality in rural western Kenya. Details of the study site and population are presented elsewhere (Phillips-Howard et al., 2003 [b]). The $200 \mathrm{~km}^{2}$ study site, Asembo, is $50 \mathrm{~km}$ west of Kisumu on the shores of Lake Victoria. The population is predominantly Luo, living in highly dispersed villages. Most inhabitants are subsistence farmers, with some fisher- 
men or marketers of food or grain. Baseline studies revealed low coverage $(<5 \%)$ with untreated bednets, with preference in bednet use given to adults and visitors to avoid mosquito nuisance (Alaii, 1997). Rainfall occurs yearround, with the long rains falling between March-April, and the short rains between November-December. Total annual rainfall averages over $1,000 \mathrm{~mm}$. Malaria is holoendemic, with entomologic inoculation rates between 60-300 infective bites per person per year, and up to $80 \%$ of under-fives infected with Plasmodium falciparum malaria at any time (Beiers et al., 1994; Bloland et al., 1999). Before and during the trial an intensive campaign was conducted to disseminate information about the trial using different media (Phillips-Howard et al., 2003 [c]). The campaign emphasised several messages: (i) children are the group most vulnerable to malaria and thus the main target for ITN use, (ii) mosquitoes alone transmit malaria, (iii) ITNs can reduce child morbidity and mortality due to malaria, and (iv) ITNs should be used every night year-round for maximum protection. Open meetings held in the villages provided an opportunity for discussions about the trial and its methods.

\section{Study design}

A pre-intervention study in March 1996 and a post-intervention survey conducted in January 1999 are the data sources for this study. Multistage sampling was used to randomly select 600 of 8,707 compounds for each survey. Computer generated lists, derived from the project-initiated household census (Phillips-Howard et al., 2003 [b], [c]) defined households with children <5 years old for sampling. Interviewers were pre-allocated lists of survey houses, by village. The post-intervention sample was stratified by intervention status prior to randomly selecting 300 homesteads each from intervention and control villages.

Baseline ethnographic studies were used to design a pre-coded questionnaire, which was translated into Dholuo, the local language, and pre-tested. Thirteen local field supervisors, trained for the interviews and fluent in Dholuo, conducted the surveys. The survey took place within the respondents' home. Respondents were not prompted on answers during interview. Questions used in the post-intervention survey were an adaptation of the pre-intervention baseline questionnaire. At both surveys respondents were asked specific questions on their knowledge of the causes of malaria, existing household protection from malaria - including use of traditional and commercial mosquito prevention measures, and cost of protective strategies deployed in the past three months. Questions on health communication asked about educational strategies to which mothers had been exposed, and key project messages they could recall. Questions on bednet use included current bednet ownership, source, cost, and advantages and disadvantages of ITNs. Since $<5 \%$ of the population used untreated bednets prior to the trial, and because health communication had just began at the time of the pre-intervention survey, questions specific to 
health communication and ITN use were asked only post intervention. The post-intervention survey included some questions about interest in investing in bednets and net re-treatment. This was not a formal contingent valuation survey such as that conducted by Onwujekwe and colleagues (Onwujekwe, 2002). Respondents were asked to rank in order of priority, without being presented with a list of alternatives, what their spending preferences would be if hypothetically given KES 1,000 (US\$ approx. 20). Respondents were also asked if they would pay for net re-treatment at KES 60 per bednet, based on local PSI estimated cost of K-O-tab ${ }^{\circledR}-$ a bednet re-treatment tablet. We also asked about the price and numbers of regular size nets people could purchase and who would get priority coverage if nets were few. Finally, we asked about sources of income and how income varied seasonally, and solicited information on household decision-making processes for cash expenditure on items such as bednets.

\section{Data analysis}

Data were entered into Clarion ${ }^{\circledR}$, Rel. 2.1 (Clarion Software Corp.) using data screens with automatic range and consistency checks. Data were further checked for consistency using SAS ${ }^{\circledR}$, Rel. 8.1 (SAS Institute Inc., Cary, NC, USA).

Analysis was done using SPSS ${ }^{\circledR}$, Rel. 9.0 and 10.0 (SPSS Inc., Chicago, IL, USA). Proportions were compared using chi-squared tests and independent-samples ttests. To reduce the number of 19 items relating to recall of key messages into meaningful categories, 13 items with non-skewed distributions were subjected to principal components analysis resulting in a 1-factor solution explaining $20.85 \%$ of the total variance. The KMO was 0.736 , and the Bartletts Test of Sphericity was 0.001 . Reliability of the factor for analysis was tested, resulting in a reduction to 9 items, $\alpha=0.70$. Based on the 9 items a recall scale was developed, assuming a score of 1 for each item in the scale. The scale had a normal distribution.

\section{RESULTS}

Of 600 different households visited in each phase of the study, data were available for analysis on 595 and 594 interviews performed pre- and post-intervention, respectively. The mean age of mothers was 28.3 years, with a mean of 7.3 years of education. Mothers had a mean of 1.6 children under the age of five years. There were no significant differences in the age, educational level, or number of children of mothers pre- and post-intervention, or between mothers residing in ITN and control villages. 
Table 4.I Perceived causes of malaria before and after the trial

\begin{tabular}{|c|c|c|c|c|c|c|}
\hline \multirow{3}{*}{ Perceived causes of malaria } & \multicolumn{3}{|c|}{ Before and after intervention } & \multicolumn{3}{|c|}{ After: by intervention status } \\
\hline & Before & After & $P$ & Control & ITN & $P$ \\
\hline & $N(\%)$ & $N(\%)$ & value & $N(\%)$ & $N(\%)$ & value \\
\hline Mosquitoes alone & $162(27.2)$ & $215(36.2)$ & 0.001 & $132(44.4)$ & $83(27.9)$ & $<0.001$ \\
\hline Getting cold & $278(47.0)$ & $304(51.2)$ & 0.146 & $135(45.5)$ & $169(56.9)$ & 0.005 \\
\hline Unclean water & $37 \quad(6.3)$ & $29 \quad(4.9)$ & 0.304 & $16 \quad(5.4)$ & $13 \quad(4.4)$ & 0.568 \\
\hline Getting rained on & $36 \quad(6.1)$ & $21 \quad(3.5)$ & 0.540 & $7 \quad(2.4)$ & I4 (4.7) & 0.120 \\
\hline Some foods & $25 \quad(4.2)$ & $21 \quad(3.5)$ & 0.540 & 10 & II (3.7) & 0.824 \\
\hline Mosquitoes, included with other causes & $443(75.1)$ & $505(85.0)$ & $<0.001$ & $254(85.5)$ & $251(84.5)$ & 0.730 \\
\hline Climate change & $35 \quad(5.9)$ & $33(5.6)$ & 0.803 & $12(4.0)$ & $21 \quad(7.1)$ & 0.107 \\
\hline Spirits & - & $3(0.5)$ & - & I $(0.3)$ & $2(0.7)$ & 0.120 \\
\hline Other: dirt, heat, etc & - & $4 \quad(0.7)$ & - & $3(1.0)$ & $\mathrm{I} \quad(.03)$ & - \\
\hline
\end{tabular}

Table 4.2 Reported measures used to prevent mosquitoes and malaria before and after the trial

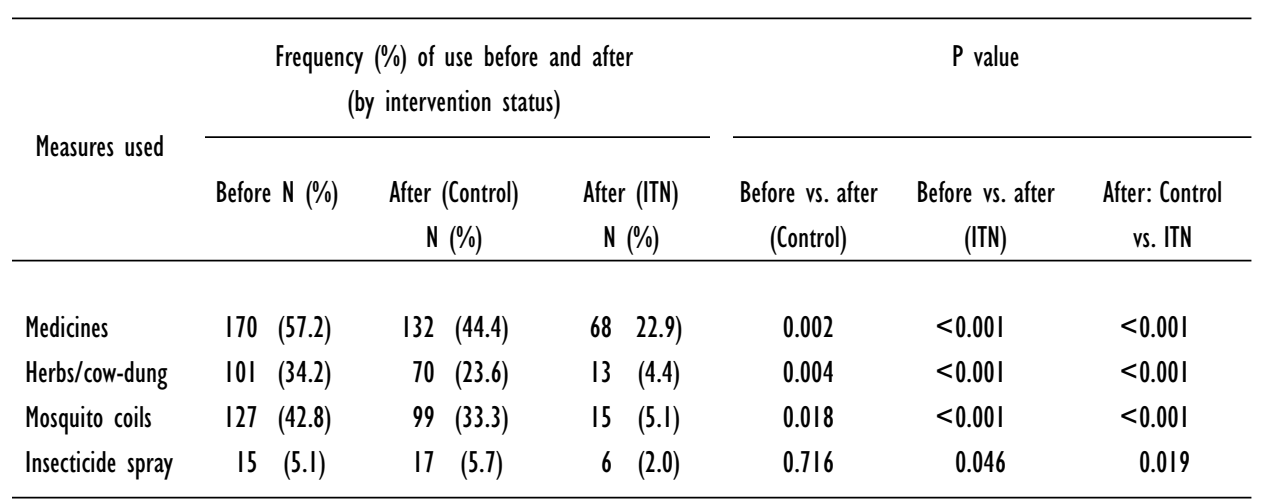

\section{Pre-intervention findings}

Before the trial started, $75 \%$ of mothers recognised mosquitoes as a cause of malaria with $27 \%$ attributing them to be its sole cause (Table 4.1 ). A higher proportion (47\%) stated that getting cold was the sole cause of this disease. Mosquito coils were reportedly used by $43 \%$ of household, and a third of mothers burned cow dung (Table 4.2). Over half indicated medicines were used for malaria (treatment not prophylaxis). Use of bednets (4\%) and insecti- 
Table 4.3 Comparison of perceived causes of malaria by mother's level of education

\begin{tabular}{lccccc}
\hline & $\begin{array}{c}\text { Primary education } \\
(I-7 y) \text { N }(\%)\end{array}$ & $\begin{array}{r}\text { Secondary education } \\
(8-12 y)\end{array}$ & $\begin{array}{r}\text { High school or college } \\
(9-13 y)\end{array}$ & P value \\
\hline Mosquito including other causes & $95(81.2)$ & $612(84.4)$ & $180(92.3)$ & 0.009 \\
Mosquito alone & $34(29.1)$ & $229(31.6)$ & $88(45.1)$ & 0.001 \\
Getting cold & $70(59.8)$ & $387 \quad(53.5)$ & $81 \quad(41.5)$ & 0.002 \\
\hline
\end{tabular}

cide sprays (5\%) were uncommon. In this preliminary phase, after information dissemination had begun, knowledge of the trial and proposed activities were limited. The focus of the trial, the prevention of malaria, was understood by $13 \%$ of those surveyed, with less than one percent recognising that prevention of malaria in children and pregnant women was a priority. None of the mothers offered knowledge about insecticide-treatment of bednets, and five percent knew that some villages would be 'controls' while others would receive bednets during the trial. When questioned on sources of information about the trial, a quarter of respondents mentioned community meetings (baraza), and a tenth said they had read an information leaflet. Participatory theatre, conducted in each village prior to the introduction of ITNs, was recalled by $6.5 \%$ of those surveyed.

\section{Post-intervention findings}

After two years of intervention, mothers' understanding about bednets, malaria, and trial activities was significantly greater. Differences were evident between intervention groups (Table 4.1). Mosquitoes were more frequently mentioned as one of several causes of malaria at the end of the trial compared with at the start $(85.0 \%$ vs. $75.1 \% ; \mathrm{P}<0.001)$. While the proportion of mothers who understood that mosquitoes alone caused malaria increased to $36 \%$, significantly more than at the trial's beginning $(\mathrm{P}<0.01)$, the association appeared to be stronger in those from control rather than from intervention villages $(44 \%$ vs. $28 \%, \mathrm{P}<0.001)$. The proportion of mothers who associated getting cold with malaria remained constant, both before and after the trial, and post-intervention between intervention and control groups. Generally, the proportion of mothers mentioning mosquitoes (anytime and alone) as a cause of malaria increased with educational level. Also, the proportion mentioning getting cold as a cause of malaria decreased with a higher level of education (Table 4.3). 
Nearly all participants were aware the trial had taken place (Table 4.4). A high proportion knew who was conducting the trial, and about three-quarters understood the trial was testing the effect of ITNs, although a lower proportion understood that the end point of the trial concerned malaria and its prevention. Independent-samples t-tests to compare scores on the recall scale showed a higher score (mean $=5.25, \mathrm{SD}=2.02)$ in intervention compared with control villages $($ mean $=3.97, \mathrm{SD}=2.21) ; \mathrm{P}<0.001$ (Table 4.5). Chi-squared tests to compare specific key messages showed that those from intervention villages better remembered information about the trial. This included the presence of local committees, length of the trial, and most details about ITN use (Table 4.4). Under a quarter of both groups mentioned that the ITNs were given free of charge by the project.

At the end of the trial, three-quarters of the mothers cited the traditional birth attendant, locally called nyamrerwa, as the main source of information about the study. Other important sources of information were the KEMRI/CDC field staff $(37.7 \%)$, community meetings (baraza), and bednet calendars ${ }^{2}(24.6 \%)$. Less frequently cited were information sheets (18\%) distributed during baraza, and village bednet committees (13.8\%). Role-play through the participatory educational theatre group was rarely mentioned (3.9\%). No significant differences were noted between the intervention and control groups. Levels of valid information recall were similar for all information sources except for village level baraza. Independent-samples t-tests showed higher $($ mean $=4.79, \mathrm{SD}=$ 2.19) message recall scores for those mentioning mosquitoes as a perceived cause of malaria, compared with those not mentioning mosquitoes at all (mean $=3.57, \mathrm{SD}=2.06) ; \mathrm{P}<0.001$.

Significantly more mothers from ITN, compared with control villages, stated bednets should be used daily (68.0\% vs.49.5\%; P<0.001). A significantly higher proportion from control villages said bednets should be used when mosquitoes were evident $(38.0 \%$ vs. $25.3 \%$; $\mathrm{P}<0.01)$, or during rain $(27.9 \%$ vs.14.2\%; $\mathrm{P}<0.001)$. Around three-quarters of mothers, from both treatment groups, understood that the purpose of bednets was to protect against malaria. Other reasons for bednet use included preventing mosquito nuisance $(45.5 \%)$, avoiding roof debris $(9.4 \%)$, and warmth (4.9\%). Privacy did not appear important (1.5\%). No significant differences were noted between ITN and control groups. The proportion of homes using additional control measures in 3 months prior to survey dropped significantly when compared with pre-intervention levels (Table 4.2). Intervention homes reportedly used significantly fewer mosquito coils $(P<0.001)$, less insecticide spray $(P=0.019)$, burned cow dung $(\mathrm{P}<0.001)$ less often, and used fewer medicines $(\mathrm{P}<0.001)$ com-

2 Bednet calendars were issued to every compound in study area. They contained messages about the trial, and were illustrated with pictures drawn by local school children 
Table 4.4 Awareness of the trial, two years after the introduction of bednets

\begin{tabular}{|c|c|c|c|c|c|c|}
\hline & Key message/question & Bedn & $\mathrm{N}(\%)$ & Contr & I N (\%) & $P$ value \\
\hline \multirow[t]{10}{*}{ The trial } & Aware the trial existed & 294 & $(99.0)$ & 293 & $(98.7)$ & - \\
\hline & Aware of village bednet committee & 256 & $(86.2)$ & 207 & $(69.7)$ & $<0.001$ \\
\hline & Aware who performs the trial & 240 & $(80.8)$ & 232 & $(78.1)$ & NS \\
\hline & $\begin{array}{l}\text { Reason for using ITNs is to test if they prevent } \\
\text { malaria }\end{array}$ & 218 & $(73.3)$ & 211 & $(71.7)$ & NS \\
\hline & How long trial would last & 160 & $(54.2)$ & 116 & $(39.1)$ & $<0.001$ \\
\hline & Aware trial is about malaria prevention & 125 & $(42.1)$ & 125 & $(42.1)$ & NS \\
\hline & Rationale for conducting census & 118 & $(39.7)$ & 99 & $(33.3)$ & NS \\
\hline & Aware why Asembo chosen for project & 115 & $(38.7)$ & 108 & $(36.4)$ & NS \\
\hline & Villages randomised as part of trial method & 15 & $(5.1)$ & 30 & $(10.1)$ & 0.020 \\
\hline & Trial mainly to protect children from malaria & I & $(0.3)$ & & & NS \\
\hline \multirow[t]{8}{*}{ Bednets } & Rationale for using insecticide in bednets & 272 & $(91.9)$ & 225 & $(75.8)$ & $<0.001$ \\
\hline & ITNs should be dipped six monthly & 228 & $(76.8)$ & 135 & $(45.5)$ & $<0.001$ \\
\hline & Who would retain nets at end of study & 224 & $(75.4)$ & 190 & $(64.0)$ & 0.002 \\
\hline & Correct use of bednets $=$ use every night & 202 & $(68.0)$ & 147 & $(49.5)$ & $<0.001$ \\
\hline & $\begin{array}{l}\text { ITNs are to be washed six-monthly just before } \\
\text { re-treatment }\end{array}$ & 143 & $(48.1)$ & 78 & $(26.3)$ & $<0.001$ \\
\hline & ITNs should be used daily/every night & 129 & $(43.4)$ & 85 & $(28.6)$ & $<0.001$ \\
\hline & ITNs are to be repaired if torn & 109 & $(36.7)$ & 72 & $(24.2)$ & 0.001 \\
\hline & ITNs are given free & 69 & $(23.2)$ & 64 & $(21.5)$ & NS \\
\hline Malaria & Mosquitoes alone cause malaria & 83 & $(27.9)$ & 132 & $(44.4)$ & 0.001 \\
\hline
\end{tabular}

Table 4.5 Comparison of recall scale§ against key sources of information, post-intervention.

\begin{tabular}{|c|c|c|c|c|c|c|}
\hline Source of information & \multicolumn{2}{|c|}{$\begin{array}{l}\text { Recall } \\
\text { N }(\%)\end{array}$} & $\begin{array}{c}\text { Mean of } \\
\text { recall scale }\end{array}$ & SD & $\mathrm{t}$ & $\begin{array}{l}P \text { value } \\
\text { (2-tailed) }\end{array}$ \\
\hline Village bednet committee & 82 & $(13.8)$ & 6.0610 & 2.1679 & 6.561 & 0.001 \\
\hline Information sheets & 107 & $(18.0)$ & 5.9346 & 2.3200 & 7.139 & 0.001 \\
\hline Bednet calendar & 146 & $(24.6)$ & 5.3904 & 2.4979 & 4.556 & 0.001 \\
\hline$C D C$ staff in general & 224 & $(37.7)$ & 5.2545 & 2.3831 & 5.471 & 0.001 \\
\hline Nyamrerwa (TBA) & 440 & $(74.4)$ & 5.7500 & 2.2571 & 2.699 & 0.007 \\
\hline Baraza (community meeting) & 96 & $(26.0)$ & 4.8592 & 2.1763 & -.442 & NS \\
\hline
\end{tabular}

$\S \quad$ Analysis using independent-samples t-tests 
pared with those in control villages. Other than a small but constant proportion of mothers using insecticide sprays, the use of other forms of protection also appeared to be lower in control villages compared with intervention villages. Use of medicines was correlated with the number of children $<5$ in both control $(\mathrm{P}<0.05)$ and intervention $(\mathrm{P}<0.001)$ villages.

\section{Advantages and disadvantages of bednets post-intervention}

Regardless of treatment group, most (64.6\%) mothers stated they liked ITNs because they protect against malaria. Some noted that ITNs gave warmth. Significantly more mothers from ITN villages stated they liked bednets because they kept off and killed mosquitoes. Other significant differences between the treatment groups related to protection against other bugs and avoiding roof debris falling on the bed. The majority $(82.3 \%)$ of mothers perceived no disadvantages of bednets, although a quarter from control villages indicated they did not know. Disadvantages listed by $<5 \%$ related to heat, chemical smell, and daily mounting of nets. Not being able to wash bednets for six months until retreatment and the dark colour of the bednets was not mentioned.

\section{Financial perceptions on insecticide-treated bednets post-intervention}

Regardless of intervention status, decisions about spending surplus money are predominantly (67\%) made by men. Nearly a quarter $(22.4 \%)$ of mothers, however, said they could make independent financial decisions - particularly about money raised through self-help projects. A few (7.7\%) indicated decision-making was made jointly among persons providing the money (e.g. next of kin) and the adult members of the individual household. A very minor role (2.9\%) appeared to be played by mothers-in-law. When questioned on the best time of year to purchase bednets or insecticide, a high proportion $(89.1 \%)$ mothers stated only after the main harvest, while $6.6 \%$ stated anytime of the year. Money could be raised by selling farm produce $(75.3 \%)$ or through payback of loans from kin $(7.4 \%)$. Three percent would sell an animal or borrow money.

If given KES 1000 (US\$ approx. 20) to spend, few (7.2\%) mothers listed bednets among the first three priority items they would wish to purchase (Table 4.6). Most listed food and clothing as the priority. Significantly more mothers from control villages indicated they would consider purchasing bednets, compared with those in the intervention villages (20.5\% vs. $8.4 \%$; $\mathrm{P}<0.001)$. The number of bednets a family would purchase - if they were to pay - was negatively correlated with intervention status. Mothers from control villages indicated needing a mean of $3.15(\mathrm{SD}=1.59)$ bednets, compared with $2.86(\mathrm{SD}=1.18)$ from intervention villages. There was no association between 
Table 4.6 Distribution of spending preferences for respondents listing bednets among priority items, post-intervention

\begin{tabular}{|c|c|c|c|c|c|c|}
\hline & \multicolumn{2}{|c|}{ Spending Preference I } & \multicolumn{2}{|c|}{ Spending Preference 2} & \multicolumn{2}{|c|}{ Spending Preference 3} \\
\hline & ITN N (\%) & Control N (\%) & ITN N (\%) & Control N(\%) & ITN N (\%) & Control N (\%) \\
\hline Food items & $166 \quad(55.9)$ & $127(42.8)$ & $58 \quad(22.3)$ & $65 \quad(27.2)$ & $36(24.5)$ & $21 \quad(18.9)$ \\
\hline Clothing items & $30(10.1)$ & $31 \quad(10.4)$ & 71 (27.3) & $64 \quad(26.8)$ & $31 \quad(21.1)$ & $32(28.8)$ \\
\hline Bednet & $21 \quad(7.1)$ & 46 (I5.5) & $4 \quad(1.5)$ & $14 \quad(5.9)$ & $\begin{array}{ll}0 & (0.0)\end{array}$ & $2(1.8)$ \\
\hline Medicine & $8 \quad(2.7)$ & 8 (2.7) & $23 \quad(8.8)$ & $22 \quad(9.2)$ & $14 \quad(9.5)$ & $7 \quad(6.3)$ \\
\hline Furnish house & $9 \quad(3.0)$ & $5 \quad(1.7)$ & 10 & 10 & $5 \quad(3.4)$ & $2(1.8)$ \\
\hline $\begin{array}{l}\text { Household } \\
\text { utensils }\end{array}$ & $4 \quad(\mathrm{I} .3)$ & 8 (2.7) & $19 \quad(7.3)$ & 8 & $14 \quad(9.5)$ & $15 \quad(13.5)$ \\
\hline Bicycle & $5 \quad(\mathrm{I} .7)$ & $\begin{array}{ll}0 & (0.0)\end{array}$ & $3 \quad(1.2)$ & I $\quad(0.4)$ & I $\quad(0.7)$ & $\begin{array}{ll}0 & (0.0)\end{array}$ \\
\hline $\begin{array}{l}\text { School } \\
\text { requirements }\end{array}$ & $8 \quad(2.7)$ & $12 \quad(4.0)$ & $17 \quad(6.5)$ & II $(4.6)$ & $12 \quad(8.2)$ & II $\quad(9.9)$ \\
\hline $\begin{array}{l}\text { Others } \\
\text { (e.g buy cow) }\end{array}$ & $46 \quad(15.5)$ & 60 (20.2) & $55 \quad(21.2)$ & 44 (18.4) & 34 (23.I) & $21 \quad(18.9)$ \\
\hline
\end{tabular}

number of children $<5$, mother's age or education, and the number of bednets that mothers hypothesized buying. When asked how much they were willing to spend on a bednet, $78.6 \%$ mothers suggested paying at least KES 200 (US\$ approx. 3.3), including 1.9\% who hypothesized paying between KES 800-1000 (US\$ approx. 13.3-16.7), while 3.2\% would pay less than KES 100 (US\$ approx. 1.4). Overall, mothers from intervention villages suggested a mean of KES 257 (SD = 131), while controls indicated a mean of KES $278(\mathrm{SD}=156)$ $(\mathrm{P}=0.07)$.

Three-quarters of the respondents said they would not pay for bednet retreatment at an estimated cost of KES 60 (US\$ approx. 1). When asked what they would pay instead, $368(61.9 \%)$ said they would not want to pay at all. Of mothers suggesting an alternative price, those from intervention villages believed a mean of KES 6.3 (SD = 23.7) was an appropriate cost, while those from control villages indicated a mean of KES 2.5 (SD = 8.4), which is significantly less than estimates from mothers in intervention villages $(\mathrm{P}<0.01)$. On the other hand, most $(88.9 \%)$ indicated they would re-treat their own purchased bednets biannually, 7\% said they would retreat annually, and 3\% suggested other time periods.

Mothers thought bednet re-treatment would be best handled through women groups $(24.7 \%)$, individual family (21.5\%), village bednet committees (19.2\%), or at clan level $(9.1 \%)$. The remaining quarter thought it was a household affair 
and would depend on individual household arrangements as appropriate. Bednet distribution, however, should be done through nyamrerwa (41.1\%), local retail shops $(9.4 \%)$, and local women groups (9.1\%). Distribution through local towns was viewed as inappropriate due to distance.

\section{DISCUSSION}

Mothers' attitudes and behaviour regarding malaria and its prevention in young children are important determinants of success in malaria control programmes promoting ITNs in rural Africa. This study suggests that some, but not all, information disseminated to mothers about ITNs and malaria was received and retained. Awareness was significantly greater in mothers residing in intervention villages than in controls. A number of factors contribute towards this. While attempts were made throughout the trial to ensure equality in distribution of information, regardless of intervention status, it is possible that those in ITN villages received more reinforcement of messages at the time of retreatment of bednets, an activity undertaken in intervention villages only. Mothers from intervention villages may also have been more receptive to information faced with the daily reality of bednet use. It was thus surprising to find that a lower proportion of mothers from intervention villages identified mosquitoes to be the sole cause of malaria, compared with those from control villages. We hypothesise this may have been motivated by their practical experience of ITN use. Information distributed during the trial indicated that ITNs reduce biting of mosquitoes and that mosquitoes are responsible for transmission of malaria. However, even with high coverage with ITNs, transmission still occurred, and mothers from intervention villages still witnessed their children becoming ill (albeit at a lower prevalence than in control areas (ter Kuile et al., 2003). This may be partly responsible for the observation that mothers in ITN villages still ascribed causation of malaria to causes other than mosquito-borne transmission. In parallel, mothers from control villages witnessed their children becoming ill and associated malaria with the absence of ITNs. Previous trials have also noted that increased knowledge did not seem to resolve the gap between biomedical terms and local understanding of illness (Marsh et al., 1996; Agyepong et al., 1992). This type of dissonance clearly becomes even more problematic if mothers do not adequately understand the rationale and importance of, re-treatment of bednets with insecticide.

This concern is further strengthened by our disappointing finding that mothers neglected to associate the ITN trial with child health - despite the emphasis placed on this as a 'number-one' health message for the trial. This message was disseminated at baraza, on information leaflets, during open-air theatre, on the 
illustrated calendars, and ingrained upon all field staff, including nyamrerwa, as a key discussion topic (Phillips-Howard et al., 2003 [c]). Furthermore, epidemiological analysis of study results showed that ITNs were most effective in young children by decreasing the prevalence of anaemia and episodes of acute malarial disease by some $40 \%$ (ter Kuile et al., 2003) by reducing the burden of sick child visits to peripheral health facilities by a third (Phillips-Howard et al., 2003 [d]) and by cutting infant mortality by $26 \%$ (Phillips-Howard et al., 2003 [a]). Despite these beneficial outcomes observed at the population level, individual mothers did not necessarily perceive these benefits. This lack of perceived benefit of ITNs for child health may be responsible for our finding that adherence with ITN use was significantly lower in young children, compared with older children and adults (Alaii et al., 2003 [a]).

Our results suggest that participants generally liked ITNs even though fewer than 5\% had prior experience of bednet use. We believe the absence of 'disadvantages' likely reflects the community's perception that mothers should give socially desirable answers, since before the trial a separate study revealed a number of limitations ascribed to bednets (Alaii et al., 2003 [b]). Because bednets were given free, and perhaps fear that they may be repossessed if negative sentiment was strong, may have prompted an absence of named 'disadvantages'. The majority of mothers could characterize advantages of bednets - although those from control villages recalled the advantages described by the field staff, while those from intervention villages offered true 'practical' advantages experienced during use. These latter attitudes are more reliable predictors of behaviour than those acquired 'indirectly' by those from control villages (Fazzio \& Zanna, 1981). Therefore, the observation of more practical likes for bednets in intervention villages may be a better indicator of likely behaviour, providing useful information for programme design. It is well understood that people tend to look for the practical benefits personally experienced than more strategic benefits such as malaria control (Hellitzer-Allen et al., 1993). The association of non-health related advantages with bednets is not unique to our study area (Winch et al., 1994; Minja, 2001). To encourage year-round use of bednets in areas with perennial malaria transmission, Winch and colleagues suggest encouraging perceived benefits not related to climate or seasonality (Winch et al., 1994). In our study area these include avoidance of roof debris and crawling bugs, but how effective this might be depends on the importance of perceived benefits (Janz \& Becker, 1984), and the degree of fear or amount of inconvenience caused by crawling creatures (Rogers, 1995). Minja suggests reinforcing messages that even the bite of a single mosquito can be fatal (Minja, 2001). This may be problematic when there is a lack of congruence between preventing nuisance biting and preventing disease, particularly when the abundance of nuisance Culex mosquitoes does not correspond seasonally with that of anophelines (Agyepong et al., 1995).

In this study bednets ranked low among household expenditure priorities, regardless of intervention status. This supports similar findings from other ITN 
trial sites (Binka \& Adongo, 1997; Kachur et al., 1999), and preliminary research in our study area (Alaii, 1997). While most respondents envisaged paying nearly the current market price for a regular size bednet, the general feeling was that nets are too expensive, highlighted by estimations up to US\$17 for the price of a regular size net. On the other hand, respondents could not envisage paying the price of an insecticide sachet at the current market value, indicating insecticide treatment of bednets may not be equally valued as owning the bednet itself. The social marketing of bednets in Tanzania experienced similar results, with people valuing bednets more than bednet re-treatment despite subsidies for re-treatment (Schellenberg et al., 2001). The problem seems less of costs, and more of the value attached to use of insecticide in bednets, perhaps due to the difficulty of perceiving direct benefits of the insecticide. While responses on willingness to purchase bednets and insecticide are hypothetical and may not reflect ability to pay, they provide useful indicators for programme planners. Portrayed lack of will to invest in nets in intervention households is understandable since they had received free bednets already, while control households did not. It has been suggested that it might be more illuminating to ask people directly if they would spend money on bednets, rather than ask open-ended questions on expenditures as we did in this study. We chose the latter course in an attempt to minimize socially desirable answers. We note that mothers from intervention villages were hypothetically willing to pay two and a half-fold more (KES 6.3 rather than 2.5) for insecticide than those from control villages, suggesting they placed a greater value on re-treatment. It was interesting to note that mothers from intervention villages failed to acknowledge that an advantage of ITNs was the financial saving associated with significantly less 'alternative' mosquito control measures. These savings, including less frequent visits to peripheral facilities, and a reduction in costs for self-medication were not reported by any participants. An absence of any perception of the financial rewards of ITNs in the home adds further support to economic studies that predict that bednet coverage will not be sustained if the financial burden falls upon this impoverished rural community (Meltzer et al., 2003). We conclude that bednets and use of insecticides are acceptable and practically valued within this community, but despite their perceived advantages, they are not valued as a tool for protecting children against malaria. Despite the health impacts of ITNs, our study offers no evidence to suggest they would be purchased as a household priority. 


\section{REFERENCES}

Agyepong, I.A.,Aryee, B., Dzikunu, H., \& Manderson, L. (1995). The malaria manual: Guidelines for the rapid assessment of social, economic and cultural aspects of malaria. (TDR/SERMSR/95-I).

Agyepong, I.A. (1992). Malaria: ethnomedical perceptions and practice in an Adangbe farming community and implications for control. Social Science and Medicine. 35, I3 I-137.

Alaii, J.A. (1997). The relevance of sleeping arrangements and bedtime mobility patterns for implementing insecticide-treated bednets in Asembo, western Kenya. M.Sc. Dissertation, London, School of Education, Politics and Social Sciences, Faculty of Health Sciences, South Bank University, UK.

Alaii, J.A., Hawley,W.A., Kolczak, M.S., ter Kuile, F.O., Gimnig, J.E., Vulule, J.M., Odhacha,A., Oloo,A.J., Nahlen, B.L., \& Phillips-Howard, P.A. (2003 [a]). Factors affecting the use of permethrin treated bednets during a randomised controlled trial in western Kenya. American Journal of Tropical Medicine and Hygiene, 68, Suppl.4.

Alaii, J.A., van den Borne, H.W., Kachur, S.P., Shelley, K., Mwenesi, H., Vulule, J., Hawley,W.A., Nahlen, B.L., \& Phillips-Howard, P.A. (2003 [b]). Community reactions to the introduction of permethrin-treated bednets for malaria control during a randomised controlled trial in western Kenya. American Journal of Tropical Medicine and Hygiene, 68, Suppl. 4.

Beiers, J.C., Oster, C.N., Onyango, F.K., Bales, J.D., Sherwood, J.A., Perkins, P.V., Chumo, D.K., Koech, D.V.,Whitmire, R.E., Roberts, C.R., Diggs, C.L., \& Hoffman, S.L. (1994). Plasmodium falciparum incidence relative to entomological inoculation rates at a site proposed for testing malaria vaccines in western Kenya. American Journal of Tropical Medicine and Hygiene, 50, 529-536.

Binka, F.N., \& Adongo, P. (1997). Acceptability and use of insecticide impregnated bednets in northern Ghana. Tropical Medicine and International Health, 2(5), 499-507.

MacCormack, C.P. (1984). Human ecology and behaviour in malaria control in tropical Africa. Bulletin of the WHO 62:8I-87.

Bloland, P.B., Ruebush, T.K., McCormick, J.B., Ayisi, J., Boriga, D.A., Oloo, A.J., Beach, R., Hawley, W.A., Lal,A., Nahlen, B., Udhayakumar,V., \& Campbell, C.C. (1999). Longitudinal cohort study of the epidemiology of malaria infections in an area of intense malaria transmission. II. Descriptive epidemiology of malaria infection and disease among children. American Journal of Tropical Medicine and Hygiene, 60, 64I-648.

D'Alessandro, U., Olaleye, B.O., McGuire,W., Langerock, P., Bennett, S., Aikins, M.K., Thompson, M.C., Cham, M.K., \& Greenwood, B.M. (1995). Mortality and morbidity from malaria in Gambian children after introduction of an impregnated bednet programme. Lancet, 345, 479-483.

D'Alessandro, U. (200I). Insecticide-treated bednets to prevent malaria:The challenge lies in implementation. British Medical Journal, 322, 250-I.

Fazzio, R.H., \& Zanna, M.P. (198I). Direct experience and attitude-behaviour consistency. Advances in Experimental Social Psychology, I4, I6I-202.

Gimnig, J., Lo, T., Vulule, J., Kamau, L., Kolczak, M.S., Phillips-Howard, P.A., Nahlen, B.L., Oloo, A., Hightower, A.W., \& Hawley,W.A. (2003). Impact of permethrin-treated bednets on entomological indices in an area of intense year round malaria transmission. American Journal of Tropical Medicine and Hygiene, 68, Suppl.4. 
Helitzer-Allen, D.L., Kendall, C., \& Wirima, J.J. (1993). The Role of Ethnographic Research in Malaria Control:An Example from Malawi. Research in the Sociology of Health Care, 10, 269 286.

Janz, N., \& Becker, M. (1984). The Health Belief Model:A decade later. Health Education Quarterly, II, I-47.

Kachur, S.P., Phillips-Howard, P.A., Odhacha,A.M., Ruebush,T.K., Oloo,A.J., \& Nahlen, B.L. (1999). Maintenance and sustained use of insecticide treated bednets and curtains three years after a controlled trial in western Kenya. Tropical Medicine and International Health, 4, 728-35.

Lengeler, C., de Savigny, D., \& Cattani, J. (Eds.). (1996). Net Gain: A New Method of Preventing Malaria Deaths. Geneva \& Ottawa:WHO/IDRC.

Lengeler, C. (2002). Insecticide-treated bednets and curtains for preventing malaria (Cochrane Review) In The Cochrane Library. Oxford: Update software (Issue 2, 2002).

Marsh,V.M., Mutemi,W., Some, E.S., Haaland,A., \& Snow, R.W. (1996). Evaluating the Community Education Programme of an Insecticide-treated Bednet Trial on the Kenyan Coast. Health Policy Plan, I I (3), 280-29I.

Meltzer, M.I., Terlouw, D.J., Kolczak, M.S., Odhacha,A., ter Kuile, F.O., Vulule, J.M., Alaii, J.A., Nahlen, B.L., Hawley,W.A., \& Phillips-Howard, P.A. (2003). The household-level economics of using permethrin-treated bednets to prevent malaria in children under 5 years of age. American Journal of Tropical Medicine and Hygiene, 68, Suppl.4.

Minja, H.D. (200I). Introducing insecticide-treated mosquito nets in the Kilombero Valley (Tanzania): Social and cultural dimensions. PhD Thesis, Swiss Tropical Institute.

Onwujekwe, O., Chima, R., Shu, E., Nwagbo, D., \& Okonkwo, P. (2002). Hypothetical and actual willingness to pay for insecticide-treated nets in five Nigerian communities. Tropical Medicine and International Health, 6, 545-553.

Phillips-Howard, P.A., Nahlen, B.L.,Wannemuehler, K., Kolczak, M.S., ter Kuile, F.O., Gimnig. J., Alaii, J.A., Odhacha,A.,Vulule, J., \& Hawley,W.A. (2003 [a]). Impact of permethrin-treated bednets on the incidence of sick child visits to peripheral health facilities. American Journal of Tropical Medicine and Hygiene, 68, Suppl.4.

Phillips-Howard, P.A., Nahlen, B.L., Alaii, J.A., ter Kuile, F.O., Gimnig, J.E., Terlouw, D.J., Kachur, S.P., Hightower, A.W., Lal,A.A., Schoute, E., Oloo, J.A., \& Hawley,W.A. (2003 [b]). The efficacy of permethrin-treated bednets on child mortality and morbidity in western Kenya. I: development of infrastructure and description of study site. American Journal of Tropical Medicine and Hygiene, 68, Suppl.4.

Phillips-Howard, P.A., ter Kuile, F.O., Nahlen, B.L., Alaii, J.A., Gimnig, J.E., Kolczak, M.S., Terlouw, D.J., Kariuki, S., Shi, Y.P., Kachur, S.P., Hightower,A.W.,Vulule, J.M., \& Hawley,W.A. (2003 [c]). The efficacy of permethrin-treated bednets on child mortality and morbidity in western Kenya. II: Design and methods. American Journal of Tropical Medicine and Hygiene, 68, Suppl.4.

Phillips-Howard, P.A., Nahlen, B.L., Kolczak, M.S., ter Kuile, F.O.,Alaii, J.A., Hightower, A.W., Gimnig, J., Arudo, J.A.,Vulule, J., Schoute, E., Kachur, S.P., Oloo, A.J., \& Hawley,W.A. (2003 [d]). Efficacy of permethrin-treated bednets in the prevention of mortality in young children in an area of high perennial malaria transmission in western Kenya. American Journal of Tropical Medicine and Hygiene, 68, Suppl.4.

Rogers, R.W. (1975).A protection motivation theory of fear appeals and attitude change. Journal of Psychology, 91, 93-II4. 
Schellenberg, J.R.M.A., Abdulla, S., Nathan, R., Mukasa, O., Marchant, T..., Kikumbih, N., Mushi, A.K., Mponda, H., Minja, H., Mshinda, H., Tanner, M., \& Lengeler, C. (200I). Effect of largescale social marketing of insecticide-treated netson child survival in rural Tanzania. Lancet, 357, 124I-47.

ter Kuile, F.O., Terlouw, D.J., Phillips-Howard, P., Hawley, W., Friedman, J., Kariuki, S., Shi, Y., Kolczak, M., Lal,A.,Vulule, J., \& Nahlen, B. (2003). Permethrin-treated bednets reduce malaria in pregnancy in an area of intense perennial malaria transmission in western Kenya. American Journal of Tropical Medicine and Hygiene, 68, Suppl.4.

WHO (2000). African Summit on Roll Back Malaria, Abuja, Nigeria, April 25, 2000. WHO/CDS/RBM/2000.17.

Winch, P.J., Makemba, A.M., Kamazima, S.R., Lwihula, G.K., Lubega, P., Minjas, J.N., \& Shiff, C.J. (1994). Seasonal variation in the perceived risk of malaria: Implications for the promotion of insecticide-treated bed nets. Social Science and Medicine, 39(63-75).

Winch, P.J., Makemba, A.M., Makame,V.R., Mfaume, M., Lynch, M.C., Premji, Z., Minjas, J.N., \& Shiff, C.J. (1997). Social and cultural factors affecting rates of regular retreatment of mosquito nets with insecticide in Bagamoyo District, Tanzania. Trop Med Int Hlth, 2(8), 760-770. 



\title{
CHAPTER 5
}

\author{
COMMUNITY REACTIONS TO THE INTRODUCTION \\ OF PERMETHRIN-TREATED BEDNETS DURING \\ A RANDOMISED CONTROLLED TRIAL \\ IN WESTERN KENYA'
}

'Published as:

Jane A. Alaii, H.W. van den Borne, S. Patrick Kachur, Karen Shelley, Halima Mwenesi, John M.Vulule, William A. Hawley, Bernard L. Nahlen, Penelope A. Phillips-Howard (2003) Community reactions to the introduction of permethrin-treated bednets for malaria control during a randomised controlled trial in western Kenya. American Journal of Tropical Medicine and Hygiene, 68, Suppl. 4. 


\begin{abstract}
Prior to implementation of a randomised controlled trial of insecticide (permethrin)-treated bednets (ITNs) in western Kenya, ethnographic studies were conducted to understand local perceptions of disease, sleeping patterns, and other factors that might affect use of ITNs. Educational activities took place prior to distribution, but immediately after distribution in Asembo only approximately half of the ITNs were in use. A qualitative study was then conducted to identify the community's perceptions about ITNs and the ITN project. While participants ranked malaria as important and recognized that malaria prevention could be beneficial, they believed ITNs would be only partly effective due to the perception that malaria has multiple causes. Concerns expressed included fear of the insecticide, thought by some to be a toxic family planning aid, the taking of blood during clinical studies, and the mixing up of family ITNs during net retreatment, which would violate cultural taboos. Attempts were made to allay fears by improved communication on these subjects and modification of the study design.
\end{abstract}




\section{INTRODUCTION}

Insecticide (permethrin)-treated bednets (ITNs) have emerged in the last several years as an effective malaria control intervention (Choi et al., 1995; Lengeler, 2000). Questions remain, however, on how best to promote correct and sustained use of ITNs, particularly in areas without a tradition of bednet use. Because of the exigencies of funding of this intervention trial, only a few months were available before project implementation to conduct baseline anthropological studies. Two rapid studies were conducted: (1) An ethnographic study to better understand community perceptions of disease, including malaria, and care seeking and (2) a study of sleeping arrangements and bednet use Alaii, 1997). Information from these rapid assessments were used to develop a wide-scale awareness campaign designed to 1) stimulate interest in the trial, 2) inform community members that mosquitoes alone transmit malaria, and 3) emphasize the importance of adherence (proper use and deployment of ITNs) for maximal benefits of the intervention (Lines, 1996). A variety of methods were used to disseminate this information, most relying upon the traditional 'word of mouth' approach: open air meetings called by local political authorities (baraza), community theatre, song, and house-to-house visits by trained local traditional birth attendants. Information leaflets were also distributed.

Pre-treated bednets, twine, and nails were distributed free of charge to those residing in intervention households. After receiving nets, each participant was given a demonstration on bednet mounting and use. Despite this, a spot-check in 1,104 randomly selected households one month after net distribution showed that about half of ITNs were not being used. At the same time, community members reported a variety of concerns about the project to traditional birth attendants (TBAs). In an effort to systematically document these concerns, we carried out a participatory rural appraisal (PRA), an anthropological research method used to motivate communities to plan and promote their own health agenda (NES, 1990). Reasons for poor initial acceptance of ITN use, as provided by participants of the PRA, are presented along with a discussion of solutions suggested by the community. Results of the pre-intervention ethnographic and sleeping behavior studies are presented as well, as these provide a useful comparison to the PRA findings. 


\section{MATERIALS AND METHODS}

\section{Study population}

The study population of Asembo, situated on the north-eastern shores of Lake Victoria in Bondo District, western Kenya, has been described elsewhere (Phillips-Howard et al., 2003 [a]). It typifies lakeside communities of eastern Africa (Cohen \& Atieno-Odhiambo, 1989). The climate is typically tropical with rainfall reaching an annual average of $1,400 \mathrm{~mm}$. The study area is holoendemic for Plasmodium falciparum malaria and transmission occurs throughout the year. Asembo comprises 79 villages with approximately 55,000 people. Ninetysix percent of the population are members of the Luo ethnic group.

Households are poor, with little variation in the distribution of wealth (Meltzer et al., 2003). Most residents are subsistence farmers who cultivate maize, sorghum, cassava and millet, and a few other vegetables. Some limited animal husbandry of cattle, goats, or poultry is also evident. Off farm activities include fishing near the shore of Lake Victoria, trading at market centres, and selling of vegetables and grain. Some adult males migrate to towns for employment, and return to their homesteads during holidays and at planting and harvesting time. Women of these homesteads become de facto heads of the household. Most men without regular jobs engage in seasonal farm labour. The most common type of house is the traditional Luo hut that has a stick framework plastered with mud and cow dung, a grass thatch roof and one door. Few houses have iron sheet roofs with sealed eaves. Before the trial, the proportion of houses with at least one bednet was about 5\% (Alaii, 1997; Sexton et al., 1990).

\section{Baseline ethnographic survey}

In 1996, TBAs recruited mothers with children less than 5 years of age to discuss child health in focus groups of 5 to 10 mothers each. Discussions, in Dholuo, the local language, were held in the home village of the mothers and lasted approximately two hours. A Luo social scientist transcribed discussions by hand, and a tape recording of the meetings was made to check for errors. In addition, a Luo researcher conducted a series of the informant interviews using a semi-structured questionnaire. Informants were teachers, TBAs, and opinion leaders. Information from focus groups and interviews was used to define ethnomedical terms used by Luo mothers in the diagnosis and treatment of childhood illnesses. The mothers' perception of the severity of each category of illness was also defined. 


\section{Sleeping arrangements study}

A small-scale baseline study of sleeping behaviour was conducted in Asembo Bay in 1996 (Alaii, 1997). The sampling unit was houses with mothers having at least one child less than 5 years of age. Houses were selected - with the assistance of TBAs - to include households from large and small compounds, as well as those with and without ITNs. Three different methods were used: (1) separate in-depth interviews of 16 mothers, (2) structured interviews of 38 mothers, and (3) three focus group discussions including a total of 30 women. Interviews were held in the home of the mother while focus group discussions occurred in the homes of TBAs. Questions and discussion centred on family sleeping arrangements, with particular attention to children's behavior. Experience with ITN use was discussed. Reasons for using or not using ITNs were elaborated in an attempt to identify factors that might prove relevant in determining ITN use during the subsequent trial.

\section{Participatory rural appraisal}

PRA was undertaken in an attempt to diagnose reasons for low net usage immediately after net distribution. PRA uses a variety of techniques to obtain information, including informal interviews with informants, interviews of selected participants using open-ended questionnaires, focus group discussions, community walks and mapping, seasonality drawing, and problem ranking (Chambers, 1994). The basic idea is to stimulate community members to think about problems in a variety of creative ways, not all of which depend upon verbal fluency or literacy so that all community members may contribute. Traditionally, this method starts with no specified problem, but we adapted the method to target the specific problem of low net usage faced by the ITN project, to explore how malaria fits into the overall picture of health-related problems affecting the community, and to identify which factors most affected the population's acceptance of the project.

Six of the 40 intervention villages within Asembo were randomly selected for study, but one village did not participate due to logistical problems. The 323 participants included mothers, village elders, teachers, health workers, village ITN committee members, and members of women's, youth, and church groups. An effort was made to ensure the participation of mothers with young children. TBAs and members of voluntary village ITN committees assisted study staffs. A team consisting of a social scientist, six field research assistants, and two community members conducted fieldwork. Team members were trained in PRA techniques and all training materials were subjected to preliminary field evaluation.

The PRA was conducted during January-February 1997, two months after ITN distribution in Asembo. Assessments in the five villages were conducted separately. Each was carried out for 3 consecutive days from mid-morning to mid-afternoon. In general, day 1 was devoted to assessment, day 2 to analysis, 
and day 3 to feedback and recommendations. Responses and information gathered were recorded verbatim by hand; at the end of each day the social scientists summarized the information, and tabulated instances of each category of response.

\section{Day I: Situational assessment}

Forty-nine women and 33 men took part in activities on day one. The starting point was an organized walk around the community, which aimed to draw in more participants and stimulate discussion. The research team and participants were divided into four groups to walk in 4 different directions of the village. Topics addressed were people's perceptions of common illnesses, problems with using ITNs, seasonality of malaria, mosquitoes, rainfall, farm activities, and labour demand, and accessibility of health facilities, shops, and transportation services. The data generated therefore provided a broad overview of the community's perception of health and ITNs.

\section{Day 2: Data synthesis and analysis}

Activities began with a recap of issues arising from the previous day. Participants included 104 women and 30 men. The main goal was to understand in more detail participants' perceptions of diseases, the relative importance of malaria, and implications for ITNs and their use. Two group discussions - one each for men and women - were conducted at each site.

\section{Day 3: Feedback and recommendations}

On day three all previous days' research was pooled together. In total, 110 participants were involved in identifying persistent problems and to suggest solutions. Activities included rank scoring of identified problems with ITN use in order of perceived seriousness and priority. The aim was to examine ways to improve compliance with ITN use. Activities on this day also helped identify misconceptions about malaria, ITNs, and project activities.

\section{RESULTS}

\section{Pre-intervention studies}

\section{Sleeping behaviour}

Two-roomed thatched houses without windows predominated in the study population, with a small proportion of the population living in larger houses. Eaves were open, and some roofs had gaps. Most houses had cross-beams that allow for tying of string to hold nets in place. Within a family compound, con- 
dition of houses varied, with the house of the head of the compound (upper house), being in best condition and that of houses serving as kitchens the worst.

All rooms in the house are potential sleeping areas. Sleeping places are governed by space and custom. The husband and wife sleep in the bedroom, sometimes in separate beds. Small children under two years of age sleep with their mothers, but two thirds of such children among the study houses were displaced from the bed by a newborn child, on account of bed wetting, or as the parents say, the child is 'old enough to sleep elsewhere'. A small proportion of displaced children under 5 years slept with another female adult, but most remained alone or slept with older siblings in the sitting room or kitchen. By Luo custom when a child reaches puberty he or she can no longer sleep under the same roof as the parents. They seek sleeping spaces in the grandparents' upper house, build a bachelors house (simba), or stay with relatives or friends. Visitors are accommodated in the upper house or kitchen depending on age and status. Visitors whose status allows them to sleep in the upper house may displace children or share their sleeping space.

Parents sleep on a bed with a mattress and have priority access to the only bednet in the house, if one exists. The rest of the family sleeps on the floor on shared papyrus reed mats (par). Asked for an explanation for this custom, several mothers said: "There is no money to buy extra beds and bednets, and furthermore, when they sleep on a hard surface like that they learn to appreciate that the comforts of life are not easy to come by. Children are still young and can endure lack of sleep due to mosquito nuisance. It is the adults who have to struggle to provide for them that need to sleep well."

Most families go to bed by $9 \mathrm{pm}$. Women wake from 5 am onwards to go to the farm, market centres, or the lakeshore. It is usual for a mother with no child caretaker to carry her baby to the farm or lakeside with her at dawn. Fishermen spend most of their night on Lake Victoria and return home in the early morning hours.

\section{Protection from mosquitoes}

A variety of methods for protection from mosquito biting were cited, including burning of traditional products (plant, cow dung, 'fire'), use of commercial products such as nets, mosquito coils, sprays, or Vaseline repellent, and environmental interventions such as clearing of bushes or draining of ponds. Twothirds claimed to use commercial means, predominantly mosquito coils. One participant from a focus group discussion illustrates this preference: "If you have KES 2.00 (US\$ 0.05) to spare you can get a mosquito coil which affords the whole household protection. It burns the whole night so mosquitoes do not disturb you in the middle of the night unlike the case with traditional plant products." Participants, nevertheless, recognized the advantage of nets: "With a bednet you do not waste money buying mosquito coils every day or expose your health to the dangers of heat and smoke caused by burning herbs." Burning herbs were thought to cause a congested chest and cough, and make the house and clothing smell. Participants noted, however: "bednets are good, yes, but we cannot afford them." 
Of 12 homes selected that had purchased their own bednet pre-intervention, most were used to lessen nuisance mosquitoes. One quarter of these homes claimed it sometimes prevented malaria; however, only one net was present per house and was invariably used by the parents. If an infant was present, and slept with the parents, then they too slept under the net. Nets were used mainly in the cold/rainy season and stopped when the mosquito population was perceived to be low. Problems experienced with ITNs included heat, nets that were too small for the beds, and nets that were not working because they were old and had holes. Heat was most often cited. Mothers also mentioned problems with washing, the inconvenience of daily opening and deployment of nets, and the problem of nets trapping small children left sleeping in bed.

\section{Willingness to purchase ITNs}

Of the 26 homes without ITNs, mothers were asked how they would allocate a large sum of money to household needs. One quarter included a mosquito net among things to be bought first. None considered buying more than one bednet. Most considered that the purchase of a net might be possible after other needs had been addressed - such as utensils, a sofa set, house renovation, setting up a business, or buying a new blanket. "Once you have a good blanket, you sleep well because you do not feel cold, and when you cover yourself properly (including the head), mosquitoes do not disturb you." Thus, respondents implied there was no perceived need for buying bednets. Participants felt nets were not a popular item in most Asembo homes because they are not affordable and, in homes where there was a net only one or two people, usually the mother and father, or mother and infant, had access to it. When further asked about the cost of ITNs, two-thirds thought one would cost between KES. 200-500 (US\$ 4-10) depending on size, excluding indirect transport costs. The overall perception was that ITNs are "very expensive."

\section{Ethnomedical terms}

The main categories of childhood illness were fever and fever-associated illness, diarrhea-related, skin rash or measles, stomach-ache, and a variety of other conditions (Table 5.1). The English term 'malaria' has been incorporated into the Luo ethnomedical system, with commonly perceived symptoms (in both adults and children) of fever, vomiting, diarrhea, and joint pain. Fudha and midhusi characterize illnesses clinically diagnosed as malaria, leading to ndulume (loss of consciousness or convulsions) if untreated. Severity of illness is not necessarily evaluated on an a priori scale or set of indicators, but requires consideration of the social and cultural situation at the time of the illness episode in addition to the mothers' appraisal of physical symptoms. A number of indigenous illness categories are perceived to be life-threatening and given greater attention. Of these, ang'iew (measles) and malaria were considered to be the most severe. 
Table 5.I Selection of ethnomedical terms used by mothers in western Kenya

\author{
Fever and fever related \\ Del maore general term describing fever, literally meaning "hot body". \\ Wich-bar general term for headache with a variety of etiological origins. \\ Malaria borrowed English term incorporated in the Luo ethnomedical system, describes a sickness category among both \\ children and adults with the most commonly perceived signs being fever, vomiting, diarrhea, and joint pain. \\ Common signs reported by mothers of young children under 5 years are chills (koyo) and shivering (tetni). \\ high body temperature (known term but not commonly used). \\ Liet hot body, joint pains, diarrhea, chills, often clinically diagnosed as malaria. \\ Fudha a more serious form or phase of malaria common among children. \\ Midhusi a severe illness in which the child experiences fever, vomiting, and convulsions. \\ Talarieya old mothers indicate that ndulume occurs when fudha is left untreated in children. Commonly reported signs \\ Ndulume $\quad$ are loss of consciousness or convulsions. Clinic staff refer to epilepsy as ndulume.
}

Diarrhea-Related Sicknesses (recognized as sometimes associated with fever and malaria)

Diep general term for common childhood illness ( $<5$ years) characterized by diarrhea, weakness in the entire body, sunken eyes, cold body.

Diep gi ng'ok diarrhea and vomiting associated with loss of weight, weakness, little urine is passed, sunken eyes, sunken fontanelle.

Orianyanja illness common among children up to two years, characterized by yellow diarrhea turning to greenish color, genitals become irritated.

Wuoyo diarrhea associated with change of skin color and hair color, characteristic signs are foamy, usually yellow diarrhea, and jaundice. Also called mbaha. Mothers further distinguish diarrhea as 'watery' diarrhea and 'bloody' diarrhea.

Fever and Skin Rash or Measles

Alura or ang'iew perceived as the most serious of all commonly reported illnesses affecting young children in Asembo, characteristic signs reported repeatedly by Asembo mothers are red lips, red eyes, fever, skin rash, and cold extremities. literally meaning 'small malady'. When speaking in Dholuo, mothers use as a code phrase for alura or

Tuo matindo ang'iew. Mothers fear using the gloss ang'iew or alura to refer to measles to avoid bringing the disease upon their child. Etiologically, measles was attributed to supernatural causes including evil spirits or to witchcraft, although some now define measles as a communicable disease affecting young children.

\title{
Stomach ache
}

Ichkach 'stomach ache'. The child cries a lot; there is diarrhea and the child refuses to breastfeed. Very common among breastfeeding infants. Some mothers say that this illness occurs frequently when the infant is first being given solid food. Attribution of causation can be complex. Sometimes it is attributed to the effects of njofni (small worms) and other times to evil eye or witchcraft.

Orip 'hardness' in the abdomen (hima). Oftentimes associated with an enlarged spleen. 
Table 5.2 Summary of the community seasonal calendar

\begin{tabular}{|c|c|c|c|c|c|c|c|c|c|c|c|c|c|c|c|c|c|}
\hline & & 而而 & 而而 & 而而 & & & & & 用 & 角 & & & & 尚而 & 塥 & 而而 & \\
\hline \multirow[t]{8}{*}{$\mathbf{W}$} & & & & & & & $\mathbf{w}$ & & & & $\mathbf{w}$ & $\mathbf{W}$ & & & & & \\
\hline & 핀 & $\Perp$ & & & & & & 世 & & & & & Ш & 世 & & & \\
\hline & & $\mathbf{W u}$ & $\mathbf{W}$ & $W$ & & & & & & & & & & W & $\boldsymbol{W}$ & $W$ & \\
\hline & & & & & & III & IIt & & & & & & & & & & \\
\hline & & & & & & & & & & $x \mathbf{x x}$ & $\mathbf{x x}$ & & & & & & \\
\hline & & & J & $\pi$ & J. & & & . J & J & & & & & & סתא & $\pi$ & J J \\
\hline & & 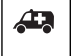 & 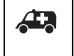 & 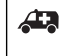 & & & & 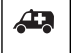 & $\Delta$ & & & & & 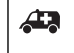 & 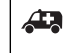 & sto & \\
\hline & 우 & 우 & 우 & \& & q & Q & Q & 우 & 우 & 우 & & & Q & 우 & 우 & Q & q \\
\hline$\sigma^{7}$ & ত্ & $\sigma^{7}$ & & & & বা & $\sigma^{\prime}$ & & & ד' & & $\sigma^{7}$ & তা & $\sigma^{\prime}$ & & & \\
\hline Jan & Feb & Mar & April & May & Jun & Jul & Aug & Sept & Oct & Nov & Dec & Jan & Feb & Mar & April & May & Jun \\
\hline 労 & & & $\begin{array}{l}\text { pioughn } \\
\text { ل planting }\end{array}$ & & 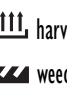 & & $\begin{array}{l}\text { \& labou } \\
\sigma^{\top} \text { labo }\end{array}$ & $\begin{array}{l}\text { Ir (women) } \\
\text { ur (men) }\end{array}$ & & peak mo & $\begin{array}{l}\text { nosquito s } \\
\text { malaria se }\end{array}$ & $\begin{array}{l}\text { reason (" } \mathrm{m} \\
\text { ason (ma) }\end{array}$ & $\begin{array}{l}\text { mosquitoes } \\
\text { nny people }\end{array}$ & $\begin{array}{l}\text { es sing a I } \\
\text { e sick) }\end{array}$ & $\begin{array}{l}\text { lot") } \\
\mathrm{XXX} \text { lar }\end{array}$ & nd clearin & \\
\hline
\end{tabular}

\section{Participatory rural assessment}

\section{Community calendar}

Seasonality information generated during the community walk was compiled into a seasonal calendar depicting community perceptions of trends in the distribution of illness (malaria), mosquito density, rainfall, and labour demand (Table 5.2). Overall, participants perceived peak malaria seasons to coincide with the long and short rains of March-May and September-October respectively. The calendar suggested an association between peak malaria and mosquito seasons, although there was no concept of a time lapse between the rains starting and the onset of acute malaria attacks. The calendar also illustrated higher labour demands on women than on men, with women performing most agricultural activities in the family fields. However, since women are also the traditional household managers, they tend to work around the home, and are easier to contact via door-to-door research activities than are men.

\section{Ranking of diseases}

A list of 21 illnesses commonly affecting adults and children was generated during the community walk. Out of 64 instances respondents listed a disease, 
Table 5.3 Participants' perceptions of the 'seriousness' of malaria and measles

\begin{tabular}{ll}
\hline Malaria (malaria) & Ang'iew (measles) \\
\hline May kill & May kill \\
Kills many & May kill a few but spreads fast \\
Bound to set in after other illnesses & Hides in other illnesses \\
Comes suddenly & Comes suddenly \\
Can cause madness (cerebral malaria) & \\
Needs fast treatment & \\
Has no traditional cure/remedy & Has no remedy (injections can kill) \\
\hline
\end{tabular}

the most frequently mentioned illness was malaria (13 of 64 ); then - less frequently - diarrhea ( 9 of 64), measles (7 of 64), coughs (7 of 64), and wichbar, a term used inter-changeably for headache and malaria fever (7 of 64). When 10 groups were asked specifically to rank the importance of these 21 illnesses, the leading diseases were perceived to be malaria (10 of 10), measles (9 of 10 ), diarrhoea (9 of 10), and coughs (8 of 10). Other childhood diseases in the list included vomiting (3 of 10), scabies (3 of 10), and wichbar (3 of 10). Disease ranking showed convergence in perceptions of men and women, except for the cases of diarrhea and coughs. Women's groups ranked diarrhea higher than coughs, and vice versa for men's groups.

Participants in grouped discussions recognized malaria and measles to be the most serious of the diseases commonly affecting children. The two diseases were considered troublesome as either could be easily confused for the other, especially early in the course of illness. Confusing the two conditions, it was said, often led caretakers to undertake the wrong treatment. In addition, 9 of 10 focus groups perceived malaria to be the most worrying of the two diseases. Participants stated that the preferred treatment for measles is traditional. Malaria treatment, on the other hand, requires non-traditional ('western') solutions that are sometimes not easily attainable for various reasons including cost (Table 5.3).

\section{Perceived causes of malaria}

While participants in all 10 group discussions cited mosquitoes as causing malaria, this co-existed with traditional beliefs that cold weather and rain (3 of 10 ), some foods (3 of 10) and dirty water ( 1 of 10) independently cause malaria. This may suggest that bednets alone are not enough protection against malaria, and has important implications for compliance with ITNs. As one participant stated: ".. what use is it to sleep under bednets daily (every night)? What about mosquitoes that bite when we are eating ..." Thus, in addition to using ITNs, cited by all 10 groups, participants also suggested a range of preventive regimens perceived 
to be equally important such as boiling drinking water (3 of 10) and taking antimalarial drugs (4 of 10).

\section{Care-seeking for sick children}

Participants in group discussions perceived drugs purchased over the counter (8 of 10) from local retail outlets (duka), and medicines dispensed at local health facilities (7 of 10) as the main forms of health care commonly sought by both adults and children. However, the norm is to seriously seek medical care only when the illness gets to a worrying stage (might cause death). Apparently, duka and health facility drugs are popular choices because 1) the duka is easily accessible and one does not require consultation fees, and 2) health facilities drugs cost relatively less compared to other care options, as long as the drugs are available at local public health facilities. Discussion sessions indicated that while dispensaries may seem on face value to be a common source of health care, this is usually as a last resort when other more accessible care options, consisting mainly of self medication, have been tried and have "failed."

\section{Factors influencing care seeking}

Group discussion participants cited low income levels (5 of 10) coupled with high cost of drugs and medical consultation (2 of 10) as obstacles to care seeking. Other problems include poor roads, some impassable in the rainy season, inadequate vehicles (2 of 10), and distances to health facilities ( 3 of 10). In view of these problems, over three quarters of the participants agreed that ITNs might play an important role in improving the welfare of the community.

\section{The likes and dislikes for ITNs}

At the time of these studies participants had little or no experience of the effectiveness of ITNs, and valued them mainly for affording people a good sleep free of mosquito nuisance. Another perceived advantage was the ITNs' potential to reduce and/or kill household bugs including bedbugs, cockroaches, and rats. It is notable that during this study, previously quoted likes for bednets such as improving the appearance of a bedroom were not listed. ${ }^{3}$ Perhaps this could be attributed to the green colour of the research nets, though there was no stated conflict about net colours during PRA. Many problems associated with mounting and using the newly acquired ITNs were listed during the community walk. Four categories of problems were identified: problems associated with insecticide, problems related to mounting and using nets, concerns and misconceptions about specific aspects of the research, and, occasionally, local practices that may hinder optimal ITN use (Table 5.4).

\section{Concerns about the use of chemical (insecticide) in bednets}

Participants commonly raised concerns about the use of the chemical in ITNs. Out of 10 groups, 8 were particularly concerned about the chemical smell evident in newly treated bednets. Apparently, people were waiting for the smell to 
Table 5.4 Problems associated with nets and general concerns about the insecticide-treated bednet project

\begin{tabular}{|c|c|}
\hline $\begin{array}{l}\text { Problems with insecticide } \\
\text { - Nets smell badly when new and re-treated } \\
\text { - Chemical causes flu-like symptoms (runny nose), and skin } \\
\text { rashes } \\
\text { - Chemical may make nets unfit for babies } \\
\text { - Chemical may be a secret fertility and/or birth control } \\
\text { device }\end{array}$ & $\begin{array}{l}\text { Problems with the nets } \\
\text { - Some nets too small } \\
\text { - Nets too hot on warm nights } \\
\text { - Not everyone was given nets } \\
\text { - Nets wear and tear easily on papyrus reed sleeping mats of } \\
\text { children } \\
\text { - Rats like to eat the netting } \\
\text { - Daily hanging and removal of nets in living rooms and } \\
\text { kitchens is tiresome } \\
\text { - Some people did not get twines for hanging }\end{array}$ \\
\hline $\begin{array}{l}\text { Concerns about research project } \\
\text { - Suspicion over blood sampling surveys } \\
\text { - Concern that free distribution of nets was a trap to later } \\
\text { get money from people } \\
\text { - Concern that researchers would repossess nets and reuse for } \\
\text { research in control areas } \\
\text { - Security worries during night compliance monitoring }\end{array}$ & $\begin{array}{l}\text { Local practices affecting compliance } \\
\text { - Mixing nets during treatment is taboo } \\
\text { - Night vigils at funerals prevent net use } \\
\text { - Influx of people into homes during funerals disrupt sleeping } \\
\text { arrangements, and prompts locking away of nets to prevent } \\
\text { theft }\end{array}$ \\
\hline
\end{tabular}

wear off before they could start using their nets. Some mothers were washing babies' nets to reduce the smell in an attempt to prevent suffocation. Three groups perceived the chemical content in nets to be a secret fertility control device imposed by the government while 2 groups thought it could cause suffocation. The general perception was that the chemical was the cause of flu-like and runny nose symptoms experienced about the same time nets were distributed to study participants. When specifically asked whether they thought insecticide-treated bednets were harmful, all 10 groups said the nets were not the problem per se. The underlying cause for reluctance to use nets, they said, was linked to the randomized controlled design of the project. They said that some people from control villages, in their attempt to outwit the intervention group of their nets, were spreading rumours as to why not all people were given ITNs. To some unsuspecting people, this suggested the ITNs were harmful.

\section{Misconceptions about project activities}

The main concern about proposed project activities, the groups said, surrounded drawing blood for clinical surveys (5 of 10) and night spot checks to monitor net use (2 of 10). Distrust for clinical surveys was traced to Luo beliefs relating to witchcraft, and termed "logo remo". It is generally believed that evil persons could use blood to bewitch donors, causing their death. This fear was com- 
pounded by rumors that the project would "drain" participant's blood in exchange for nets. Not knowing the exact quantities of blood to be drawn made people reluctant to start using nets lest the so-called free nets turned out to be a trap to get blood donors. As heard from listening surveys: “... I am waiting to see if they come and say they want blood...and then I will say to them; here is your net ... you can have it back ... I have no use for it ...". Night spot-checks caused concern not as an imposition on family privacy, but as a security risk with fears that robbers might pose as staff.

\section{Problems relating to mounting and using ITNs}

The two main problems in this category related to sleeping arrangements and perceived heat under nets. Sleeping arrangements were generally perceived as posing a major logistical challenge to good ITN use. Sleeping arrangements for children in living rooms and kitchen require a daily commitment to mount and dismount nets, making this job tedious and difficult to sustain. Five of 10 groups recognized heat under nets as a major determinant of when and if people would use nets. Although this was listed only 5 times during the community walk, participants stated it was common knowledge that few people would use nets in the hot dry season. It was encouraging to note, however, that some people thought one could still sleep comfortably under nets in the hot season: "... bednets do not bring heat! The land (general climatic condition) is hot.

Therefore he (participant) can stop covering himself with a blanket and sleep under a net without any covering." (Male participant during open discussion session).

\section{Problems relating to culture and other practices}

While we could not define any cultural taboos against ITN use, participants articulated concerns about the ignorance of researchers regarding taboos governing family relations and social networks in terms of sharing or mixing bedding items including ITNs. Fertility beliefs prohibit mixing bedding items of parents and their children who have attained puberty. This was cited as a major reason for rejection and/or exchange of ITNs in the first weeks of ITN distribution. Some study participants were said to be awaiting reassurance that such oversights would not occur during ITN retreatment periods. Funerals, often involving temporary migrations are a cultural practice that indirectly impact on adherence with ITN use. With so many people sharing sleeping spaces on such occasions it may not be practical to mount and use nets. In addition, families tend to lock up nets during times when many visitors are present to prevent theft.

Ranking exercises showed the effect of family hierarchical systems on members' access to items such as ITNs and people's reasons for using ITNs (Alaii, 1997). Traditionally, adults, by virtue of their age and position as family income earners get priority coverage. These exercises also showed the divergence between people's opinion and scientific evidence about persons most at risk for malaria. The rankings showed that although over three quarters of par- 
ticipants perceived children to be most vulnerable to malaria (perhaps because researchers said so), the general perception was that everyone was equally vulnerable and needed equal protection. This, coupled with the persistent notion that adults needed priority coverage, has implications for child ITN use in households where there may not be enough ITNs to go around.

\section{Community suggestions for enhanced ITN use}

Participants were encouraged to outline elements of the project that needed to be reviewed in order to improve adherence, and how best to achieve such changes. The underlying cause of problems, they said, was gaps in community knowledge and understanding of project activities and their purpose. The best solution, it was suggested, was to educate community members at various levels, and address their concerns about ITNs and proposed project activities. Particular emphasis was placed on the need to understand the nature of clinical surveys, detailing their purpose, inclusion and exclusion criteria, and how often they would be conducted, including estimated quantities of blood to be drawn per sample. Other areas of concern related to proposed night spot-checks, and their timing. In order to counter fears about robbers posing as staff it was recommended that staff be accompanied by a villager held in high esteem during night-time studies. Recognition of family relations and fertility beliefs required that plans to treat nets at a central point in the village be reviewed, to which participants proposed door-to-door dipping as the best possible option.

\section{Improvements to the project following PRA}

Many of the problems with ITN use were related to misconceptions about the bednets and insecticide and the project purposes in general. Our findings give a clear indication for the need to revisit general health communication for the project. The original focus was on awareness creation with the main objective of persuading people that ITNs were a worthwhile disease control tool. These findings showed it was time to shift to more practical issues if people were to start using ITNs; provide correct information designed specifically to address people's concerns and fears about the intervention. Rogers (1995) calls this the innovation decision stage, during which people require information to reduce uncertainty. We sought to involve community members at all levels including schools. Greater emphasis was placed on more personalized discussions with the community, at both the individual and community level. This involved shifting ITN meetings from the framework of the local community meetings convened by chiefs to existing community networks including women groups, village ITN committees, and church groups where people felt more at ease to discuss their fears. To supplement these group meetings, community theatre was used to raise topics of concern to which villagers were welcomed to participate and role-play. ITN drawing and poetry competitions were designed to target pri- 
mary school children, and winning items went into compiling a project calendar incorporating monthly messages about key project activities. A workshop was held for the village ITN committees to familiarize them with underlying principles for project activities to enable them to address people's concerns at community meetings project staff could not attend. Similarly, all data collection training for project field staff included understanding the underlying principles for any field activities they may be assigned to carry out so that they might accurately answer questions and allay concerns about project activities. For the quarterly spot checks, performed to monitor ITN use during the project, interviewers from the local villages were given ID cards to show to householders before entering their homes (Alaii et al., 2003).

\section{DISCUSSION}

Information from this study was used to design subsequent educational campaigns that aimed to maximize ITN use. We also easily took into account community taboos in designing an effective method for net retreatment. It is likely - though impossible to verify - that the exercises described herein helped the researchers and community to work together to implement a trial that was successful - at least in the sense that the intervention reduced infant mortality by 26\% (Phillips-Howard et al., 2003 [b]). Further, compliance levels for the overall trial were close to $70 \%$ over a two-year period (Alaii et al., 2003), considerably higher than levels observed immediately after net distribution.

Some of the concerns raised by participants in the qualitative surveys were later quantitatively validated. In particular, net use by adults was consistently higher than for children and use during periods of hot weather tended to decrease. However, no association between observed net use and numbers of mosquitoes was observed (Alaii et al., 2003). It is also worth noting that TBAs and ITN village committees often made requests for PRA were often made by ITN village committees and TBAs in non-PRA villages as a means of improving people's perceptions of ITNs. Our study population's reluctance to use ITNs was quite contrary to previous indications from formative research that participants people desired bednets, but were only mainly barred by financial constraints (Alaii, 1997). Overall, the results suggest high potential for the acceptance and use of ITNs for malaria control in this area. The apparent absence of any cultural barriers to ITN use (Alaii, 1997; Sexton, 1995) is an added advantage.

Our observed community reaction raises questions about programmes placing too much emphasis on "action" to the extent that implementers fail to recognize the processes of behaviour change (Prochaska et al., 1992). Our experience may be typical of attempts to introduce new ideas (Roger, 1995) and attests to 
the common problem of how best to speed the uptake of ITNs as a malaria control tool (Winch et al., 1994; D’Alessandro et al., 1995; Binka \& Adongo, 1997). It is generally assumed that an advantageous innovation, such as ITNs (Choi et al., 1995; Lengeler, 2000) will diffuse rapidly. The uncertainty inherent in new ideas is of course a concern, and a major determinant of people's evaluation of a new idea against previously existing alternatives (Rogers, 1995): “... we (our family) are waiting to see how it (insecticide in nets) reacts on those who have started using it ..." (Excerpt from informal conversations heard making rounds in the community).

How the uncertainty involved is addressed is of crucial importance. Health communication plays an important role in predisposing people to an intervention. However, the relationship between knowledge and behaviour is not linear. Often, a window period of information processing follows the first knowledge and the decision stages. As in our case, people would first need to acquire a new perception (Rogers, 1995), that the chemical concentration in nets is not toxic (Basakaran et al., 1992) and that it is, therefore, safe to sleep under nets treated with insecticide. It is arguable, therefore, that what we observed was not necessarily failure, but rather a stage in the process of adopting the intervention (Rogers, 1995), raising questions of how to overcome negative influences while enhancing positive factors. Perhaps, at this stage, health communication would be best used to provide correct information aimed specifically at addressing people's concerns rather than bombard people with more scientific evidence. Although it was too early in the programme for people to realize any benefits, it has been noted that the absence of direct and immediate benefits often result in limited response to programmes relying on consistent, repeated behavior. The transmission of malaria, for instance, is quite complicated, and participants may fail to see the utility of their efforts (Oaks et al., 1991). In our experience, misconceptions about insecticide, lack of congruity between preventing nuisance biting versus disease prevention, and concepts of multiple causation of malaria collectively prevented people from perceiving the potential benefits of ITNs for malaria control: “... it does not make a difference how I use the net ... I will still get malaria if I am rained on ..."

If other threats for the transmission of malaria remain equally relevant, over which ITNs have no effect, maintaining ITN use by explicitly talking about reducing mosquito burden throughout the year clearly becomes more problematic. At the onset of this project, people viewed protection from mosquito biting in terms of avoiding nuisance biting, rather than preventing disease. Consequently, ITNs were the preserve of adults who are perceived to need better sleep in order to effectively meet their daily obligations as family breadwinners (Alaii, 1997). In other studies, the emphasis on good sleep was exacerbated by seasonal changes in temperature, particularly in the hot season, and when mosquitoes are perceived not to be abundant (Winch et al., 1994; D’Alessandro et al., 1995). It has been suggested that acknowledgement of any factor that motivates people to sleep under ITNs, even when it is not directly 
related to health, may help in trying to win people over to public health awareness and action (Winch et al., 1994; Brieger et al., 1996). Sole focus on the reduction of nuisance biting or killing household bugs may backfire, however, because people will stop using ITNs when they do not perceive those benefits (D’Alessandro et al., 1995; Binka \& Adongo, 1997). In our quantitative studies of ITN deployment (adherence), we found no seasonal correlation between high abundance of nuisance biting culicines and malaria-transmitting anophelines, nor did we find that numbers of either culicines or anophelines were associated with ITN use (Alaii et al., 2003). Nonetheless, our entomological studies showed that proper deployment of ITNs was associated with reduced numbers of indoor-resting Anopheles gambiae (Gimnig et al., 2003).

People in this community are poor (Meltzer et al., 2003). The priority in their daily life is subsistence; they can barely afford to invest in items such as ITNs. As with former trials elsewhere (D’Alessandro et al., 1995; Snow et al., 1999) ITN coverage and compliance rates may drop considerably once participants have to pay for ITNs and insecticides themselves. Our baseline study illustrated that ITNs were not considered a priority (Alaii, 1997) and were, thus, valued as a luxury rather than a public health item at distribution. In a former site, ITNs continued to be used although access to insecticides and new nets limited effectiveness (Kachur et al., 1999). Ultimately, however, it remains to be seen whether the population will value ITNs because of perceived health or subsidiary benefits, and whether bednets and insecticide will be ranked as a household priority. As with questions of affordability (Meltzer et al., 2003; Rozendaal, 1989), correct use of ITNs will be largely determined by the perceived need to use a bednet in the first place.

In summary, findings from our anthropological studies early in the project indicated that the study population would accept and use ITNs. After introduction, an array of social and cultural issues associated with the ITN project became apparent. While the majority of these problems could be addressed during the project they illustrate the shifting roles of communication, time, and the social system in the diffusion process. Individuals seek information at various stages of the diffusion process to decrease uncertainty about its expected consequences (Rogers, 1995). The decision leads to either rejection or adoption of the innovation - and success or failure of the intervention. 


\section{REFERENCES}

Alaii, J.A. (1997). The relevance of sleeping arrangements and bedtime mobility patterns for implementing insecticide-treated bednets in Asembo, western Kenya. MSc Dissertation, London, Faculty of Health Sciences, South Bank University, UK.

Alaii, J.A., Hawley, W.A., Kolczak, M.S., ter Kuile, F.O., Gimnig, J.E., Vulule, J.M., Odhacha,A., Oloo,A.J., Nahlen, B.L., \& Phillips-Howard, P.A. (2003). Factors affecting the use of permethrin treated bednets during a randomised controlled trial in western Kenya. American Journal of Tropical Medicine and Hygiene, 68, Suppl. 4.

Basakaran, S., Kalyanasandaram, M., Das, L.K., \& Das, P.K. (1992). Preliminary evaluation of safety aspects in mosquito net impregnation with lambda cyhalothrin. Indian Journal of Medical Research A, Inf Dis, 95(47-48).

Binka, F.N., \& Adongo, P. (1997). Acceptability and use of insecticide impregnated bednets in northern Ghana.Tropical Medicine and International Health, 2(5), 499-507.

Brieger,W.R., Onyido,A.E., Sexton, J.D., Ezike,V.I., Breman, J.G., \& Ekanem, O.J. (1996).

Monitoring community response to malaria control using insecticide-impregnated bednets, curtains and residual spray at Nsukka, Nigeria. Health Education Research, I I (2), I33145.

Chambers, R. (1994). The origins and practice of Participatory Rural Appraisal. World Development, 22, 953-969.

Choi, H.W., Breman, J.G., Teusch, S.M., Liu, S., Hightower, A.W., \& Sexton, J.D. (1995). The effectiveness of insecticide impregnated bednets in reducing cases of malaria infection: a metaanalysis of published results. American Journal of Tropical Medicine and Hygiene, 52, 377-82.

Cohen, D.W., \& Atieno-Odhiambo, E.S. (1989). Siaya: The historical anthropology of an African landscape. London: James Currey Ltd.

D'Alessandro, U., Olaleye, B.O., McGuire,W., Langerock, P., Bennett, S., Aikins, M.K., Thompson, M.C., Cham, M.K., \& Greenwood, B.M. (1995). Mortality and morbidity from malaria in Gambian children after introduction of an impregnated bednet programme. Lancet, 345, 479-483.

Gimnig, J., Lo, T., Vulule, J., Kamau, L., Kolczak, M.S., Phillips-Howard, P.A., Nahlen, B.L., Oloo,A., Hightower, A.W., \& Hawley,W.A. (2003). Impact of permethrin-treated bednets on entomological indices in an area of intense year round malaria transmission. American Journal of Tropical Medicine and Hygiene, 68, Suppl. 4.

Kachur, S.P., Phillips-Howard, P.A., Odhacha, A.M., Ruebush,T.K., Oloo,A.J., \& Nahlen, B.L. (1999). Maintenance and sustained use of insecticide treated bednets and curtains three years after a controlled trial in western Kenya. Tropical Medicine International Health, 4, 728-35.

Lengeler, C. (2000). Insecticide-treated bednets and curtains for preventing malaria. Cochrane Database System Review 2: CD000363.

Lines, J.D. (1996). Net Gain:The technical issues In: Lengeler, C., de Savigny, D., \& Cattani, J. (Eds.). (1996). Net Gain:A New Method of Preventing Malaria Deaths. Geneva \& Ottawa: WHO/IDRC. I7-54 
Meltzer, M.I., Terlouw, D.J., Kolczak, M.S., Odhacha,A., ter Kuile, F.O.,Vulule, J.M., Alaii, J.A., Nahlen, B.L., Hawley,W.A., \& Phillips-Howard, P.A. (2003). The household-level economics of using permethrin-treated bednets to prevent malaria in children under 5 years of age. American Journal of Tropical Medicine and Hygiene, 68, Suppl. 4.

NES (1990). Participatory Rural Appraisal Handbook. National Environment Secretariat, Kenya; Clark University; Egerton University; and the Center for International Development and Environment of the World Resources Institute: Nairobi, Government Printers.

Oaks, S.C., Mitchell,V.S., Pearson, G.W., \& Carpenter, C.C.J. (Eds.). (1991). Malaria: Obstacles and Opportunities. Washington D.C: Institute of medicine, National Academy Press.

Phillips-Howard, P.A., ter Kuile, F.O., Nahlen, B.L.,Alaii, J.A., Gimnig, J.E., Kolczak, M.S., Terlouw, D.J., Kariuki, S., Shi, Y.P., Kachur, S.P., Hightower,A.W., Vulule, J.M., \& Hawley,W.A. (2003 [a]). The efficacy of permethrin-treated bednets on child mortality and morbidity in western Kenya. II: Design and methods. American Journal of Tropical Medicine and Hygiene, 68, Suppl. 4.

Phillips-Howard, P.A., Nahlen, B.L., Kolczak, M.S., ter Kuile, F.O.,Alaii, J.A., Hightower, A.W., Gimnig, J., Arudo, J.A., Vulule, J., Schoute, E., Kachur, S.P., Oloo, A.J., \& Hawley,W.A. (2003 [b]). Efficacy of permethrin-treated bednets in the prevention of mortality in young children in an area of high perennial malaria transmission in western Kenya. American Journal of Tropical Medicine and Hygiene, 68, Suppl. 4.

Prochaska, J.O., DiClemente, C.C., \& Norcross, J.C. (1992). In search of how people change: Applications to the addictive behaviours. American Psychologist, 47(9), I I02-I I I 4.

Rogers, E.M. (Ed.). (1995). Diffusion of innovations (4th ed.). New York:The Free Press.

Rozendaal, J.A. (1989). Impregnated mosquito nets and curtains for self-protection and vector control. Tropical Diseases Bulletin, 86, R29-R30.

Sexton, J., Ruebush,T.K., Brandling-Bennett, A.D., Breman, J.D., Roberts, J.M., Odera, J.S., \& Were, O.B.J. (1990). Permethrin-impregnated curtains and bed nets prevent malaria in western Kenya. Am J Trop Med Hyg, 43, II-- I8.

Snow, R.W., McCabe, E., Mbogo, C.N.M., Molyneux, C.S., Some, E.S., Mung'ala,V.O., \& Nevill, C.G. (1999). The effect of delivery mechanisms on the uptake of bed net re-impregnation in Kilifi District, Kenya. Health Policy and Planning, I4(I), I8-25.

Winch, P.J., Makemba, A.M., Kamazima, S.R., Lwihula, G.K., Lubega, P., Minjas, J.N., \& Shiff, C.J. (1994). Seasonal variation in the perceived risk of malaria: Implications for the promotion of insecticide-treated bed nets. Social Science and Medicine, 39, 63-75. 


\title{
CHAPTER 6
}

\author{
FACTORS AFFECTING USE OF PERMETHRIN-TREATED \\ BEDNETS DURING A RANDOMISED-CONTROLLED \\ TRIAL IN WESTERN KENYA'
}

\section{IPublished as:}

Jane A. Alaii, William A. Hawley, Margarette S. Kolczak, Feiko O. ter Kuile, John E. Gimnig, John M. Vulule, Amos Odhacha , Aggrey J. Oloo, Bernard L. Nahlen, Penelope A. Phillips-Howard (2003) Factors affecting use of permethrin-treated bednets during a randomised-controlled trial in western Kenya. American Journal of Tropical Medicine and Hygiene, 68, Suppl. 4. 


\begin{abstract}
Adherence with permethrin-treated bednet (ITN) use, and their proper deployment was directly observed in 2,178 individuals (784 households) participating in a large-scale trial of ITNs on child mortality in western Kenya. ITNs were distributed free of charge to ensure high coverage, resulting in a ratio of 1.46 persons per ITN. About $30 \%$ of ITNs present were unused. Percentage adherence overall was $72.3 \%$. The probability of adherence by individuals depended strongly on age (relative risk $[\mathrm{RR}]=0.86,95 \%$ confidence limits $[\mathrm{Cl}]$ 0.78-0.94), where children less than 5 years of age were less likely to use ITNs than older individuals, and temperature, where ITNs were more likely to be used in periods of cooler weather. A marginally significant diminution in adherence during the second year of the project was also observed $(\mathrm{RR}=0.83$, 95\% Cl 0.68-1.01). Neither mosquito numbers, relative wealth, number of house occupants, nor educational level of the head of the household, had any effect on adherence. In unstructured questioning of house residents, excessive heat was often cited as a reason for not deploying the child's ITN. The most important reason for non-adherence was 'disruption of sleeping arrangements', indicating that ITNs were not readily redeployed in the face of shifting sleeping patterns due to visitors, funerals, house construction, and other events.

Challenges faced by health education programmes to maximize adherence with ITN use are discussed.
\end{abstract}




\section{INTRODUCTION}

Multi-centre trials have shown that insecticide-treated nets or curtains reduce allcause childhood mortality by $14-33 \%$ in rural sub-Saharan Africa (Alonso et al., 1991; D’Alessandro et al., 1995; Binka et al., 1996; Nevill et al., 1996; Habluetzel et al., 1997) resulting in advocacy for the inclusion of ITNs, in particular, in a malaria control strategy for Africa (WHO, 1999). While coverage of a population - defined as the proportion of the population possessing ITNs - is primarily influenced by the mechanism and economics of ITN distribution, adherence proper deployment of ITNs - is influenced by a range of environmental and social factors. In northern Ghana, for example, ITNs were perceived to be of benefit for protection from seasonally abundant nuisance mosquitoes (Gyapong et al., 1996; Binka \& Adongo, 1997). A drop in use of ITNs was reported over the two-year trial in Ghana, falling to $20 \%$ in the last dry season, when temperatures were high and mosquito populations were low (Binka \& Adongo, 1997). In coastal Kenya the proportion of ITNs in use decreased slightly during the project period, but deteriorated sharply after the project finished (Snow et al., 1999). The changing patterns of ITN use by season, and difficulties in encouraging community-sustainable approaches to ITN use were also described in Tanzania (Winch et al., 1994; Winch et al., 1997). We describe here factors affecting directly observed adherence with ITN use in rural western Kenya in the context of a large-scale trial to assess the impact of ITNs on child morbidity and mortality where malaria transmission is both perennial and intense (Phillips-Howard et al., $2003[\mathrm{a}])$. In this paper, we test the hypotheses that age, temperature, rainfall, entomological indices (Gimnig et al., 2003), relative wealth, and educational status are associated with the probability that an individual will properly deploy his or her ITN. We associate these findings with results of unstructured interviews of study participants on reasons for non-adherence. Findings are discussed in relation to problems faced in the design and implementation of health education programmes for this promising malaria control tool.

\section{MATERIALS AND METHODS}

\section{Study population}

The approximately 55,000 mainly ethnic Luo inhabitants of Asembo are highly dispersed, living in approximately 8,500 family compounds, each comprising an average of 4 houses surrounded by family-owned fields (Phillips-Howard et al., 2003 [b]). The major occupation is subsistence farming and limited animal husbandry, but some people fish in Lake Victoria while others engage in local 
business. The most common type of house has a stick framework plastered with mud, a thatched roof, one door, and one or two windows. Eaves are open, allowing easy entrance and exit for mosquitoes. Though some houses have corrugated iron roofs, few of these have sealed eaves. Rainfall is bimodal with the long rains falling March through May and the short rains around November and December. The predominant malaria vectors in the area are Anopheles gambiae and An. funestus. Malaria transmission in the area is intense year round, with the average number of bites of potentially infective mosquitoes ranging from 60 to 300 per person per year (Beiers et al., 1994).

Baseline studies revealed few $(<5 \%)$ houses using bednets, with preference given to adults and visitors to prevent the biting of nuisance mosquitoes (Alaii, 1997). None of the bednets in use before the project began were treated with insecticide. Children less than 3 years old sleep with the mother, older children sleep in the kitchen and sitting room, and teenagers may sleep in a house in their home compound or in surrounding compounds of relatives and friends.

\section{Educational activities and ITN distribution}

The ITN project, described in detail elsewhere (Phillips-Howard et al., 2003 [b]), incorporated extensive educational activities, including community wide meetings in every village, informal discussions with traditional birth attendants (TBAs) associated with the project, participatory educational theatre, an art competition for a calendar design involving schoolchildren that attracted hundreds of entries, and distribution of information sheets in Dholuo. Messages stressed through all routes were:

(i) Take ill children to health clinics promptly.

(ii) Sleep under ITNs all year round every night. Tuck in ITNs to keep mosquitoes from entering.

(iii) Correct and consistent ITN use can reduce illness and death in young children.

(iv) Wash ITNs only just before insecticide re-treatment.

(v) Keep ITNs in good condition by sewing up holes.

Upon ITN distribution in November and December 1996, participants were shown how to hang ITNs over either beds or floor mats, and were provided with twine and nails if needed. By the beginning of 1997, over 17,000 permethrin-treated dark green bednets (Siam Dutch, Thailand) had been distributed in the 40 of 79 villages randomised to receive ITNs in Asembo. Our aim was to cover all previously counted and measured sleeping places (beds or mats) with an ITN of appropriate size. During 1998 a further 4,600 ITNs were distributed for new immigrants and newborns. Bednets were pre-impregnated with $0.5 \mathrm{~g}$ of permethrin per $\mathrm{m}^{2}$ of netting and were re-treated to that target dose every 6-9 months. At each re-treatment exercise, net and sewing materials were provided to residents whose ITNs were in need of repair. ITNs were distributed to residents of the 39 control villages in the first quarter of 1999. 


\section{Data collection methods}

Presence and use of ITNs were monitored through direct observation by study staff during early morning hours (4:30-6:00 a.m.). All communities had consented to participate in the process, with the understanding that no house would be surveyed more than once; nonetheless, residents of survey houses were not aware that they would be monitored on a specific day. Monitoring was done quarterly during the two-year project; sampling was thus done on 8 separate occasions, beginning in March 1997. We attempted to quantify ITN use in 100 intervention houses each quarter, or 800 houses total. Observations were actually recorded from 784 houses reflecting some under sampling and 3 refusals. Houses were sampled in clusters: the nine nearest neighbors of randomly selected index houses were sampled, yielding 10 samples per cluster. A similar method was used to select houses in control villages for entomological monitoring. Prior to each survey, ITN distribution forms of selected houses were reviewed to ascertain the number of ITNs initially issued. At survey, study staff recorded (i) the number and age of all people sleeping in the house (ii) the number of ITNs in use, (iii) the number of ITNs present but not in use, and (iv) the number and ages of individuals either using or not using ITNs and (v) why household members, and specifically why children $<5$ years of age might fail to use their ITNs. This last question was asked whether or not children had been observed to use their ITNs. Any response was allowed; similar results were categorized together by the investigators.

Two hours after the initial visit, study staff revisited each household to ask more detailed questions about ITN use and travel in the previous month. Caretakers of children were interviewed, if present; otherwise, an adult household resident was asked. At the same time, an entomological survey were done in each house (including houses from control villages) to estimate the number of mosquitoes of different species found resting indoors. Details of entomological methods are described elsewhere (Gimnig et al., 2003).

For most houses, baseline socio-economic data were collected during the first year of the study to allow construction of an index of wealth, based upon observation of house construction, ownership of goods and livestock, and educational status of the head of the household and wives (Meltzer et al., 2003). Daily rainfall and temperature were collected at four locations in Asembo throughout the project (Phillips-Howard et al., 2003 [b]).

\section{Statistical methods}

Data were entered by study staff, and validated and cleaned by the investigators using SPSS, Rel. 9.0 (SPSS Inc., Chicage, IL, USA). Analysis was performed using SAS Rel. 8.1 (SAS Institute Inc, Cary, NC, USA) and SUDAAN (Research Triangle Park, NC, USA) software packages. The following summary statistics were calculated: 
(i) Coverage ratios, or number of people per project-issued ITN.

(ii) Percentage of ITNs lost, as 1 - (number project-issued ITNs present/number ITNs issued) x 100 .

(iii) Percentage of ITNs present that were in use.

(iv) Percentage adherence, as number persons under ITNs/total number persons in house, for houses with ITNs present.

The percentage of people adhering with ITN use was calculated for two age categories: children $<5$ years of age, and all other individuals $>5$ years of age. Seventy-six nets observed in houses that were not issued by the project were included in calculation of (iii) and (iv), since these were treated with permethrin whenever project-issued ITNs were retreated.

Entomological indices were calculated based upon the mean densities of indoor resting An. gambiae, An. funestus, or Culex quinquefasciatus in control villages. Data for the two anopheline species were combined to produce an index of abundance for these two species combined. Anopheline or culicine densities in control villages were dichotomised into 'high' or 'low' categories with a cut-off value of 2 (the median value) per house. Use of numbers of mosquitoes collected from intervention houses was deemed inappropriate for this analysis, since adherence with ITN use markedly affects mosquito numbers (Gimnig et al., 2003).

Socio-economic variables included in the analysis were a wealth index, based upon house type and number and type of goods and livestock per house and an education index, based upon completion of secondary school for the head of the household.

SUDAAN software for dichotomous comparisons allowed for correlation among observations taken from the same village. Similarly, for multiple Poisson regression modelling of factors affecting adherence, the GENMOD procedure in SAS assumed an exchangeable correlation structure for measures from the same village.

\section{RESULTS}

Eight quarterly surveys were conducted between March 1997 and January 1999 consisting of visits to 784 houses (384 in year 1; 400 in year 2), containing a total of 2,178 persons, of whom 446 were children $<5$ years of age or $11 \%$ of all children in the intervention villages. The initial ratio of people to projectissued ITNs, based upon records of ITNs issued, was 1.46 (2176 people to 1488 ITNs). Coverage ratios in houses with children were higher than in houses without children (1.82 vs.1.19) reflecting the fact that children are more likely to share sleeping places, and thus ITNs, than adults. Of the 1488 ITNs issued to the households we sampled, we found a total of 1372 , or $92 \%$, 
Table 6.I Multivariate Poisson regression analysis of percent change in proper use of ITNs associated with year of project implementation, age of net user, temperature, number of culicine mosquitoes present in control village houses, number of anopheline mosquitoes present in control village houses, and wealth index. Results for all variables in the final model are shown.

\begin{tabular}{lcclll}
\hline Variables & $\begin{array}{c}\text { \% Change in } \\
\text { adherence }\end{array}$ & RR $(95 \%$ cl) & P value & Risk group & $\begin{array}{l}\text { Comparison } \\
\text { group }\end{array}$ \\
\hline Year & $-17 \%$ & $0.83(0.68-1.01)$ & 0.064 & 1998 & 1997 \\
Age group & $-14 \%$ & $0.86(0.78-0.94)$ & 0.001 & $<5$ years old & $\geq 5$ years old \\
Maximum temp. previous day & $+31 \%$ & $1.31(1.01-1.69)$ & 0.039 & Lowest quartile & Highest quartile \\
Maximum temp. previous day & $+29 \%$ & $1.29(0.98-1.70)$ & 0.064 & Med-Low quartile & Highest quartile \\
Maximum temp. previous day & $+21 \%$ & $1.21(0.97-1.50)$ & 0.088 & Med-High quartile & Highest quartile \\
Culicine density & $-9 \%$ & $0.91(0.74-1.11)$ & 0.35 & $\geq 2$ per house & $<2$ per house \\
Anopheline density & $+6 \%$ & $1.06(0.91-1.24)$ & 0.45 & $\geq 2$ per house & $<2$ per house \\
Wealth index & $+8 \%$ & $1.08(0.97-1.21)$ & 0.16 & Top 25\% & Bottom 75\% \\
\hline
\end{tabular}

still in place. The percentage of ITNs present in houses that were in use was $73.5 \%$ in 1997 and $67.5 \%$ in 1998 , but this difference is also not statistically significant $(\mathrm{P}=0.10)$.

For all surveys combined, the percentage of individuals found using an ITN was $72.3 \%(1539 / 2128)$. In univariate analysis, percentage adherence did not vary by year $(75.3 \%$ in 1997 vs. $69.4 \%$ in $1998, P=0.21)$, but did vary significantly by age group $(65.9 \%$ for $<5 \mathrm{~s}$ vs. $74.0 \%$ for $>5 \mathrm{~s}, \mathrm{P}=0.0062)$.

The final regression model of factors affecting ITN use included year, age group, temperature, culicine abundance in control villages, anopheline abundance in control villages, and household wealth (Table 6.1). Various interaction terms were tested, but these were not significant, so were dropped from the final model, which contains only main effects. Of these, the most clearly significant effect was age group, for which a $14.5 \%$ reduction in the probability of adherence was observed in children $<5$ years of age, when compared to individuals $>5$ years of age (relative risk $[R R]=0.86, P=0.001$ ). Relatively low temperatures were associated with increased adherence $(\mathrm{RR}=1.31 ; \mathrm{P}=$ 0.039 ), while the probability of adherence was marginally lower in year 2 of the project compared to year $1(\mathrm{RR}=0.83 ; \mathrm{P}=0.064)$. Neither mosquito densities nor relative wealth of the household had any effect on the probability of ITN use. This model does not include mother's secondary education as an effect since this variable was missing for $49 \%$ of households surveyed. In a model constructed using this reduced data set, and adjusted for all of the effects listed in Table 6.1, mother's education had no influence on the probability of adherence $(P=0.31)$. 
Table 6.2 Reasons given by caretakers or household residents for lack of net ITN by children $<5$. The number of responses of each type is noted in parenthesis.

\section{Environmental}

- Too hot $(20)$

- No mosquitoes (9)

- Too hot and no mosquitoes (2)

\section{Social}

- Disruption of sleeping arrangements (16)

- Child temporarily lacks caretaker (7)

- Child is a visitor, not a resident (7)

- Child's net used by another (5)

- Forgot to put up the net (4)

- Cannot use since child is sick (3)

- Funeral affected net use (2)

- Child is usually at another house (I)

- Visitor is using child's net (I)

- Mother or caretaker is away (I)

- Child fears ants will climb up net (I)
$21 \% \quad(3 \mathrm{I})$

$32 \% \quad(48)$

$21 \% \quad(31)$

- No room to hang child's net (6)

- House reconstruction affects net use (5)

- Net is too small for bed or mat (3)

- Child rolls out of net (3)

- Roof is leaking, so cannot spread the net (3)

- Cannot hang the net properly (3)

- Child's net has been taken for mending (2)

- Difficult to spread net over mat (2)

- Returned home too late to put up the net (I)

- Net is too hard to put up and take down (I)

- Child's net is torn (I)

- Child's net was washed (I)

Child is a new resident, so no net is available

- Net is lost or misplaced (3)

- Unable to give reason (3)

- Net is stored (I) 
Of 286 households queried about reasons for lack of ITN use by children, 186 (65\%) replied that no problems were encountered. Remaining households gave a wide range of reasons for lack of children's adherence with ITN use. These have been grouped into four general categories in Table 6.2, along with details of specific responses. More than half of respondents cited a social or technical reason for lack of adherence, while $21 \%$ said that the children simply lacked ITNs.

\section{DISCUSSION}

The major outcome of this study - proper use of ITNs - was directly observed by study staff and modelled as a function of various environmental, social, and economic effects. A complementary open-ended qualitative approach was used to assess reasons for non-adherence with ITN use. Adherence is apparently simple: one must ensure that the corners of a rectangular ITN are attached to eaves and walls of one's room, lower the ITN before sleeping, and tuck the ITN under the bed or mat. The results of this study show that the probability these actions will be taken are dependent upon a range of variables, and that some variables that one would have predicted to affect ITN use do not, in fact, have an effect. The qualitative surveys done in conjunction with the direct observation of adherence support the results of the quantitative analysis while revealing the importance of unquantified social effects.

The study was conducted in a population with little experience with bednets. ITNs were given away to maximize coverage. We observed a ratio of 1.46 persons per ITN and found that about $30 \%$ of ITNs were unused, indicating that our efforts to saturate this population with ITNs were successful. Nonetheless, only $72 \%$ of individuals properly used their ITNs, when assessed by direct observation.

Both age and temperature affect the probability that an individual will deploy his or her ITN: people are less likely to use ITNs when it is hot, and older people are more likely to use ITNs than young children. While the effect of temperature is not surprising, it was disappointing to observe that young children - the age group most likely to suffer from malaria - were less likely to adhere with ITN use than older people. During surveys conducted at the beginning of the project, residents expressed the view that ITN use is a higher priority for adults than for children. For this reason, the project's educational efforts focussed on the idea that since malaria is a more serious ailment for children than for older people, it is particularly important for young children to use ITNs. Despite these efforts, ITN use was nearly 15\% lower in children than in older people. 
Caregivers gave diverse reasons for lack of adherence with ITN use by children (Table 6.2). The leading single reason - "too hot" - is supported by the quantitative analysis, but the second most common reason in the "environmental' category - "no mosquitoes" - is not. While other studies (Winch et al., 1994; Binka \& Adongo, 1997) have indicated that 'lack of mosquitoes' is a disincentive for ITN use, our results indicate that while some individuals may express such an opinion, objective behavioral change does not necessarily occur on a scale sufficiently wide to allow detection. However, given the year-round presence of at least some biting mosquitoes in Asembo, the fact that relatively low mosquito populations were not associated with reduced adherence does not necessarily imply that nuisance biting is not a motivating factor for ITN use in our population. It is worth noting that the pestiferous $\mathrm{Cx}$. quinquefasciatus is $50 \%$ more abundant in our study area than anopheline malaria vectors (Gimnig et al., 2003).

Of the social reasons given for non-adherence, 'disruption of sleeping arrangements' was most commonly cited. In general, this response implies that 'normal' sleeping arrangements were disrupted for one reason or another, and that therefore the ITN could not be deployed over the child. Many of the more specific reasons cited in the 'social' category - 'funeral affected net use', for example - are also instances where deployment of ITNs did not adequately track flexibility in sleeping arrangements, making this the most common reason overall for lack of adherence. Other social reasons relate to childcare and concepts of ownership that may affect the ability of people to effectively and promptly deploy ITNs while others, such as, 'forgot to put up net' may reflect low motivation. Low motivation may also be the underlying cause for some of the technical problems reported - 'cannot hang the net properly', 'difficult to spread net over mat', 'returned home too late to put up the net', and 'net is too hard to put up and take down', but some of the more common problems in this category reflect problems with space and house construction - 'no room to hang child's net', 'house reconstruction affects net use', or 'roof is leaking so cannot spread the net'. One of the technical problems reported - 'net is too small for bed or mat' - is a consequence of the fact that some residents were given the wrong size net by the project, and some locally made single beds were larger than single ITNs.

Though one might expect that adherence with ITN use might increase over time as these various social and technical problems are worked out by individuals, in fact the trend was marginally $(\mathrm{P}=0.064$ in the multivariate analysis) towards decreasing adherence over time, in both adults and in young children, as has been observed in other efficacy trials. That this occurred in spite of our educational campaign illustrates how difficult it is to impact on human behaviour, and supports the idea that a careful and sustained health education programme must accompany any ITN intervention. It is unlikely that this trend was due to unavailability of ITNs, given that $30 \%$ of ITNs present in the population were unused. 
The degree to which lack of adherence with ITN use results in diminished protection against malaria is unknown, but results of a parallel analysis modelling numbers of blood-fed indoor resting mosquitoes shows that houses with ITNs deployed have significantly fewer fed mosquitoes than houses with no ITNs deployed (Gimnig et al., 2003). This lends objective biological support to the commonsense notion that deployed ITNs ought to provide more protection than those that are not. How then, does one design a health education programme to maximize adherence? In our study, social and technical reasons stand out as barriers to ITN use. As visitors come and go, ITNs may or may not be moved to ensure coverage of children as sleeping arrangements change and the relative status of house occupants varies (a child may be allowed to use his or her ITN only when no adult is visiting). Further, some children sleep in sitting rooms or kitchens, making necessary daily removal and nightly re-hanging of ITNs. ITNs may not be taken along when a child visits another compound, since the ITN may be viewed as a valued possession to safeguard rather than a tool to protect against malaria. Such problems may be directly addressed, once identified, using various techniques - role play, community discussion, or other methods - but there is no way to predict the effectiveness of each. On the other hand, some of the difficulties associated with putting up and taking down ITNs might be ameliorated by distribution of easily removable and transferred screw-in eyelets, rather than nails, for hanging of ITNs.

As the impetus for implementation of ITNs for malaria control has grown, emphasis has rightly been on problems of cost and coverage. Problems related to adherence with ITN use may be implicitly dismissed by use of the adjective 'simple' when describing ITN interventions. Our results illustrate the vital role that intelligently crafted health education programmes must play to ensure that ITNs are used appropriately to achieve maximum efficacy. 


\section{REFERENCES}

Alaii, J.A. (1997). The relevance of sleeping arrangements and bedtime mobility patterns for implementing insecticide-treated bednets in Asembo, western Kenya. M.Sc. Dissertation, London, School of Education, Politics and Social Sciences, Faculty of Health Sciences, South Bank University, UK.

Alonso, P.L., Lindsay, S.W., Armstrong, J.R.M., Conteh, M., Hill,A.G., David, P.H., Fegan, G., de Francisco,A., Hall, A.J., Shenton, F.C., Cham, K., \& Greenwood, B.M. (199I). The effect of insecticide-treated bednets on mortality of Gambian children. Lancet, 337, I 449-I 502.

Beiers, J.C., Oster, C.N., Onyango, F.K., Bales, J.D., Sherwood, J.A., Perkins, P.V., Chumo, D.K., Koech, D.V., Whitmire, R.E., Roberts, C.R., Diggs, C.L., \& Hoffman, S.L. (1994). Plasmodium falciparum incidence relative to entomological inoculation rates at a site proposed for testing malaria vaccines in western Kenya. Am J Trop Med Hyg, 50, 529--536.

Binka, F.N., Kubaje,A.,Adjuik, M.,Williams, L.A., Lengeler, C., Maude, G.H.,Armah, G.E., Kajihara, B.,Adiamah, J.H., \& Smith, P.G. (1996). Impact of permethrin-impregnated bednets on child mortality in Kassens-Nankana District, Ghana:A randomized-controlled trial. Trop Med Int HIth, I, I47-I 54.

Binka, F.N., \& Adongo, P. (1997). Acceptability and use of insecticide impregnated bednets in northern Ghana. Tropical Medicine and International Health, 2(5), 499-507.

Binka, F.N., Indome, F., \& Smith,T. (1998). Impact of spatial distribution of permethrin-impregnated bed nets on child mortality in rural northern Ghana. American Journal of Tropical Medicine and Hygiene, 59, 80-85.

Cham, M.K., Olaleye, B., D'Alessandro, U.,Aikins, M., Cham, B., Maine, N.,Williams, L.A., Mills, A., \& Greenwood, B.M. (1997). The impact of charging for insecticide on the Gambian National Impregnated Bednet Programme. Health Policy Plan, I2, 240-247.

D'Alessandro, U., Olaleye, B.O., McGuire,W., Langerock, P., Bennett, S., Aikins, M.K., Thompson, M.C., Cham, M.K., \& Greenwood, B.M. (1995). Mortality and morbidity from malaria in Gambian children after introduction of an impregnated bednet programme. Lancet, 345, 479-483.

Gimnig, J., Vulule, J., Lo, T., Kamau, L., Kolczak, M.S., Phillips-Howard, P.A., Nahlen, B.L., Oloo,A., Hightower, A.W., \& Hawley,W.A. (2003). Impact of permethrin-treated bednets on entomological indices in an area of intense year round malaria transmission. American Journal of Tropical Medicine and Hygiene, 68, Suppl. 4.

Gyapong, M., Gyapong, J.O., Amankwa, J., Asedem, J., \& Sory, E. (1996). Introducing insecticide impregnated bednets in an area of low bednet usage: an exploratory study in north-east Ghana. Tropical Medicine and International Health., I, 328-333.

Habluetzel, A., Diallo, D.A., Esposito, F., Lamizana, L., Pagnoni, F., Lengeler, C., Traoré, C., \& Cousens, S.N. (1997). Do insecticide-treated curtains reduce all-cause mortality in Burkina Faso? Trop Med Int Hlth, 2, 855-862.

Hawley,W.A., ter Kuile, F.O., Steketee, R.S., Nahlen, B.L., Terlouw, D.J., Gimnig, J.E., Shi,Y.P., Vulule, J.M., Alaii, J.A., Hightower,A.W., Kolczak, M.S., Kariuki, S.K., \& Phillips-Howard, P.A. (2003). Implications of the western Kenya permethrin-treated bednet study for policy, program implementation, and future research. American Journal of Tropical Medicine and Hygiene, 68, Suppl. 4. 
Kroeger,A., Gonzalez, M., Ordonez-Gonzalez, J. (1999). Insecticide-treated materials for malaria control in Latin America: to use or not to use. Transactions of the Royal Society for Tropical Medicine and Hygiene 93: 565-570.

Meltzer, M.I., Terlouw, D.J., Kolczak, M.S., Odhacha, A., ter Kuile, F.O.,Vulule, J.M.,Alaii, J.A., Nahlen, B.L., Hawley,W.A., \& Phillips-Howard, P.A. (2003).The household-level economics of using permethrin-treated bednets to prevent malaria in children under 5 years of age. American Journal of Tropical Medicine and Hygiene, 68, Suppl. 4.

Nevill, C.G., Some, E.S., Mung'ala,V.O., Mutemi,W., New, L., Marsh, K., Lengeler, C., \& Snow, R.W. (1996). Insecticide treated bednets reduce mortality and severe morbidity from malaria among children on the Kenyan coast. Trop Med Int Hlth, I, I39--46.

Phillips-Howard, P.A., Nahlen, B.L., Kolczak, M.S., ter Kuile, F.O., Alaii, J.A., Hightower,A.W., Gimnig, J., Arudo, J.A., Vulule, J., Schoute, E., Kachur, S.P., Oloo, A.J., \& Hawley,W.A. (2003 [a]). Efficacy of permethrin-treated bednets in the prevention of mortality in young children in an area of high perennial malaria transmission in western Kenya. American Journal of Tropical Medicine and Hygiene, 68, Suppl. 4.

Phillips-Howard, P.A., ter Kuile, F.O., Nahlen, B.L., Alaii, J.A., Gimnig, J.E., Kolczak, M.S., Terlouw, D.J., Kariuki, S., Shi,Y.P., Kachur, S.P., Hightower,A.W., Vulule, J.M., \& Hawley,W.A. (2003 [b]). The efficacy of permethrin-treated bednets on child mortality and morbidity in western Kenya. II: Design and methods. American Journal of Tropical Medicine and Hygiene, 68, Suppl. 4.

Snow, R.W., McCabe, E., Mbogo, C.N.M., Molyneux, C.S., Some, E.S., Mung'ala, V.O., \& Nevill, C.G. (1999). The effect of delivery mechanisms on the uptake of bed net re-impregnation in Kilifi District, Kenya. Health Policy and Planning, I4(I), I8-25.

WHO (1999). Rolling Back Malaria. Geneva,World Health Organization.

Winch, P.J., Makemba, A.M., Kamazima, S.R., Lwihula, G.K., Lubega, P., Minjas, J.N., \& Shiff, C.J. (1994). Seasonal variation in the perceived risk of malaria: Implications for the promotion of insecticide-treated bed nets. Social Science and Medicine, 39, 63-75.

Winch, P.., Makemba, A.M., Makame, V.R., Mfaume, M., Lynch, M.C., Premji, Z., Minjas, J.N., \& Shiff, C.J. (1997). Social and cultural factors affecting rates of regular retreatment of mosquito nets with insecticide in Bagamoyo District, Tanzania. Trop Med Int HIth, 2(8), 760-770. 



\title{
CHAPTER 7
}

\author{
INSECTICIDE-TREATED BEDNETS \\ IN WESTERN KENYA: \\ SOCIAL AND CULTURAL VARIABLES IN RELATION TO \\ ADHERENCE DURING AND AFTER \\ A RANDOMISED-CONTROLLED TRIAL'
}

ITo be published as:

Jane A. Alaii, H.W. van den Borne, S. Patrick Kachur, Halima Mwenesi, John Vulule, K. Lindblade, Penelope A. Phillips-Howard, L. Slutsker. Insecticidetreated bednets in western Kenya: Social and cultural variables in relation to adherence during and after a randomized-controlled trial. 


\begin{abstract}
Villagers were issued insecticide-treated bednets (ITNs) free of charge during a randomised controlled trial of ITNs in western Kenya. Pre-dawn spot-checks were conducted three to four times each year in a random sample of households to monitor adherence with bednet use during (1996-1999) and after the trial (1999-2001). Bednet coverage was estimated at 1.49 persons per bednet. The proportion of bednets in use and adherence with use was $78 \%$ and $76 \%$ respectively. Adherence with bednet use appeared stable and higher with longterm use than during the trial, $80 \%$ versus $73 \%(\mathrm{P}<0.01)$. While rates of adherence were higher for persons above five years of age compared to children below five years during the trial ( $72 \%$ vs. $66 \%)$, rates by age group were comparable during long-term follow-up (80\% vs.79\%). Of factors affecting adherence, bednet coverage in households and perceived heat under bednets appeared most important. Bednet use was highest in the cooler months. The more people in the household relative to the number of bednets available, the less likely family members were adherent $(\mathrm{OR}=1.19$; 95\% CI 1.14-1.25) $\mathrm{P}<0.001$, with children least likely to benefit from limited availability $(\mathrm{OR}=$ 1.26; 95\% CI 1.09-1.46). In households with high coverage, bednet adherence reached $85 \%$. Data from western Kenya suggest that high bednet coverage rates per household are important in the maintenance of high adherence.
\end{abstract}




\section{INTRODUCTION}

The use of insecticide-treated bednets (ITNs) as a malaria control tool, pioneered in studies that demonstrated their effectiveness in the Gambia (Snow et al., 1987; Snow et al., 1988; Alonso et al., 1993), has gained prominence in the current global battle against malaria (WHO, 1989; Lengeler et al., 1996; WHO, 2002). While bednets have received wide acceptability even when introduced into communities where their use was previously low or non-existent, challenges with implementing the tool for disease control continue, with important implications for the cost-effectiveness of the intervention (D'Alessandro, 1995). Quite often, the motive for bednet use is not disease prevention. People use bednets for a wide range of reasons, the main one being avoidance of nuisance biting (Winch et al., 1994; Winch et al., 1997; Zimicki, 1996; Binka \& Adongo, 1997), hence seasonal use motivated by perceived mosquito abundance. Other people may use bednets because they perceive a privacy aspect (MacCormack \& Snow, 1986; MacCormack, 1989) or perceive bednets as making bedrooms neat (Gyapong et al., 1996). For people relying on privacy as documented in some Gambian communities (MacCormack \& Snow, 1986; MacCormack et al., 1989), bednet use may be more consistent although the same does not apply for the requirement of re-treatment of bednets with insecticide (Alonso et al., 1991; D’Alessandro et al., 1995). Using bednets for perceived room neatness may be the most problematic since this might be reduced to opening nets over the bed in the day and folding them up in the night. Whichever the case, the protective behaviours of communities are continually implicated in increased risks of disease and death from malaria, thus bednets may not achieve quite as impressive protective results in real life as recorded in ideal research conditions. This study was set up to monitor adherence with bednet use following their free distribution during a randomized controlled trial of ITNs in a rural community in western Kenya (Phillips-Howard et al., 2003 [a]). The studies reported here were conducted pre-dawn about every quarter of the year over $4-5$ years, with the aim of describing adherence patterns over the years and to determine social and cultural factors affecting adherence with bednet use in the study area. The specific outcome variable was observed household adherence rates by age group; children below 5 years of age versus persons above 5 years of age (henceforth referred to as adults), and at household level, henceforth referred to as overall family adherence. The independent variables in analyses to explore factors statistically correlated with adherence included daily rainfall and temperature recorded throughout the study period, household bednet coverage ratios recorded at survey, and numbers of persons observed sleeping in households at survey. 


\section{METHODS}

\section{Background}

From the outset during the trial (March 1996-Jan. 1999) and throughout a follow-up period thereafter (Feb. 1999-May 2001) ${ }^{2}$, an intensive educational campaign delivered malaria and bednet messages by word of mouth to each household, and at community gatherings. Key messages emphasized children are the main targets of malaria interventions, hence the need for preferential child access to insecticide-treated bednets in the household, and the importance of consistent bednet use. Other information explained the role of ITNs in reducing child morbidity and mortality due to malaria, and associated benefits of reduced illness and death. Health education was delivered equally and at the same time to all study villages, and reinforced through information leaflets and bednet calendars bearing specific monthly messages.

\section{Study site and population}

The study site is situated in Siaya District, Western Kenya. The climate is typically tropical and has a bimodal rainfall pattern, with average rainfall estimated at 1000-1800 mm per year. Some rain falls in every month, thus malaria transmission occurs all year round. Rarieda Division (Asembo), covers $200 \mathrm{~km}^{2}$ on the north-eastern shores of Lake Victoria, and has a population of between 55,000-60,000 people, 15\%-17\% children below five years of age (PhillipsHoward et al., 2003 [a]; Government of Kenya [GoK], 1994). Ninety-six percent of the study population are members of the Luo ethnic group, living in family homesteads (dala/mier) surrounded by their agricultural fields. Homesteads within each village consist of one or more (average of four) houses. The most common type of house is the 1-2 roomed traditional Luo hut, which has a stick framework plastered with mud, a grass-thatch roof, and one door. It is common to find huts without windows, although eaves are open, allowing easy entrance and exit for mosquitoes. Living rooms and kitchens are turned into sleeping spaces for children in the night. Formative studies estimated bednet use to $<5 \%$ prior to the bednet project. Bednets were considered a luxury, and preserved for adult use to prevent nuisance biting. It was common for people to sleep unprotected from mosquito biting, although

\footnotetext{
2 The bednet study was conducted in two phases. The trial (efficacy) phase aimed to determine the effect of permethrin-treated bednets on child morbidity and mortality due to malaria in an area intense malaria transmission. The follow-up phase sought to determine the impact of long-term use of ITNs on the development of natural immunity to malaria in children $<5$ years of age.
} 
families sometimes invested in mosquito coils, or burned traditional mosquito repellents during high mosquito abundance. There was indication everyone liked bednets [so as to have good sleep], but were mainly limited by costs (Alaii, 1997). The economy is subsistent, based on peasant farming. Off farm activities include fishing and operation of retail outlets. Men mostly migrate to seek jobs in the big towns, returning home monthly or yearly depending on distance. Women and children remain in the rural home, both to cut down costs of living in towns, and to take care of family property in the rural home.

Available Kenya Government statistics indicate malaria illness accounts for nearly $50 \%$ of outpatient hospital visits, and is the cause of half of all hospital deaths in young children (GoK, 1994). Estimates from a previous study in the area (Spencer et al., 1987) indicate an overall mortality rate in children less than five years of age to have been 210/1000. Studies in the course of the bednet trial estimate under-five mortality at 275/1000 live births, suggesting an increase in child mortality in 1990s (Phillips-Howard et al., 2003 [c]).

\section{Data collection}

Bednet use and adherence were monitored approximately every quarter of the year for about 4 years, beginning at the start of the efficacy trial (March 1997 January 1999) and continuing into the follow-up phase (May 1999 - May 2001). Simple cluster sampling was performed using the GIS census database and computer-simulated tables, which randomly picked equal numbers of the bednet project's experimental and control village clusters per quarter, finally picking one house and the sequential nine houses clustered around the primary house. This sampling method was adopted for logistical reasons, since the surveys were scheduled for early morning (3:00-6:30 a.m.), without vehicles, in unlit rural villages. During the randomized-controlled trial phase, herein called "efficacy phase", 10 households each were picked out of a randomized group of 10 villages. In the follow-up phase, after control villages received bednets also, the sample size was doubled to 20 villages to cover extra 10 villages previously in the control group. Participants were not informed that they would be visited on a particular night, though the study population had been informed of the need for such impromptu visits and their consent elicited.

On the night of survey they were reminded that their participation was voluntary, and a reputable local villager accompanied the spot-check team to facilitate identification. Compliance monitors used a one-page structured observation checklist to document actual bednet coverage and bednet use in specific households. Data were recorded including 1) the number of nets observed in houses against number of nets recorded as issued in distribution records, 2) all persons sleeping in the house by age category, 3) the number of nets seen in use, and those seen but not in use, 4) the number of persons sleeping under nets, by age category, and 5) reasons why a child was observed not sleeping under bednets. 


\section{Statistical methods}

Data were entered into a Clarion data screen with consistency checks and validated by data managers using SAS (The SAS system for Windows, Release 8.1; SAS Institute Inc., Cary, NC, USA) software. Analysis was performed using SPSS (SPSS for Windows, Release 11.0, SPSS Inc). While spot check households were randomly drawn and some households may, by chance, have been visited more than once, the data were analysed as independent sample data. We adopted statistical methods used in a short-term adherence study (Alaii et al., 2003 [a]) to calculate bednet coverage and bednet use ratios below.

Coverage ratios describe the number of bednets in the surveyed houses measured as a ratio of the number of persons counted in houses at survey, and were calculated as;

Number of persons in all houses at survey

Number of bednets counted in all houses at survey

Bednet use describes the percentage of bednets available and in use in surveyed houses, and was calculated as;

$\frac{\text { Number of bednets in use in all houses at survey }}{\text { Number of bednets present in all houses at survey }} \times 100$

Percent adherence rates defined the proportion of persons observed to be sleeping under bednets at survey. It was our premise that household factors might influence individual members' adherence with bednet use, therefore, the proportion of adherence was defined in two age categories, children below 5 years, and all persons above 5 years of age. Percent adherence was calculated as;

Number of persons observed to be sleeping under bednets at survey $\times 100$

Total number of persons counted in same age category at survey

\section{Exclusion of households}

Overall, 2384 households were visited over 16 study quarters. However, data are presented from 1,480 (62.1\%) households only. This excludes, all households with "zero" persons $(\mathrm{N}=5)$, those with "zero" bednets $(\mathrm{N}=20)$, and all households participating in public health educational studies ${ }^{3}(\mathrm{~N}=133)$. Because no significant differences were apparent between households previously assigned as controls versusthose under experimental status during the efficacy trial, data collected on control households $(\mathrm{N}=746)$ were excluded from analyses to facilitate analysis of adherence patterns in the former experimental group.

3 Public health educational studies included "elicitation interviews" based on an adaptation of the motivational interviewing [MI] approach (Miller and Rollnick, 199I; Miller, 1996), and child training in bednet mounting skills to describe household level factors affecting child adherence with bednet use. 


\section{Regression models}

Regression analysis was performed to test for significant changes in adherence over time (>1997). Because adherence appeared generally high and their distribution skewed we computed a dichotomous variable, grouping age groups and households by percentage of family sleeping under bednets [in same age category]; thus either adherent $(100 \%)$ or non-adherent $(<100 \%)$. A direct logistic regression analysis was performed on this variable as outcome $(1=$ adherent; $0=$ nonadherent), against variables thought to relate to or affect adherence including study year (essentially measuring duration of exposure to bednets), time of spot-check, average temperature and rainfall recorded on the day of spot-check (calculated as an average of minimum and maximum temperature and rain recorded), total bednets in the household, total persons in the house, and total children in the household. We also explored interaction terms between rainfall and temperature, and between number of persons and bednet count. We included all variables at the first step, sequentially dropping every variable that did not appear to have a significant association with adherence. The final model retained only factors appearing statistically associated with observed family adherence. Since mosquito densities were not associated with adherence in a previous study (Alaii et a., [a], 2003), and following indication that entomological inoculation rates were quite low in the long-term (Lindblade, K. personal communication, late 2002), entomological data were excluded from the model. A P value 0.05 was considered significant.

\section{RESULTS}

\section{Study population}

A total of 1,480 households visited during 16 quarterly spot-checks conducted between March 1997 and May 2001 were retained in the analyses. These comprise 761 (51.4\%), and $719(48.6 \%)$ households visited during the efficacy (March 1997 - January 1999) and follow-up (May 1999 - May 2001) study phases respectively. Of 4,149 persons overall, 775 (18.8\%) were children $<5$ years of age, recorded sleeping in 512 (34.6\%) households.

Spot-checks were conducted between 3.00 a.m. and 6.00 a.m. The mean time of spot-check was 4.40 a.m. ( $S D=.96$; median 4.00 a.m). A one-way between-groups analysis of variance to explore differences in spot check time across quarters indicated statistical difference in mean time of spot check for the 16 surveys $[\mathrm{F}(15)=53.4, \mathrm{P}<0.001]$. Notably, the efficacy phase spot-checks were done nearer dawn (mean $=4.90, \mathrm{SD}=.87$ ) compared to the follow-up phase $($ mean $=3.89, \mathrm{SD}=.74)[\mathrm{F}(1)=589.0, \mathrm{P}<0.001]$. 


\section{Coverage and adherence}

Bednet coverage for all surveys combined was estimated at 1.49 persons per bednet $(4120 / 2764)$ recorded in the house at spot-check, with $78 \%$ nets in use at the time. Bednet coverage was equal in both study phases. The percentage of bednets in use was significantly higher $(\mathrm{P}<0.001)$ in the follow-up phase, $84 \%$ compared with the efficacy phase, $73 \%$. The coverage rate in households with a child below five years of age was significantly lower $(\mathrm{P}<0.001)$ than in households without young children, estimated at 1.87 versus 1.23 persons per bednet - reflecting that children more commonly share a sleeping space than adults.

An overall family adherence rate of $76 \%$ was achieved, with adherence in children $<5$ years of age appearing lower compared to that of persons $>5$ years of age, $72 \%$ versus $77 \%$. While compliance appeared to fluctuate and was lower in the efficacy phase $(72 \%)$, the pattern was generally stable and higher during the follow-up phase $(80 \%) \mathrm{P}<0.01$. Figure 7.1 summarizes adherence patterns for different age groups across 16 surveys. A disparity in adult versus $<5$ years adherence was evident in the efficacy phase ( $72 \%$ vs.66\%) while adherence between the age groups appeared comparable follow-up (79\% vs.80\%), (Figure 7.2). Adherence continued throughout the study, to be lower in households with children below five years, compared to those without under fives; 74\% versus 78\% (Figure 7.3).

\section{Factors affecting adherence}

Overall, 268 (18.1\%) caretakers listed household level problems they perceived with using bednets. Perceived heat was listed by $51.5 \%$ of the caregivers. Other problems included difficulty with mounting of bednets (20.1\%), or perceptions that it was tedious mounting children's bednets (i.e. in kitchens and living rooms) daily $(12.7 \%)$, and inadequacies relating to bednet sizes and quantity $(10.1 \%)$. The majority $(56.5 \%)$ of complaints about heat occurred in the efficacy phase, compared to $38.7 \%$ in the follow-up. Conversely, complaints about an inadequate number of bednets for family members were significantly listed $\mathrm{X}^{2}(5)=52.958$; $\mathrm{P}<0.001$ during long-term $(30.7 \%)$ compared with during the trial $(2.1 \%)$, an indication of a combination of increase in family sizes and an estimated $9 \%$ net loss.

Of $234(15.8 \%)$ households with a child not sleeping under bednets on spotcheck night, the majority (35.9\%) cited not having enough bednets as the main problem, followed by problems related to sleeping arrangements ${ }^{4}$ for children

\footnotetext{
4 Changes in where children sleep due to funerals, visitors, and repair of thatch roofs are common in the study area. Space for hanging children's nets in kitchens and living rooms - where children mainly sleep, is often inadequate. Children's inability, due both to environmental and cognitive factors, to mount their own nets (when caretakers travel, are sick, or feel too tired and/or forget to mount nets for them) further compound these problems.
} 


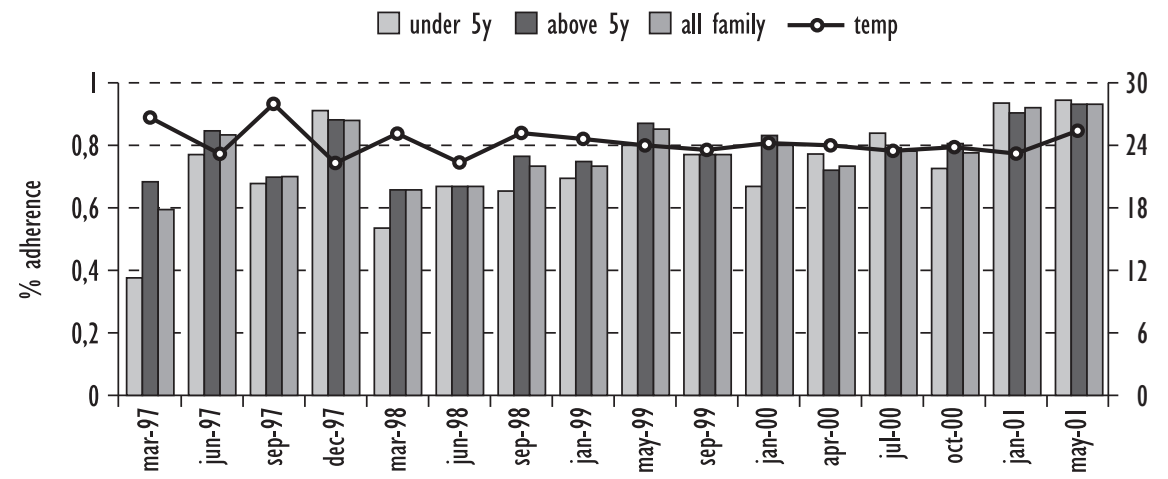

Figure 7.I Observed quarterly bednet adherence by age group

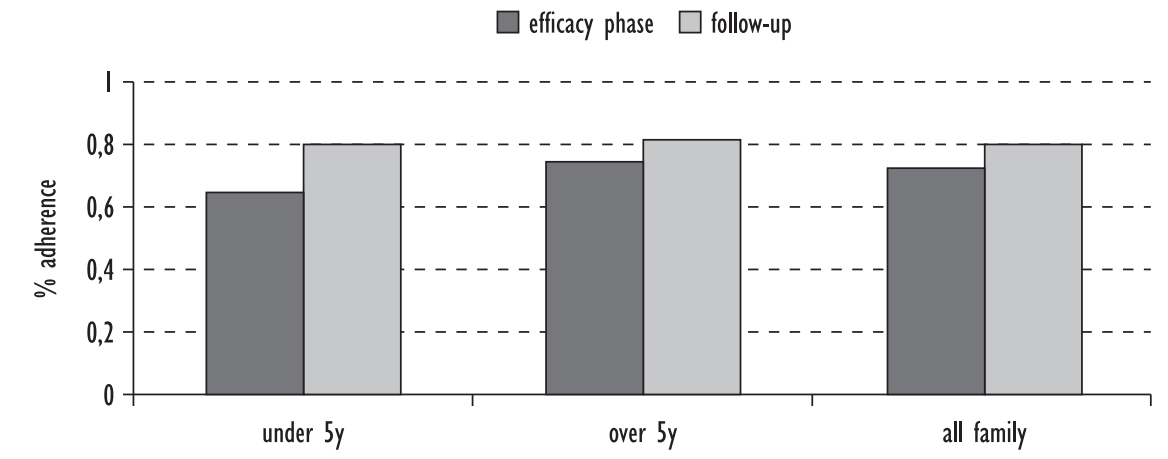

Figure 7.2 Bednet adherence across age groups by study phase

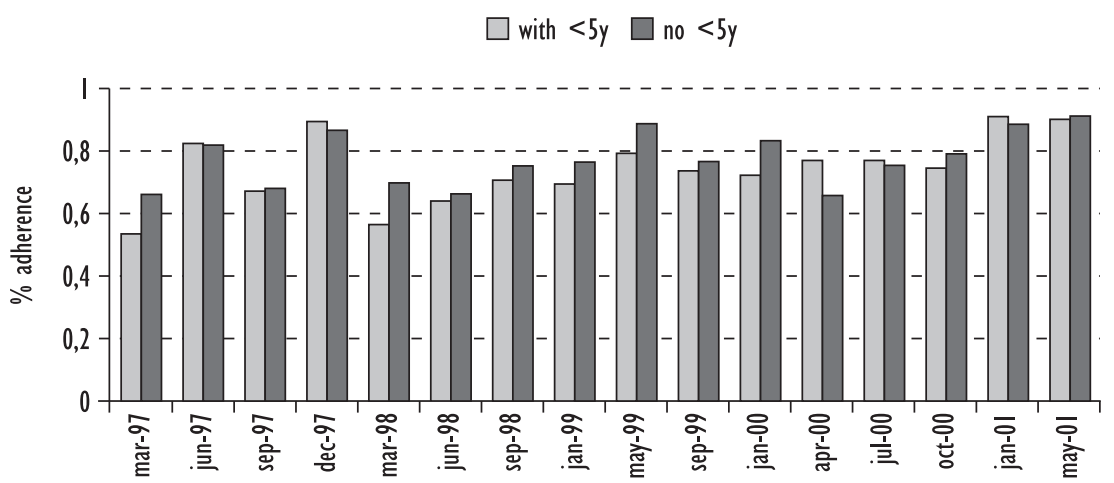

Figure 7.3 All household bednet adherence across quarters, by child status 
(23.1\%). At least $15.8 \%$ caretakers stated it was tedious mounting children's bednets daily, while $12.8 \%$ cited heat as a problem (Table 7.1 ). Importantly, the proportion of complaints on these problems was consistent between the efficacy and the longer-term follow-up phase.

Table 7.2 summarizes the final regression model of factors associated with family adherence with bednets, including total number of people in the household, study year, average daily temperature, interaction terms between total persons in the household and total number of bednets, and between number of children $<5$ years of age and bednet count. Other interaction terms (see regression models in methods) were tested but were not significant, thus dropped from the final model.

In the regression model, the total count of persons in the household, and the interaction between total people and total bednets in the household appeared to most influence family adherence with bednet use (both at $\mathrm{P}<0.001$ level). The more people in the household relative to the number of bednets available, the less likely family members were to be compliant. Study year was significant as a variable and for each year, except for year three ${ }^{5}$. Average daily temperatures also appeared important $(\mathrm{OR}=0.87,95 \%$ CI $0.80-0.95 ; \mathrm{P}<0.01)$. A crosscheck of adherence patterns with average daily temperatures indicated a trend of reduced adherence with an increase in the temperature in the early phases of the study. The effect was not observed during the longer-term follow-up (Figure 7.1).

The overall regression model was significant, $\mathrm{X}^{2}(\mathrm{df} 8)=236.414, \mathrm{P}<0.001$. There were no missing cases $(\mathrm{N}=1480)$ and overall the model predicted $76.8 \%$ of the responses correctly. However, while the model appeared to predict well responses for the probability of being adherent (95.1\%), it seemed unable to predict responses for the probability of being non-adherent $(28.9 \%)$.

\section{DISCUSSION}

Successful malaria prevention using insecticide-treated bednets depends on correct bednet re-treatment and adherence with bednet use. Our study population received bednets free of charge for maximal bednet coverage in households,

\footnotetext{
5 Separate regression analysis with the study quarter as the sole predictor variable indicate the variations in study year may be explained by lower household adherence rates in specific surveys in those years; namely surveys I, $3,5,6$, and 12 (Figure 7.I). Low adherence in survey $I$ is attributable to a mix of the newness of the intervention in the study, and daily high temperatures. Adherence in surveys 3 and 5 appeared affected by increase in daily temperature. We cannot readily explain low adherence in surveys 6 and 12 .
} 
Table 7.I Reasons given for a child $<5$ y not sleeping under bednet

\begin{tabular}{|c|c|c|c|c|c|c|}
\hline \multirow[b]{2}{*}{ Reasons given } & \multicolumn{4}{|c|}{ Spot-check phase } & & \\
\hline & \multicolumn{2}{|c|}{$\begin{array}{l}\text { Efficacy } \\
\text { N }(\%)\end{array}$} & \multicolumn{2}{|c|}{$\begin{array}{c}\text { Follow-up } \\
\text { N (\%) }\end{array}$} & \multicolumn{2}{|c|}{$\begin{array}{c}\text { Total } \\
\text { N }(\%)\end{array}$} \\
\hline Size and quantity & 46 & (33.3) & 38 & $(39.6)$ & 84 & $(35.9)$ \\
\hline Sleeping arrangement & 34 & $(24.6)$ & 20 & $(20.8)$ & 54 & $(23.1)$ \\
\hline Tedious job & 23 & $(16.7)$ & 14 & $(14.6)$ & 37 & $(15.8)$ \\
\hline Too hot now & 19 & $(13.8)$ & II & $(\mathrm{II} .5)$ & 30 & $(12.8)$ \\
\hline Childs net not in house & 7 & (5.I) & 9 & $(9.4)$ & 16 & $(6.8)$ \\
\hline No mosquitoes & 6 & $(4.3)$ & 3 & $(3.1)$ & 9 & (3.8) \\
\hline Child problem using & 3 & $(2.2)$ & I & $(1.0)$ & 4 & (1.7) \\
\hline
\end{tabular}

Table 7.2 Direct regression analysis of observed all family adherence with bednet use ( $I=$ adherent; $0=$ nonadherent) as a function of total persons in household, year of study (duration of exposure), average daily temperature, interaction terms between numbers of people and total bednets in the household, and between number of $<5 y$ olds and bednet numbers.

\begin{tabular}{|c|c|c|c|c|c|c|c|c|}
\hline \multirow[b]{2}{*}{ Variables } & \multirow[b]{2}{*}{$\beta$} & \multirow[b]{2}{*}{ S.E. } & \multirow[b]{2}{*}{ Wald } & \multirow[b]{2}{*}{$\mathrm{df}$} & \multirow[b]{2}{*}{ Sig. } & \multirow[b]{2}{*}{$O R$} & \multicolumn{2}{|c|}{$95.0 \%$ C.I. of OR } \\
\hline & & & & & & & Lower & Upper \\
\hline No. persons & -1.054 & .088 & $|43.48|$ & I & $<0.001$ & 0.349 & 0.293 & 0.414 \\
\hline YEAR & -.758 & .288 & 19.831 & 4 & 0.001 & 0.469 & 0.267 & \\
\hline Year (I) & -1.027 & .286 & 6.915 & I & 0.009 & 0.358 & 0.204 & 0.825 \\
\hline Year (2) & -.464 & .293 & 12.907 & I & $<0.001$ & 0.629 & 0.354 & 0.627 \\
\hline Year (3) & -.976 & .276 & 2.510 & 1 & 0.113 & 0.377 & 0.219 & 1.116 \\
\hline Year (4) & -.136 & .045 & 12.511 & I & $<0.001$ & 0.873 & 0.799 & 0.647 \\
\hline Avg. daily temp & .175 & .025 & 9.130 & 1 & 0.003 & 1.192 & 1.136 & 0.953 \\
\hline Persons*nets & .229 & .076 & 51.007 & I & $<0.001$ & 1.258 & 1.085 & 1.250 \\
\hline No. $<5 y^{*}$ nets & 6.858 & 1.123 & 9.202 & 1 & 0.002 & 951.661 & & 1.459 \\
\hline Constant & & & 37.314 & I & $<0.001$ & & & \\
\hline
\end{tabular}

Model Chi Square: $(\mathrm{df8})=236.414, \mathrm{P}<.00 \mathrm{I}$ 
accompanied by health education to enhance adherence with bednet use. We observed $78 \%$ of 2,764 bednets counted in households were in use, and 76\% of 4,120 persons observed in households were sleeping under bednets. While we achieved 59 percent adherence immediately after the introduction of bednets, adherence picked up by the second survey conducted three months later, remaining high over time and increasing significantly by the end of the study period $(\mathrm{P}<0.01)$. It seemed quite promising that as the study progressed longer-term into the third and fourth years adherence between the age groups ( $<5$ years vs. $>5$ years) appeared comparable, with child adherence surpassing that of adults towards the end of the study (Figure 7.1).

At least $18.1 \%$ of households overall perceived some problems with bednet use. Of factors reportedly affecting adherence with bednets, average daily temperature and bednet count relative to the number of people in the house were statistically associated with adherence; $\mathrm{P}<0.01$, and $\mathrm{P}<0.001$ respectively - with children appearing less likely to access bednets when there were not enough to cover all sleeping spaces $(\mathrm{P}<0.01)$. Similar observations were noted of adherence in the study area in the short-term (Alaii et al., 2003 [a]), and indicated in qualitative studies with the bednet project population (Alaii et al., 2003 [b]; Alaii et al., in preparation). Bednet size and quantity problems at the beginning of the study in the efficacy phase were related to early project implementation and bednet distribution problems (Alaii et al., 2003 [a]). Towards the end of the study in the long-term follow-up phase, bednet size and quantity problems may be attributed to bednet loss, and increased family sizes making it difficult for children to share sleeping spaces and bednets. Reasons given for a child failing to sleep under bednets on the spot-check night suggest that social factors including sleeping arrangements are just as important as coverage issues for this age group. Sleeping arrangements and low adult motivation are implicated in low child adherence in this study, as was in the short-term study of adherence (Alaii et al., 2003 [a]). Children mainly sleep in temporary bed spaces including kitchens, living rooms, and other houses within the family homestead where beddings and bednets have to be spread every night and folded for storage during the day. While only $15.8 \%$ caregivers readily stated bednet mounting in children's sleeping spaces was a tedious job, other reasons given such as changes in or disruption of sleeping arrangements are essentially an indication of reluctance to redeploy bednets as children are relocated for the night elsewhere.

Overall, increased adherence by the end of the study, and indication that child adherence with bednet use could be improved to match that of adults is very encouraging. In particular, the indication during long-term follow-up that former bednet control households appeared to take up bednet use as well as their experimental counterparts (see methods: exclusion of households) who had had the advantage of using bednets for a longer time suggests promising implications for future implementation. In our study area we conclude that initial experience of bednet use in the intervention population was suffice for the whole community; lessons learned and benefits gained were passed onto con- 
trol villages, precluding their need to go through the early 'teething' problems of first use. It appears that when people are exposed to bednets in the longterm demand is created, and although there may be cost issues, once coverage is assured people become accustomed to using bednets more frequently, regardless of extraneous factors such as heat. While we cannot be sure about the exact impact of our health education campaign to promote and maintain adherence (since we did not have a condition in which bednets were provided in the absence of concerted health communication), the observed success might be attributed partly to the health education. The fact that part of the study population had a chance to try out the intervention as an experimental group for the trial points to the possible additional effect that modelling (Bandura, 1997) may also have had on the control population, resulting in their impressive adherence with the intervention. Previously, we had encountered reluctance to use bednets when they were newly issued to experimental households - reticent study participants commonly explained that they would pick up bednet use after observing the effects of insecticide (perceived toxic at the time) on those who had quickly adopted the innovation (Alaii et al., 2003 [b]). Our results concur with Rogers (1995), and Prochaska \& Di Clemente (1983) that not all people will adopt an intervention at the same time. Thus a health promotion programme might benefit more from understanding the specific characteristics of different bednet users, to determine the underlying patterns of their adherence with the disease control intervention as a basis for intervention design and implementation. Perceived heat under bednets, and a decline in mosquito density in some seasons appear documented universally as deterrents to adherence with the intervention (MacCormack et al., 1986; Marsh et al., 1996; Zimicki et al., 1996; Winch et al., 1994; Binka \& Adongo, 1997, Alaii et al., 2003 [a], [b]). It is apparent that contextual differences will exist in different study populations, including at the country level. MacCormack et al., (1989) indicated that perceived heat and mosquito density do not appear to apply for Gambian populations that use bednets for cultural reasons. Ascertaining differences must also consider how people use language, to understand the exact meaning in different contexts. We noted during qualitative research that when study participants claimed they used bednets "all the time" this was in reference to the times they are most likely to use bednets only - in the cold/wet season, and when mosquitoes are perceived to be in abundance (Alaii et al., 2003 [b]). Thus despite recorded high adherence rates, our spot-check studies could not tell us exactly how consistent bednet use was. In the effort to ascertain behavioural characteristics of different people (households) with bednet use we have undertaken qualitative elicitation interviews with caregivers, using an adaptation of the motivational interviewing [MI] approach (Miller, 1996; Miller and Rollnick, 1991), an intervention tool integrating behavioural theory including the stages of change model and concepts of behavioural theories including the social cognitive theory and the theory of planned behaviour. This integrative framework facilitates, after ascertaining peoples bednet use patterns, questioning specific to 
each identified bednet use pattern. The aim is to understand what motivates and/or hinders caregivers to mount bednets for children at all, and whether they perceive any benefits in child bednet use at all. Specifically, we seek to understand why some might appear more inclined to ensure consistent bednet use by children, while others might adopt a seasonal pattern of use, and yet others might not appear to care for child bednet use at all. The findings of these interviews, yet to be analysed, will be useful in designing a comprehensive health education and promotion intervention to promote and maintain adherence in this study population, especially targeting children.

In conclusion, our studies generally concur with indications elsewhere that people are less inclined to use bednets when they perceive the night to be hot, and adults rather than children, appear to get preferential access to bednets whenever bednets are few in the household (Zimicki, 1996; Marsh et al., 1996; Binka \& Adongo, 1997). Perceptions that adults must get priority access to bednets in the household did not change even by the end of the studies - caregivers categorically said a child failed to sleep under bednets because there were not enough. This makes it imperative for a programme targeting children to issue bednets to cover all sleeping spaces if children are to benefit from the intervention. It is of concern that bednet programmes may distribute bednets freely to pregnant mothers and infants only. We surmise, based on our data, these bednets will be transferred over to adults and males, soon after acquisition into the household. 


\section{REFERENCES}

Alaii, J.A. (1997). The relevance of sleeping arrangements and bedtime mobility patterns for implementing insecticide-treated bednets in Asembo, western Kenya. Master of Science, London, South Bank University.

Alaii, J.A., Hawley, W.A., Kolczak, M.S., ter Kuile, F.O., Gimnig, J.E., Vulule, J.M., Odhacha,A., Oloo,A.J., Nahlen, B.L., \& Phillips-Howard, P.A. (2003 [a]). Factors affecting the use of permethrin treated bednets during a randomised controlled trial in western Kenya. American Journal of Tropical Medicine and Hygiene, 68, Suppl. 4.

Alaii, J.A., van den Borne, H.W., Kachur, S.P., Shelley, K., Mwenesi, H., Vulule, J., Hawley,W.A., Nahlen, B.L., \& Phillips-Howard, P.A. (2003 [b]). Community reactions to the introduction of permethrin-treated bednets for malaria control during a randomised controlled trial in western Kenya. American Journal of Tropical Medicine and Hygiene, 68, Suppl. 4.

Alonso, P.L., Lindsay, S.W.,Armstrong, J.R.M., Keita, K., Gomez, P., Shenton, F.C., Konteh, M., Keita, K., Marshall, C., Phillips, A., Cham, K., \& Greenwood, B.M. (1993).A malaria control trial using insecticide-treated bed nets and targeted chemoprophylaxis in a rural area of The Gambia, west Africa: the impact of the interventions on mortality and morbidity from malaria. Transactions of the Royal Society of Tropical Medicine and Hygiene, 87 (Suppl 2: S37-S44).

Bandura, A. (1997). Self-efficacy:The exercise of control. New York: Freeman.

Binka, F.N., \& Adongo, P. (1997). Acceptability and use of insecticide impregnated bednets in northern Ghana. Tropical Medicine and International Health, 2(5), 499-507.

Cohen, D.W., \& Atieno-Odhiambo, E.S. (1989). Siaya:The historical anthropology of an African landscape. London: James Currey Ltd.

D'Alessandro, U., Olaleye, B.O., McGuire,W., Langerock, P., Bennett, S., Aikins, M.K., Thompson, M.C., Cham, M.K., \& Greenwood, B.M. (1995). Mortality and morbidity from malaria in Gambian children after introduction of an impregnated bednet programme. Lancet, 345, 479-483.

Gyapong, M., Gyapong, J.O.,Amankwa, J., Asedem, J., \& Sory, E. (1996). Introducing insecticide impregnated bednets in an area of low bednet usage: an exploratory study in north-east Ghana. Tropical Medicine and International Health., I, 328-333.

Government of Kenya [GoK]. (1994). Siaya District Development Plan, 1994-1996. Nairobi: Government printers.

Lengeler, C., de Savigny, D., \& Cattani, J. (Eds.). (1996). Net Gain:A New Method of Preventing Malaria Deaths. Geneva \& Ottawa:WHO/IDRC.

MacCormack, C.P., \& Snow, R.W. (1989). Gambian cultural preferences in the use of insecticide-treated bednets. Journal of Tropical Medicine, 89, 295-302.

MacCormack, C.P. (1989). People's attitudes. Paper for WHO informal consultation on the use of impregnated bednets and other materials for vector-borne disease control. World Health Organization.

Marsh,V.M., Mutemi,W., Some, E.S., Haaland,A., \& Snow, R.W. (1996). Evaluating the Community Education Programme of an Insecticide-treated Bednet Trial on the Kenyan Coast. Health Policy Plan, I I (3), 280-29I.

Miller,W.R., \& Rollnick, S. (199I). Motivational Interviewing: Preparing people for change. New York: Guilford Press. 
Miller,W.R. (1996). Motivational Interviewing: Research, practice, and puzzles. Addictive Behaviours, 2 I (6), 835-842.

Phillips-Howard, P.A., ter Kuile, F.O., Nahlen, B.L.,Alaii, J.A., Gimnig, J.E., Kolczak, M.S., Terlouw, D.J., Kariuki, S., Shi, Y.P., Kachur, S.P., Hightower,A.W.,Vulule, J.M., \& Hawley,W.A. (2003 [a]). The efficacy of permethrin-treated bednets on child mortality and morbidity in western Kenya. II: Design and methods. American Journal of Tropical Medicine and Hygiene, 68, Suppl. 4.

Phillips-Howard, P.A., Nahlen, B.L., Alaii, J.A., ter Kuile, F.O., Gimnig, J.E., Terlouw, D.J., Kachur, S.P., Hightower,A.W., Lal,A.A., Schoute, E., Oloo, J.A., \& Hawley,W.A. (2003 [b]). The efficacy of permethrin-treated bednets on child mortality and morbidity in western Kenya. I: development of infrastructure and description of study site. American Journal of Tropical Medicine and Hygiene, Malaria Supplement, 68, Suppl. 4.

Phillips-Howard, P.A., Nahlen, B.L., Wannemuehler, K., Kolczak, M.S., ter Kuile, F.O., Gimnig. J., Alaii, J.A., Odhacha,A.,Vulule, J., \& Hawley,W.A. (2003 [c]). Impact of permethrin-treated bednets on the incidence of sick child visits to peripheral health facilities. American Journal of Tropical Medicine and Hygiene, 68, Suppl. 4.

Prochaska, J.O., \& DiClemente, C.C. (1983). Stages and processes of self-change of smoking: Toward an integrative an integrative model of change. Journal of Consulting and Clinical Psychology, 5 I , 390-395.

Rogers, E.M. (Ed.). (1995). Diffusion of innovations (4th ed.). New York:The Free Press.

Snow, R.W., Rowan, K.M., \& Greenwood, B.M. (1987). A trial of permethrin-treated bednets in the prevention of malaria in Gambian children. Transactions of the Royal Society of Tropical Medicine and Hygiene, 8I, 563-567.

Snow, R.W., Lindsay, S.W., Hayes, R.J., \& Greenwood, B.M. (1988). Permethrin-treated Bednets Prevent Malaria in Gambian Children. Transactions of the Royal Society for Tropical Medicine and Hygiene, 82, 838-842.

Spencer, H.C., Kaseje, D.C., Mosley,W.H., Sempebwa, E.K., Huong,A.Y., \& Roberts, J.M. (1987). Impact on mortality and fertility of a community-based malaria control programme in Saradidi, Kenya. Annals of Tropical Medicine and Parasitology, 8 I (Suppl I), 36-45.

$\mathrm{WHO}$ (1989). The use of impregnated bednets and other materials for vector borne disease control. WHO/VBC/8998I.

WHO (2002). Scaling-up inseticide-treated netting programmes in Africa:A strategic framework for coordinated national action. WHO/CDS/RBM/2002.43.

Winch, P.J., Makemba, A.M., Kamazima, S.R., Lwihula, G.K., Lubega, P., Minjas, J.N., \& Shiff, C.J. (1994). Seasonal variation in the perceived risk of malaria: Implications for the promotion of insecticide-treated bed nets. Social Science and Medicine, 39, 63-75.

Winch, P.J., Makemba, A.M., Makame,V.R., Mfaume, M., Lynch, M.C., Premji, Z., Minjas, J.N., \& Shiff, C.J. (1997). Social and cultural factors affecting rates of regular retreatment of mosquito nets with insecticide in Bagamoyo District, Tanzania. Trop Med Int Hlth, 2(8), 760-770.-

Zimicki, S. (1996). Net Gain: Promotion in Sub-Saharan Africa. In Lengeler, C., de Savigny, D., \& Cattani, J. (Eds.). Net Gain:A New Method of Preventing Malaria Deaths. Geneva \& Ottawa: WHO/IDRC. 


\title{
CHAPTER 8
}

\author{
EFFECT OF CHILD TRAINING \\ IN BEDNET MOUNTING SKILLS \\ ON CHILD ADHERENCE WITH BEDNET USE \\ IN WESTERN KENYA'
}

ITo be published as:

Jane A. Alaii, H.W. van den Borne, S. Patrick Kachur, Halima Mwenesi, Penelope A. Phillips-Howard, John Vulule, K. Lindblade, L. Slutsker. Effect of child training in bednet mounting skills on child adherence with bednet use in western Kenya 


\begin{abstract}
Qualitative and quantitative studies to monitor adherence with insecticidetreated bednets in western Kenya indicated low motivation for caregivers to mount bednets daily in children's temporary sleeping spaces in kitchens and living rooms. Drawing from the social cognitive theory, and on indication that children's bednet use in some households was a result of their direct effort, we trained children aged 6-10 years in bednet mounting skills to assess their potential for improving bednet use for themselves and their younger siblings. A quasi-experimental approach was used. Firstly, 188 children from willing households previously participating in elicitation interviews to understand factors governing child bednet use in individual households were included in training - conducted at central points in participating villages. Secondly, effectiveness of training was evaluated to assess skills improvements and effect on child adherence with bednet use, three and six months after training respectively. Significantly more children appeared to have adequate skills post-training than before; $63.8 \%$ versus $36.2 \%$; $P<0.001$. However, a mix of high mounting points and inadequate adult support hindered children's effective applications of acquired skills. Households participating in child training and elicitation interviews appeared generally more compliant than households not receiving any interaction. Better adherence rates appeared statistically associated with elicitation interviews rather than child training $(\mathrm{P}<0.05)$. The implications for improving child adherence through the participation of family members, particularly children, are discussed.
\end{abstract}




\section{INTRODUCTION}

Insecticide-treated bednets (ITNs) are a key tool in global efforts to control malaria morbidity and mortality, particularly in young children in Africa (WHO, 2000). Its is estimated insecticide-treated bednets provide $17 \%$ more protective efficacy than untreated bednets, with at least 6 lives saved annually for every 1,000 children sleeping under insecticide-treated bednets (Lengeler, 2003). A recently completed trial of permethrin-treated bednets in western Kenya concludes that 35 lives of every 1,000 children protected could be saved if bednets are used correctly, including regular bednet re-treatment with insecticide (Phillips-Howard et al., 2003 [a]). Outside of controlled trials, social-cultural, behavioural and economic effects are implicated in the effectiveness of bednets. The aim of treating bednets with insecticide is to increase their effectiveness against mosquitoes - to make them repel or kill the disease vector before they can bite. It is also suggested that treated bednets in a house extends protective value to family members not sleeping under bednets (Lengeler, 1996; RBM, 2002). While people appear to readily adopt bednet use, the uptake with bednet re-treatment is rather low when people have to pay for the insecticide (Alonso et al., 1991; D’Alessandro et al., 1995; Schellenberg et al., 2001). This has implications for the cost-effectiveness of the intervention, making actual adherence critical for malaria control using bednets. In areas of low bednet use and where bednets are used mainly for reasons other than disease prevention, there have been tendencies to sleep under bednets for some times of the year only. People primarily use bednets to avoid nuisance biting, rather than for malaria prevention hence inconsistent bednet use (Winch et al., 1994; Zimicki, 1996; Binka \& Adongo, 1997). Coverage and adherence issues regarding children, the main targets of malaria control using bednets are particularly important. Children appear to be relegated to the lower family hierarchy ranks, with likely implications for their access to valued household items such as bednets (MacCormack, 1989; Alaii, 1997). While issuing bednets to cover all sleeping spaces assures equitable access to bednets in a household, questions of when, and who accesses bednets remain important for the success of interventions targeting children. 


\section{BACKGROUND, OBJECTIVES, AND RATIONALE}

Formative research during a multi-disciplinary study of permethrin-treated bednets $^{2}$ in western Kenya (Phillips-Howard et al., 2003 [b]) indicated daily bednet mounting in children's temporary sleeping spaces would be a problem (Alaii, 1997). These findings were validated during spot-checks conducted every quarter of the year to monitor adherence with bednet use, suggesting that while adherence generally appeared high (approx. 73.2\%), children were 15\% less adherent than adults (Alaii et al., 2003 [a]). Follow-up elicitation interviews with child caregivers confirmed low caregiver motivation to mount bednets daily in children's sleeping spaces - suggestive of the need for novel ways to help mothers ensure children's nets were hung. Mothers in their traditional role as household managers are often quite over-burdened with domestic chores to the extent that child bednet use takes second place in their daily routine. Assuming that the enthusiasm of children lives longer than that of adults, and based on indication that regular child bednet use in some households was a result of direct intervention of children or strict husbands, that training children in bednet mounting skills would provide valuable support for mothers.

Children linked with houses and/or compounds previously participating in elicitation motivational interviews were recruited for short interviews and training in bednet mounting skills. The overall objectives of the study were to assess the effectiveness of training in providing relevant skills, and the effect of training on child adherence with bednet use. The specific objectives were 1) to document current child participation in bednet mounting and willingness to learn relevant skills, 2) to train children in bednet mounting skills, 3) to evaluate whether they had acquired skills, 4) to evaluate the effect of child training on adherence, and 5) to make recommendations for child participation in public health matters with regards to bednets and malaria control.

2 From the outset and throughout the study an intensive educational campaign delivered malaria and bednets messages by word of mouth door-to-door and at community gatherings. Key messages emphasized children are the main targets of malaria interventions, hence the need for preferential child access to insecticide-treated bednets in the household, and the importance of consistent bednet use. Other information explained the role of ITNs in reducing child morbidity and mortality due to malaria, and associated benefits of reduced illness and death. Health education was delivered equally and at the same time to all study villages, and reinforced through information leaflets and bednet calendars bearing specific monthly messages. 


\section{Conceptual framework}

The framework underlying our study draws from cognitive models of adherence with specific reference to behavioural capability and enactive learning, constructs of the Social Cognitive Theory [SCT] (Bandura, 1986; 1997). The concept maintains that for one to perform a given behaviour, he must first know what the specific behaviour is, and secondly, how to perform it. Emphasis is placed on a process called mastery learning which provides cognitive knowledge of what is to be performed, how to perform it, and practise and feedback to refine performance. For children to be effective helpers they had to understand that they did not only need to sleep under bednets every night, but that they could play a role in getting bednets mounted, if equipped with relevant skills. We aimed to initiate the process of involving children in achieving public health outcomes by training them in relevant skills and perhaps igniting their enthusiasm particularly through the interactive modelling they underwent as they shared in tasks given during training. To complete the enactive learning process, the presumption was that caregivers would create a favourable environment back home including positive feedback, and assistance with overcoming physical barriers identified in the home. These issues were addressed with caregivers when seeking consent for participation and after training as appropriate.

\section{Definition of terms}

The term bednets is used to refer to mosquito nets and all netting material used as barriers to mosquito biting. Bednets have long been used as a form of personal protection against malaria. The only less familiar aspect of bednet use is the combination of insecticide and netting material (Lengeler et al., 1996), although it has a long history (Lindsay \& Gibson, 1988) dating back to the World War II (Harper et al., 1947).

Adherence or compliance is the extent to which a person's behaviour (in terms of taking medications, or executing lifestyle changes) coincides with recommended advice. While the term compliance conjures up images of coercion and adherence suggests dialogue and compromise, we use both terms interchangeably within the context of the main definition.

Lastly, we use the terms "households receiving additional interaction" versus "households NOT receiving additional interaction" to mean those participating in either elicitation interviews or training, and those not participating in either of the two activities respectively. Normal interaction common to both groups relates to the general health education campaign. The use of the terms experimental and control villages means villages that had previously been assigned experimental or control status during the randomised-controlled trial of insecticide-treated bednets (ITNs) (Phillips-Howard et al., 2003 [a]). 


\section{METHODS}

\section{Study site and population}

This paper forms part of a multi-disciplinary investigation into insecticidetreated bednets for malaria control in rural western Kenya (1996-2001). The study site Asembo, covers $200 \mathrm{~km}^{2}$ on the north-eastern shores of Lake Victoria, with a population of approximately 60,000 persons ( $17 \%$ less than 5 years old) (GoK, 1994). The population is typically rural, living in family homesteads consisting of 1-4 households, surrounded by their agricultural holdings. The main type of housing is one to two-roomed traditional Luo huts made of a stick framework plastered with mud, a thatched roof, one door, and one or two windows. Eaves are open, allowing easy entrance and exit for mosquitoes. A few "modern type" households with corrugated iron roofs with sealed eaves can be located in some compounds. Baseline studies revealed a low level of bednet use $(<5 \%)$, and of those using bednets, preference was given to adults and visitors to protect them against nuisance mosquitoes (Alaii, 1997). Sleeping arrangements are governed by customs, age, and space. Children less than 3 years sleep with the mother until they are displaced by a newborn.

Older children sleep in the kitchen and sitting rooms, and teenagers in the surrounding compounds of family and friends.

Ninety-six percent of the study population are members of the Luo ethnic group. The economy is based on subsistence farming including cultivation of maize, sorghum, cassava, millet, and raising a few cattle, goats, or chicken. Men mostly migrate to seek employment in big towns, leaving women as de facto household heads.

\section{Sampling and design}

The data came from two separate studies, an activity involving children in training in bednet mounting skills (Dec. 2000), and a study of adherence with bednet use six months after child training (May 2001). A quasi-experimental approach was applied for 1) ethical reasons to avoid overwhelming study participants since they might already have been involved in other randomised and/or matched activities with other research disciplines in the study area, and 2) to cope with resource and time constraints, considering especially the nature of family and household relocation characteristic of the study area. The training targeted young school age children (6-10 years) - the age group suggested already engaging in bednet mounting in various households. A list of two hundred households (spread over 20 villages) previously participating in elicitation motivational interviews were revisited, explaining the rationale and objectives of child training, and to seek consent to include their children in the training. Participation was voluntary, and children from other households in the same 
homestead were allowed to participate - based on the assumption that children often shared sleeping spaces in the homestead (Alaii, 1997). Final inclusion in the training was based on pre-training interviews with children, asking their willingness to participate.

The study to evaluate effectiveness of the training was linked to night spotchecks to monitor bednets, usually conducted in a sample of 200 randomly selected households spread out over 20 villages (Alaii et al., 2003 [a]). For this specific study villages previously participating in child training and motivational interviews were targeted, followed by a random selection of houses in two categories. Firstly, the original list of households participating in motivational interviews (from which child trainees were drawn) was used to randomly select five (5) households per village in the list. Secondly, to provide a comparison group not receiving extra interaction, five other households per village were randomly selected from a list excluding households receiving additional interaction. The next nearest household was visited to substitute for failure to locate a targeted household.

\section{Elicitation interviews}

Elicitation interviews were conducted with caregivers, based on an adaptation of the motivational interviewing [MI] approach (Miller \& Rollnick, 1991; Miller, 1996), an intervention tool integrating behavioural theory including the stages of change model and concepts from theoretical models including the social cognitive theory and the theory of planned behaviour. Interviews explored specific contextual factors with regards to determinants of child bednet use, and to define local stages of change with child bednet use in individual households. The integrative framework of MI and its principles of person-centred communication and empathy was practical for applying a set of question guides (a specific guide for each stage of change) used without making mothers feel they needed to give socially desirable answers. Appendix.8.1 shows a staging guide used by interviewers to ascertain the stage of a household based on caregiver responses, after which they were asked questions specific to the identified adopter level. These included information on if and when children below five years of age had access to a bednet in the house, the consistency with which they used their bednets, and caregiver motivations and/or other factors governing child bednet use in the household. Caregivers were specifically asked if they perceived any benefits or losses with children sleeping under bednets.

Interviews were conducted in two stages. In the first stage a preliminary staging at one of three levels was used; 1) pre-contemplation, 2)

contemplation/preparation, and 3) action/maintenance (Appendix 8.1). During data processing and coding we assigned a specific stage in either category that a caregiver had been placed in based on their responses. In the second stage of interviews, six months later, and coinciding with child training, their adopter 
level was ascertained in the same process followed by interviews based on their pre-coded stages as appropriate. While the MI approach was mainly developed as an intervention to help people reflect on their addictive behaviours and address sources of ambivalence to facilitate required behavioural changes (Miller \& Rollnick, 1991; Miller, 1996), we applied it mainly as a data collection tool. However, we took cognisance of the possibility that the behaviour change mechanism inherent in the process may have an effect on caregivers - our data analysis reflects this presumption.

\section{Components of child training}

Child training was conducted over a period of one month between December 2000 and January 2001. Training at each individual village was conducted midmorning at a central point, either in an empty school kitchen or in the living room of a willing family. Five trained research assistants led the field activities, assisted by two community health workers from each target village. Two trainings were conducted per day, with two research assistants and their support team at each site. The fifth member of the team coordinated with other community health workers for forthcoming training in their villages.

A set of short questions and training checklists were used to guide fieldwork. Firstly, trainees answered a short questionnaire assessing their access to bednets in the household, whether they knew how to mount a bednet and if so, whether they ever mounted their own bednet at bedtime. Lastly, confirmation was sought for willingness to learn bednet-mounting skills, and the motive for it. One hundred eighty-eight (188) children were eventually trained. Only one child was excluded from training as he just wished to stay and watch. Secondly, a pre-training checklist was used to practically assess required skills for children. Children demonstrated in groups defined by age, any bednet mounting skills they knew - including identifying all things required for sleeping and bednet use ranging from the sleeping mat, the bednet itself, and twines for hanging the bednet. Other skill requirements included ability to mount the bednet and to remove it for storage, and special skills for care against fire and how to reach high points such as ceiling beams. All necessary tools were provided, including chairs to reach high points. Pre-training demonstrations were held at school compounds under a relatively low tree or school kitchen.

For the actual training which was conducted the same day, a checklist including all questions children had been asked to engage in during the pre-training demonstration was used to check specific skills imparted to children during training, noting skills that were given particular emphasis. The aim of training was to impart relevant skills to the children in groups of $4-5$, focusing on how to mount a bednet (in general), and more importantly, skills for reaching high points (by climbing on a chair for, example), and skills for care against fire. Children were also encouraged to request help from adults at home to help 
reach particularly high points; rather than risk falling and getting hurt. This information was relayed to caregivers during requests for consent to participate, and reinforced through information leaflets children carried home from training. Three months after the training a post-training checklist was used to assess children during revisits with them at central points to assess participation in net mounting at home. Firstly, confirmation was sought whether they had received training, followed by requirement to demonstrate their net mounting skills. They were finally asked questions on factors that might hinder their effective participation in bednet mounting for themselves or their siblings.

\section{Spot-check evaluation}

Family use of bednets was monitored through direct observation by a team of 13 male field staff accompanied by a recognized villager in the early morning hours (3:00-6:00 a.m.). Standard methodology used in our spot-check studies to quantify bednet use was applied (Alaii et al., 2003 [a]) - participants were not aware that they would be monitored on a specific day. A limit of two households per homestead were visited for spot-check, one interviewer going into each household at the same time. Also, the standard rule for substitution used in all our surveys was applied - the next nearest household or homestead was assessed if enumerators failed to access a targeted household either due to household relocation or absence of someone at home.

Staff used an observation checklist to record information including the number and ages of all persons sleeping in the house, and the number and ages of individuals either using or not using bednets. Lastly, an open ended question was asked why a child $<5$ years of age might not be sleeping under nets on the spot-check night. Households were revisited at daybreak to ask child caregivers more detailed questions about ITN use and travel in the past month.

\section{Data handling, classification, and measurements}

Child training data was checked for consistency at training sites. Spot-check data was checked for consistency at the field office. All checked data was transported to the field station in Kisumu for coding and data entry. Data entry staff entered data into Clarion ${ }^{\circledR}$, Rel. 2.1 (Clarion Software Corp.) using data screens with automatic range and consistency checks. As per standard practise at the field station, data were further checked for consistency using SAS ${ }^{\circledR}$, Rel. 8.1 (SAS Institute Inc., Cary, NC, USA). Analysis was done using SPSS ${ }^{\circledR}$, Rel. 11. (SPSS Inc., Chicago, IL, USA).

Child skills were defined as lacking, low, average, or high. A child was lacking in skills if he could not even perform the simplest possible tasks including tucking in edges of the bednet to prevent mosquitoes coming in from the open 
bottom (important especially when bednets are not treated with insecticide). A child low in skills was defined as only able to perform the simplest tasks lacking in the previously mentioned category, but could not mount bednets. A child with average skills was defined as able to mount bednets without help, but lacked key skills for reaching high points like ceiling beams, or skills for care against fire. A child with high level of skills could not only mount a bednet, but also had key skills for reaching high ceiling beams and care against fire.

For spot-check data we calculated adherence as the number of persons under bednets divided by the total number persons in the house at survey time. Adherence rates were calculated for three age categories; children $<5$ years of age, children 5-10 years of age, and other family members above 10 years of age. By the time of this study all bednets regardless of source were treated with insecticide, therefore all bednets in the house were included in the analyses.

Chi squared tests and direct logistic regression analyses were used to check relationships in key variables. For these analyses, dichotomized key outcome variables were used including portrayed skill levels (training data) and household adherence types (spot-check data). A dichotomous variable used with regression analysis of the effectiveness of training defined levels of child skills as either inadequate (lacking + low skills) $=0$, or adequate (average + high skills) $=1$. The level of skills portrayed was the dependent variable checked against child training status, household bednet status, age of child, gender, and an interaction of these. For the analysis of the effect of training on child adherence (spot-check) a dichotomous variable defined household adherence types as either adherent (all persons sleeping under bednets)=1, or non-adherent (some persons not sleeping under bednets, regardless of age) $=0$. The effect of training on adherence was assessed by age group, and based on overall household adherence as the outcome variables. Predictor variables included type of interaction including training only, motivational interviews (MI) only, an interaction between training and MI, and no interaction. A P value 0.05 was considered significant.

\section{RESULTS}

\section{Child training}

\section{Characteristics of child trainees}

A total of 188 children were included in the child training exercise, $61.7 \%$ boys and $38.3 \%$ girls, and traced back for evaluation. The training attendance ranged from 10-15 between sites, with an average attendance of 12.1, Standard 
Deviation (SD) 1.6 per site. The mean age was $8.0, \mathrm{SD}=1.5$, with ages ranging between 5-10 years. A dichotomous age grouping indicated an average attendance of 3.3, SD $=1.6$ for the below 7 year olds and mean attendance $8.8, \mathrm{SD}=2.5$ for the $7-10$ years age group.

\section{Pre-training interviews}

Only $2(1.1 \%)$ of the children reported their family were not issued with project bednets. Of 186 reporting they had been issued nets, $51.4 \%$ always had access to a bednet, $31.9 \%$ stated they had no access to a bednet, while the remaining $16.8 \%$ stated they had access to a bednet occasionally. No significant differences were noted in comparisons between former experimental and control villages, or by age of child. Children reported they mainly slept in the living room $(25.7 \%)$ in their house or on a floor mat in the parents' bedroom (23.5\%). Others mainly slept at their grandparents' living room (18.7\%) or in the kitchen $(12.8 \%)$. At least $8.6 \%$ slept in a children's bedroom, while the remaining $10.7 \%$ said they had no specific sleeping space as this changed all the time.

Sixty-four (34.4\%) children stated they knew exactly how to mount a bednet, $40 \%$ versus $14.6 \%$ in the $7-10$ year age and below 7 years of age respectively, $\mathrm{X}^{2}$ (9.112, df 1 , OR $=3.9$; 95\%, CI 1.5-9.8) $\mathrm{P}<0.01$. Nevertheless, almost all children (94\%) stated they often had to mount their own bednets to be able to use them. No clarification was sought whether this was done with the help of their older siblings; though on further questioning only $23.6 \%$ said they always mounted their own bednets, while the rest said they did so occasionally. At least $6.9 \%$ of the children said they never ever mounted bednets. The main reason for wanting skills was reported by children as to enable them mount bednets for themselves when they wanted to use them (96.9\%), with the rest saying they wanted to learn for the simple sake of acquiring the skills.

\section{Pre-training skills demonstrations and post-training evaluation}

Overall, $133(70.7 \%)$ and 157 (83.5\%) children demonstrated their bednet mounting skills before the training and at evaluation respectively. At evaluation, more children appeared to have adequate skills than before; $63.8 \%$ versus $36.2 \%, \mathrm{X}^{2}$ (45.163, df 1 [OR=.4.3; 95\% CI 2.7-6.6]) $\mathrm{P}<0.001$. Table 8.1 shows that the training appeared to have imparted required skills to children. No children portrayed total lack of skills post-training. Also, the proportion of children having basic skills only reduced, accompanied by an increase in proportions portraying average and high skill levels.

Children reported the main problems with applying their skills related to high ceiling beams $(43.6 \%)$, and how to avoid fire $(27.7 \%)$, indicating lack of adult support at home. At least $13.6 \%$ of the children stated before and after training that they were just not keen on mounting their bednets - not related to age. To avoid antagonizing children, we did not seek clarification why they 
Table 8.I Observed skill levels before and 3 months after child training

\begin{tabular}{lcccc}
\hline & Lacking N (\%) & Low N (\%) & Average N (\%) & High N (\%) \\
\hline Before training & $19(10.1)$ & $114(60.6)$ & $51(27.1)$ & $4(2.1)$ \\
At evaluation & - & $68(36.2)$ & $76(40.4)$ & $44(23.4)$ \\
\hline
\end{tabular}

$X 2(68.88 I)$ df $3, P<.001$

Table 8.2 Logistic regression analysis of children's demonstrated skills as an outcome of training, and other key variables

\begin{tabular}{|c|c|c|c|c|c|c|c|c|}
\hline \multirow[b]{2}{*}{ Variables } & \multirow[b]{2}{*}{$\beta$} & \multirow[b]{2}{*}{ S.E. } & \multirow[b]{2}{*}{ Wald } & \multirow[b]{2}{*}{ df } & \multirow[b]{2}{*}{ Sig. } & \multirow[b]{2}{*}{ OR } & \multicolumn{2}{|c|}{$95.0 \%$ C.I. of OR } \\
\hline & & & & & & & Lower & Upper \\
\hline Training status & -2.14 & .43 & 24.27 & I & $<0.001$ & 0.12 & 0.05 & 0.28 \\
\hline Net status & -.32 & .33 & .93 & I & 0.334 & 0.73 & 0.38 & 1.39 \\
\hline Age & -2.7 & .75 & 12.89 & I & $<0.001$ & 0.07 & 0.02 & 0.30 \\
\hline Age by training & 1.03 & 1.23 & .64 & I & 0.424 & 2.80 & 0.22 & 34.92 \\
\hline Net by training & .64 & .61 & 1.08 & I & 0.298 & 1.89 & 0.57 & 6.25 \\
\hline Gender & .13 & .23 & .20 & I & 0.652 & 1.14 & 0.65 & 1.98 \\
\hline Constant & -.20 & .28 & .50 & I & 0.480 & 0.82 & & \\
\hline
\end{tabular}

might not be so keen. Overall, $19.1 \%$ of the trainees reported they were outright denied consent at home to mount bednets, with mothers deciding when to avail bednets for child use. Villages in the former control groups appeared twice as likely as their former experimental counterparts to deny consent to mount bednets; $15.2 \%$ versus $8.2 \%, \mathrm{X}^{2}(\mathrm{P}<0.05)$. It was encouraging to note post-training that children were less encumbered by lack of relevant support (particularly with regards to high ceiling beams and care against fire) than before (37.2\% vs.74.5\%); $\mathrm{X}^{2}(1)=52.851$, [OR $=0.20 ; 95 \%$ CI $\left.0.13-0.31\right]$ ) $\mathrm{P}<0.001$.

Logistic regression analysis was performed on a dichotomous variable of portrayed level of child skills against key variables including training status, bednet status defined by previous bednet project experimental groupings, and age, and gender. The interaction between training status and age, and training status and bednet status were also explored. The model had no missing cases. Table 8.2 shows regression coefficients, Wald statistics, odds ratios and 95\% confidence 
Table 8.3 Age distribution and adherence rates by bednet intervention status

\begin{tabular}{|c|c|c|c|c|}
\hline & & Persons counted & Persons using nets & Adherence $(\%)$ \\
\hline \multirow{2}{*}{ Child $<5 y$} & Ex-control & 94 & 81 & 86 \\
\hline & Ex-experimental & 93 & 88 & 95 \\
\hline \multirow{2}{*}{ Child 5-10y } & Ex-control & 87 & 70 & 80 \\
\hline & Ex-experimental & 93 & 89 & 96 \\
\hline \multirow{2}{*}{ Adults $(>10 y)$} & Ex-control & 179 & 169 & 94 \\
\hline & Ex-experimental & 197 & 191 & 97 \\
\hline \multirow{2}{*}{ All family } & Ex-control & 360 & 320 & 89 \\
\hline & Ex-experimental & 383 & 368 & 96 \\
\hline
\end{tabular}

intervals for the odd ratios for each predictor. The significance values of the Wald statistics for each predictor indicate that separately, training in net mounting skills and age of child significantly predict their ability to master key skills required to effectively use bednets by themselves, $(\mathrm{P} \leq 0.001)$. The effect of training on adherence is assessed in the next sections, with separate data indicating household interaction status as appropriate.

\section{Bednet adherence spot-checks}

\section{Characteristics of households}

Two hundred (200) households were successfully visited for spot-checks, with equal representation of former experimental and former control groups. Due to constant household relocation we failed to locate equal representation by form of additional interaction received, thus $84(42 \%)$ households visited had received no additional interaction, 37 (18.5\%) had participated in both training and motivational interviews, $14(7 \%)$ had participated in training only, and 65 (32.5\%) had participated in motivational interviews only. The mean caretaker age were $35.16, \mathrm{SD}=11.91$; with ages ranging from 17-68 years. Caregivers had a mean education of 7.23 (years), $\mathrm{SD}=2.32$, with education years ranging from 1-15. Of 743 occupants recorded on spot-check night, $25.2 \%$ were children below 5 years of age, located in 109 (54.5\%) households. The rest of the population consisted of children 5-10 years of age (24.\%), and adults (50.6\%). Table 8.3 shows age distribution and estimated adherence by former experimental and control group status. The overall adherence rates were estimated at 
93\% for all age groups combined, and 90\% for children less than 5 years of age. Adherence in former control households appeared generally lower than in the former experimental groups. Calculation of adherence in households by child status indicated adherence was lower in households having children $<5$ years than in those with persons above 5 years of age only; $92 \%$ versus $94 \%$. Also, adherence of children $<5$ years of age appeared lower than that of persons above 5 years of age in the same households; $90 \%$ versus $93 \%$. All differences noted between former bednet intervention groupings were not significant. The dichotomous variable of household adherence had a distribution of $85 \%$ and $15 \%$ for adherent and non-adherent households respectively.

\section{Effect of extra intervention}

The spot-check data showed that adherence rates in this specific survey was generally high estimated at 93\% at the household level, 90\% for children $<5$ years of age, and 93\% for persons above five years of age. However, comparisons by interaction status indicated that households receiving additional interaction including motivational interviews and/or child training recorded better adherence compared to those receiving none (Figure 8.1). Training and motivational interviews combined appeared to result in a better adherence overall, estimated at 99\%. Motivational interviews on their own also recorded a better adherence rate than households not receiving additional interaction; $94 \%$ versus $88 \%$. The effect of motivational interviews and training combined, and motivational interviews alone seemed to be particularly positive for bednet use among children 5-10 years (the target of training). Training alone did not appear to achieve quite as impressive results, particularly for the 5-10 years age group.

Chi squared analyses using the dichotomous variable breaking households into adherent or non-adherent groups suggested persons above 5 years of age in households receiving motivational interviewing were generally likely to be adherent than households not participating in the interviews; $54.3 \%$ versus $28 \%, \mathrm{X}^{2}$ (6.048, df 1 , [OR $=3.1 ; 95 \%$ CI 1.2-7.7]) $\mathrm{P}<0.05$. Direct logistic regression analyses using the dichotomous variable as outcome of key variables denoting additional interaction with families suggested motivational interviews rather than child training explained some of the observed improvement in adherence. Table 8.4, for example, shows for each predictor tested against all family adherence as outcome, only motivational interviewing appeared to explain some of the observed improvement in adherence $(\mathrm{P}<0.05)$. Similar analyses across different age groups suggested that the observed benefits were only significant with regards to persons above five years of age; Wald $(1)=6.158 ;(B=-1.39,[\mathrm{OR}=0.25 ; 95 \%$ CI $0.08-0.75]) ; \mathrm{P}<0.05$. Separate direct logistic regression analysis indicated caretaker age (in years) could significantly predict overall family adherence with bednet use Wald (10) 4.759; ( $B=$ .0 .062 , $[\mathrm{OR}=1.06 ; 95 \%$ CI $1.01-1.13]), \mathrm{P}<0.05$ - suggesting that family adherence appeared to improve with advancement in caretaker age. 


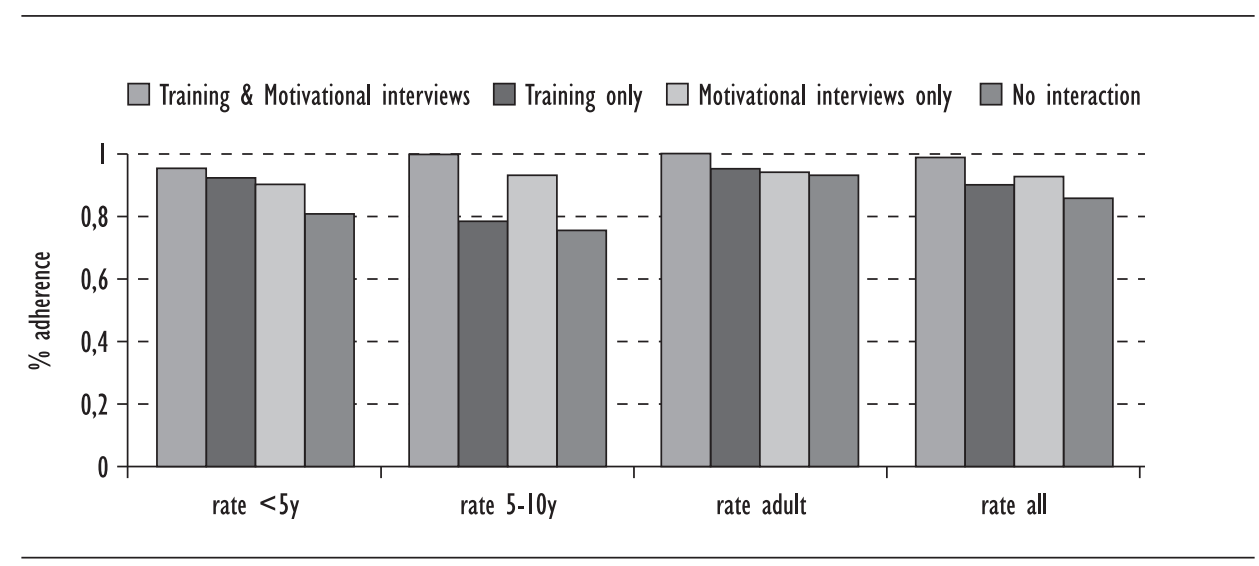

Figure 8.I Adherence rate across age group

Table 8.4 Logistic regression analysis of overall family adherence rate as a function of interaction status, including other key variables

\begin{tabular}{|c|c|c|c|c|c|c|c|c|}
\hline \multirow[b]{2}{*}{ Variables } & \multirow[b]{2}{*}{$\beta$} & \multirow[b]{2}{*}{ S.E. } & \multirow[b]{2}{*}{ Wald } & \multirow[b]{2}{*}{ df } & \multirow[b]{2}{*}{ Sig. } & \multirow[b]{2}{*}{$O R$} & \multicolumn{2}{|c|}{$95.0 \%$ C.I. of OR } \\
\hline & & & & & & & Lower & Upper \\
\hline Interviewed & -2.17 & .97 & 5.03 & I & 0.025 & 0.11 & 0.02 & 0.76 \\
\hline Trained & -1.20 & .81 & 2.20 & I & 0.138 & 0.30 & 0.06 & 1.47 \\
\hline Net status & -.30 & .42 & .52 & 1 & 0.470 & 0.74 & 0.33 & 1.68 \\
\hline Caretaker age & -.88 & .53 & 2.73 & 1 & 0.098 & 0.41 & 0.15 & 1.18 \\
\hline Caretaker education & -.65 & .51 & 1.67 & I & 0.196 & 0.52 & 0.19 & 1.40 \\
\hline Interviewed by trained & 1.76 & 1.06 & 2.77 & 1 & 0.096 & 5.83 & 0.73 & 46.42 \\
\hline Constant & 4.18 & 1.00 & 17.40 & 1 & $<0.001$ & 65.06 & & \\
\hline
\end{tabular}

* Interviewed $=$ motivational interviews

\section{DISCUSSION}

The training resulted in significant improvements in bednet mounting skills by participating children. Also, although not statistically significant, training appeared to improve the likelihood that children would sleep under their bednet. The biggest challenge, it seems, remains with attaining parental support in creating an enabling environment for children to effectively use bednets in households. 
Due to constant household relocation practices typical of the study area (and Luo communities in general), and because children often share sleeping spaces in houses within a homestead, we were not able to match exactly our child training activities to households participating in elicitation interviews. Therefore some households had only child training, while some participated in elicitation interviews alone. Household relocation practices also made it difficult for us to recapture an adequate representation of households participating in child training for the adherence spot-check. This, coupled with the fact that overall adherence with bednet use was quite high (93\%) might explain why we could not detect a significant association between training and with adherence.

Our studies monitoring adherence generally indicate high levels of compliance with bednet use (Alaii et al., 2003 [a]). However, they concur with findings elsewhere that adults are generally more likely than children to use bednets at any given time (MacCormack, 1989; Kachur et al., 1999; Chavasse et al., 1999), and indicate that effective child bednet use is not necessarily improved by adequate household bednet coverage. Often, due to cost implications, people appear to value bednets to the extent that, in the attempt to save bednets for future use, children might not always be allowed access to bednets for fear that they might damage them. The desire to save bednets for future use beats all reason for issuing bednets to cover all sleeping spaces - with serious implications for the effectiveness of the intervention. This, however, highlights a dire need to recognize that if children's access to bednets is to be improved coverage issues must go beyond simply saturating families with bednets, and also target the manufacture of longer-lasting bednets that do not wear and tear easily, or easily catch fire. Children's sleeping arrangements are implicated in their access to delicate items such as bednets. Children commonly sleep on rudimentary beddings including papyrus reed mats on which bednets tear easily. They also often sleep in temporary spaces including kitchens where fires are traditionally not put out unless the family travels. Often, for fear of house fires, caregivers in our study area have expressed sentiments that children cannot be trusted to mount and/or use bednets in the absence of an adult. With these conditions, some mothers might have allowed their children to acquire bednet-mounting skills, not for immediate application of the intervention, but for the future when they were perceived "big enough to take care". At least $19.1 \%$ of children in our study were outright denied consent to remove bednets from where they were stored, so they could not mount their bednets despite portraying relevant skills. This may also explain why some caregivers failed to provide necessary support to enable children reach high mounting points including ceiling beams. Perceived social norms are also implicated in the failure of some mothers to facilitate effective participation of children in bednet mounting. Mothers are traditionally responsible for childcare, and some perceive any attempt by children below 10 years of age to undertake in certain activities as indication that a caregiver does not know her duties. 
Children tend to be passive members of households, not allowed to access valued household items unless such a provision is made for someone in authority in the household. The potential of children in helping achieve public health outcomes has been proven in studies including asthma prevention in western countries (Bartholomew et al., 2000). Children in this community already portray competence in handling domestic chores involving valued family possessions including baby-sitting younger siblings, and herding livestock. In neighbouring areas they even actively engage in their own health care (Geissler et al., (2000). Strangely, when it comes to bedtime arrangements matters take a completely different turn, with caregivers expected to shoulder all responsibility. Efforts are required to consciously involve children in interventions aimed at enhancing adherence with bednet use. Social cognitive theory (Bandura 1986) distinguishes between skills acquisition and performance, emphasizing that people often do not enact everything they learn. However, for a given behaviour to be performed, it must not only be perceived to serve a functional purpose, but also be accompanied by positive incentives (Bandura, 1986). The implication is that unless parental support is expressed verbally or through direct physical assistance for example, children will not feel the worth of their contribution and might not engage in certain behaviours (Bandura, 1997). The social cognitive theory also recognizes that people's orientations differ according to social circumstances (Bandura, 1986). Proximal antecedents to behaviour do not lie entirely within individuals, but in their social environments, too. Collectively orientated cultures such as this community often face a dilemma, placing social value above self-interest (Triandis, 1995). Mothers obviously need a helping hand, but, some, for fear of social disapproval, might fail to recognize the valuable role their children could play in attaining much needed assistance. Targeting the social context in which decisions are based is a critical component of any attempt to inculcate new attitudes and/or behaviours (Bracht, 1990). Some caregivers already allow their children to independently mount bednets, indicating that a crucial requirement is carefully planned health communication targeting self-liberating attitudinal changes (Prochaska \& DiClemente, 1983). Our elicitation interview results are a promising indication that mothers can be motivated enough, using novel ways, to value consistent child adherence with bednet use. In the same way they might be persuaded to facilitate effective participation of children in deploying public health interventions such as insecticide treated bednets. When asked what resulted in improved child adherence during follow-up interviews, caregivers often remarked, "...It is because of those questions you were asking me...they made me think about it..." This concurs that an approach based on dialogue rather than on passive information dissemination improves chances of success. Simply "giving knowledge" risks interpretation as an attempt to impose external values on target communities, while dialogue holds promise for equal participation through information sharing, feedback, and reflection (Freire, 1973). Our findings concur with a diarrhoeal diseases control study in rural Zambia (Thevos et al., 2000), suggesting a role 
for applying the principles of motivational interviewing (MI) in programmes targeting behaviour change in Africa. Using motivational interviews as an intervention (Miller \& Rollnick, 1991) might not be feasible in large communitybased studies. However, the results are a clear indication that addressing people's motivations in a listening-dialogue-reflection approach is critical for achieving public health outcomes. Valuable techniques based on similar principles including Participatory Rural Appraisal already exist and have been applied with success in health settings in the tropics (Rifkin, 1992). Programmes could benefit from applying such approaches, not only to learn about people's aspirations, but to also enhance community understanding and application of interventions such as insecticide-treated bednets. Ways could also be sought to integrate these two methodologies for maximal benefits in mobilizing and empowering communities to take the initiative for achieving public health outcomes. 


\section{REFERENCES}

Alaii, J.A. (1997). The relevance of sleeping arrangements and bedtime mobility patterns for implementing insecticide-treated bednets in Asembo, western Kenya. Master of Science Thesis, London, South Bank University.

Alaii, J.A., Hawley, W.A., Kolczak, M.S., ter Kuile, F.O., Gimnig, J.E., Vulule, J.M., Odhacha,A., Oloo,A.J., Nahlen, B.L., \& Phillips-Howard, P.A. (2003 [a]). Factors affecting the use of permethrin treated bednets during a randomised controlled trial in western Kenya. American Journal of Tropical Medicine and Hygiene, 68, Suppl. 4.

Alonso, P.L., Lindsay, S.W., Armstrong, J.R.M., Conteh, M., Hill,A.G., David, P.H., Fegan, G., de Francisco,A., Hall,A.J., Shenton, F.C., Cham, K., \& Greenwood, B.M. (1991). The effect of insecticide-treated bednets on mortality of Gambian children. Lancet, 337, I449-I 502.

Alonso, P.L., Lindsay, S.W.,Armstrong, J.R.M., Keita, K., Gomez, P., Shenton, F.C., Konteh, M., Keita, K., Marshall, C., Phillips, A., Cham, K., \& Greenwood, B.M. (1993).A malaria control trial using insecticide-treated bed nets and targeted chemoprophylaxis in a rural area of The Gambia, west Africa: the impact of the interventions on mortality and morbidity from malaria. Transactions of the Royal Society of Tropical Medicine and Hygiene, 87 (Suppl 2: S37-S44).

Bandura,A. (1986). Social foundations of thought and action:A social cognitive theory. New Jersey: Prentice-Hall.

Bandura, A. (1997). Self-efficacy: the exercise of self control. New York:W. H. Freeman and Company.

Bartholomew L.K., Gold, R.S., Parcel G.S., Czyzewski, D.I., Sockrider, M.M., Fernandez, M., Shegog, R., \& Swank, P.R. (2000).Watch, Discover, Think, and Act: Evaluation of computerassisted instruction to improve asthma self-management in inner-city children. Patient Education and Counseling, 39(2-3), 269-280.

Beiers, J.C., Oster, C.N., Onyango, F.K., Bales, J.D., Sherwood, J.A., Perkins, P.V., Chumo, D.K., Koech, D.V., Whitmire, R.E., Roberts, C.R., Diggs, C.L., \& Hoffman, S.L. (1994). Plasmodium falciparum incidence relative to entomological inoculation rates at a site proposed for testing malaria vaccines in western Kenya. Am J Trop Med Hyg, 50, 529-536.

Binka, F.N., \& Adongo, P. (1997). Acceptability and use of insecticide impregnated bednets in northern Ghana. Tropical Medicine and International Health, 2(5), 499-507.

Bloland, P.B., Ruebush, T.K., McCormick, J.B., Ayisi, J., Boriga, D.A., Oloo,A.J., Beach, R., Hawley, W.A., Lal,A., Nahlen, B., Udhayakumar,V., \& Campbell, C.C. (1999). Longitudinal cohort study of the epidemiology of malaria infections in an area of intense malaria transmission. II. Descriptive epidemiology of malaria infection and disease among children. Am J Trop Med Hyg, 60, 64I-648.

Bracht, N. (Ed.). (1990). Health Promotion at the Community Level. California, USA: Sage Publications Inc.

D'Alessandro, U., Olaleye, B.O., McGuire,W., Langerock, P., Bennett, S., Aikins, M.K., Thompson, M.C., Cham, M.K., \& Greenwood, B.M. (1995). Mortality and morbidity from malaria in Gambian children after introduction of an impregnated bednet programme. Lancet, 345, 479-483.

D'Alessandro, U. (200I). Insecticide-treated bednets to prevent malaria:The challenge lies in implementation. British Medical Journal, 322, 250-I. 
Freire, P. (1973). Education for critical consciousness. New York: Seabury Press.

Geissler, P.W., Nokes, K., Prince, R.J., Odhiambo, R.A., Aagaard-Hansen, J., \& Ouma, J.H. (2000).

Children and medicines: self treat of common illnesses among Luo school children in western Kenya. Social Science and Medicine, 50, I77I-1783.

Government, of Kenya. (1994). Siaya District Development Plan, 1994-1996. Nairobi:

Government printers.

Haynes, R.B., Taylor, D.W., \& Sackett, D.L. (1979). Compliance in Health Care. Baltimore: Johns Hopkins University Press.

Kachur, S.P., Phillips-Howard, P.A., Odhacha,A.M., Ruebush,T.K., Oloo,A.J., \& Nahlen, B.L. (1999). Maintenance and sustained use of insecticide treated bednets and curtains three years after a controlled trial in western Kenya. Trop Med Int Hlth, 4, 728-35.

Lengeler, C., de Savigny, D., \& Cattani, J. (Eds.). (1996). Net Gain:A New Method of Preventing Malaria Deaths. Geneva: Publ. IDRC, ISBN 0-88936-792-2. Ottawa and WHO.

Lengeler, C. (2003). Insecticide-treated bednets and curtains for preventing malaria. (Cochrane Review) The Cochrane Library (Issue I, 2003, Oxford: Update Software).

Lindsay, S.W., \& Birley, M.H. (1996). Climate change and malaria. Annals of Medicine and Parasitology, 90(6), 573-88.

MacCormack, C.P. (1989). People's attitudes. Paper for WHO informal consultation on the use of impregnated bednets and other materials for vector-borne disease control.World Health Organization.

Miller,W.R., \& Rollnick, S. (199I). Motivational Interviewing: Preparing people for change. New York: Guilford Press.

Miller,W.R. (1996). Motivational Interviewing: Research, practice, and puzzles. Addictive Behaviours, $2 I$ (6), 835-842.

Phillips-Howard, P.A., Nahlen, B.L., Kolczak, M.S., ter Kuile, F.O., Alaii, J.A., Hightower, A.W., Gimnig, J.,Arudo, J.A.,Vulule, J., Schoute, E., Kachur, S.P., Oloo, A.J., \& Hawley,W.A. (2003 [a]). Efficacy of permethrin-treated bednets in the prevention of mortality in young children in an area of high perennial malaria transmission in western Kenya. American Journal of Tropical Medicine and Hygiene, 68, Suppl. 4.

Phillips-Howard, P.A., ter Kuile, F.O., Nahlen, B.L.,Alaii, J.A., Gimnig, J.E., Kolczak, M.S., Terlouw, D.J., Kariuki, S., Shi, Y.P., Kachur, S.P., Hightower, A.W.,Vulule, J.M., \& Hawley,W.A. (2003 [b]). The efficacy of permethrin-treated bednets on child mortality and morbidity in western Kenya. II: Design and methods. American Journal of Tropical Medicine and Hygiene, 68, Suppl. 4.

Rifkin, S. (1992). Rapid appraisal for health:An overview. In RRA notes No 16: Special issues on applications in health Sustainable Agriculture Programme. London, UK: International Institute for Environment and Development (IIED).

Schellenberg, J.R.M.A., Abdulla, S., Nathan, R., Mukasa, O., Marchant, T.J., Kikumbih, N., Mushi, A.K., Mponda, H., Minja, H., Mshinda, H., Tanner, M., \& Lengeler, C. (200I). Effect of largescale social marketing of insecticide-treated netson child survival in rural Tanzania. Lancet, 357, I24I-47.

Thevos, A.K., Quick, R.E., \& Yanduli,V. (2000). Motivational Interviewing enhances the adoption of water disinfection practices in Zambia. Health Promotion International, 15(3), 207214.

Triandis, H.C. (1995). Individualism and collectivism. Boulder, Colorado:Westview. 
Winch, P.J., Makemba, A.M., Kamazima, S.R., Lwihula, G.K., Lubega, P., Minjas, J.N., \& Shiff, C.J. (1994). Seasonal variation in the perceived risk of malaria: Implications for the promotion of insecticide-treated bed nets. Social Science and Medicine, 39, 63-75.

RBM. (2002). Roll Back Malaria 200I-20I 0 United nations Decade to Roll Back Malaria: Insecticide-treated bednets (RBM Infosheet 5 of I I; March 2002), I-2

WHO (1996). Tropical diseases control: Malaria in the world. Geneva: Division of control of tropical diseases (CTD/TDT/96.12),WHO.

WHO/RBM (2000). African Summit on Roll Back Malaria, Abuja, Nigeria, April 25, 2000. WHO/CDS/RBM/2000. 17.

Zimicki, S. (1996). Net Gain: Promotion in Sub-Saharan Africa. In Lengeler, C., de Savigny, D., \& Cattani, J. (Eds.). (1996). Net Gain:A New Method of Preventing Malaria Deaths. Geneva \& Ottawa:WHO/IDRC. 



\section{SUMMARY}

Malaria is a major cause of human deaths worldwide, and thrives in the world's poorest countries, with an estimated 300-500 million clinical cases and approximately 2.7 million deaths occurring globally annually. Young children and pregnant women are most at risk. Currently, bednets appear to be the most promising tool against malaria and have been incorporated into global malaria control initiatives.

The effectiveness of bednets is associated with high levels of adherence. Thus if bednets are to be incorporated into malaria control initiatives in Africa, research efforts are required to investigate those effects that impact detrimentally on correct bednet use, particularly with regards to young children. The studies presented in this thesis addressed factors relevant for bednet utilization within the context, and following the completion, of a multi-disciplinary randomised-controlled trial of insecticide-treated bednets in a rural population of 55-60,000 people in western Kenya. While we recognized that randomized controlled trials are set up to monitor the efficacy of an intervention, bednets differ from most other control interventions in that they require continued active participation by the study population, to adhere each night with bednet use. This provides an opportunity to learn about behavioral traits that might impact on effectiveness, thus generating relevant information for national programmes. Implicit and explicit use of behavioral theory guided assessments. Ethnographic studies were used to culturally define malaria including current strategies and attitudes towards prevention and treatment. Environmental and structural variables impacting on adherence with bednet use were determined using qualitative and quantitative methods.

Malaria was perceived to be from multiple causes including mosquitoes, getting cold, and being rained on. While bednets could prevent mosquito biting they were thus not perceived to affect other causes of malaria, and the risk of malaria - thus malaria drugs were considered the ideal control strategy. Two pertinent issues for bednet use in this community included bednet acquisition, and patterns of adherence with bednets. Bednet ownership was less than 5\% before the implementation of the bednet trial, and perceived to be a luxury item both due to cost implications and their perceived function (mainly avoidance of mosquito nuisance biting). Adherence with bednet use was generally high (approx. 76\%) after bednets were issued free of charge. However, bednet use was mostly seasonal and age dependent, impacted by lack of congruence between avoiding nuisance biting and prevention of disease on the one hand, and insufficient bednets on the other hand - with preference given to adults rather than children. When the community was saturated with bednets other factors affecting child bednet use emerged, including disinclination of caregivers to mount bednets daily in children's temporary sleeping spaces (kitchens and living rooms), and the desire to store bednets to reduce damage (to save bednets for future use). A quasi-experimental pilot study with children 6-10 years 
of age resulted in improvements in child skills for mounting bednets, but caregivers appeared reticent to allow children to apply their skills, attributable both to perceived social norms about mother's responsibility for child care, and to caregiver fear that bednets might accidentally catch fire.

Our studies suggest that, despite the advantage of trying bednets, bednets and insecticides would not be purchased as a household priority in this impoverished rural community, with adults given first preference when bednets are insufficient. As with questions of affordability correct bednet use will be largely determined by the perceived need to use a bednet in the first place. This suggests that during bednet delivery programmes, public health staff need to be aware that community perception of disease, and their consequent actions may not tally with expected public health agenda. To maximize ITN use, a crucial first step involves understanding the social context of the health problem and factors relevant for the utilization of a proposed intervention as a basis for health education and promotion design. Specifically, a needs assessment will include understanding what motivates and/or hinders caregivers, and whether they perceive any benefits at all in child bednet use. In addition, if children are to benefit, programmes must ensure coverage of all sleeping spaces in the household, while at the same time explaining and improving understanding on why they will need preferential coverage. Lastly, coverage does not necessarily assure consistent bednet use - concerted health education and promotion will be required to constantly remind people of the importance of adherence for maximal effectiveness of bednets. 


\section{SAMENVATTING}

Malaria is wereldwijd een belangrijke doodsoorzaak en komt vooral erg veel voor in de armste landen van de wereld. Men schat het aantal ziektegevallen per jaar op 300 tot 500 miljoen en er sterven per jaar gemiddeld 2.7 miljoen mensen aan malaria. Jonge kinderen en zwangere vrouwen lopen de meeste risico's.

Momenteel blijken muskietennetten het meest belovende middel tegen malaria te zijn en ze zijn over de hele wereld als instrument opgenomen in de initiatieven om malaria onder controle te krijgen.

De effectiviteit van muskietennetten wordt sterk bepaald door de consistentie waarmee ze worden gebruikt. Als muskietennetten opgenomen dienen te worden in initiatieven om in Afrika malaria onder controle te krijgen, dan zijn onderzoeksinspanningen vereist om de factoren te onderzoeken die een nadelige invloed hebben op het correct gebruik van deze netten, in het bijzonder met betrekking tot het gebruik door jonge kinderen. De onderzoeken die in dit proefschrift worden gepresenteerd, richtten zich op het identificeren van factoren die relevant zijn voor het gebruik van muskietennetten in de context van en in aansluiting op een multidisciplinair experimenteel onderzoek naar de toepassing van met insecticide behandelde muskietennetten (ITNs) bij een plattelandsbevolking van 55-60.000 mensen behorende tot de ethnische Luo gemeenschap in Asembo in het westen van Kenya.

Vergeleken met gerandomiseerde experimentele onderzoeken die worden opgezet om de effectiviteit van interventies te bepalen, verschilt onderzoek naar het gebruik van muskietennetten van dergelijke interventiestudies omdat dit onderzoek een voortdurende actieve deelname vereist van de onderzoekspopulatie vanwege het consistent moeten gebruiken van het net.

Dit onderzoek bood de mogelijkheid om meer te weten te komen over gedragspatronen die van invloed zijn op de effectiviteit van muskietennetten waardoor relevante informatie zou worden verkregen voor de ontwikkeling van nationale programma's. Het onderzoek werd gebaseerd op theorieën over menselijk gedrag en gedragsbeïnvloeding. Om malaria cultureel te definiëren werd gebruik gemaakt van etnografische studies die waren gericht op het vaststellen van de huidige strategieën en houdingen ten opzichte van preventie en behandeling van malaria. Structurele en omgevingsvariabelen die van invloed zijn op het blijven gebruiken van de muskietennetten, werden bepaald door toepassing van kwalitatieve en kwantitatieve methoden van onderzoek.

Volgens de bewoners in deze streek kan men malaria krijgen door verschillende oorzaken, waaronder muskietenbeten, kou pakken en natregenen. Hoewel men er zich van bewust was dat netten muskieten konden verhinderen te steken, geloofde men bijgevolg niet dat alleen al door het consistent gebruiken van muskietennetten malaria kon worden voorkomen. Met name het gebruiken van medicijnen tegen malaria werd beschouwd als de ideale manier van behandeling. 
Twee belangrijke aspecten met betrekking tot het gebruiken van muskietennetten in deze gemeenschap, waren de aanschaf van de netten en het systematisch gebruik ervan. Vóór de implementatie van het experiment met de muskietennetten had minder dan 5\% een net ter beschikking en het werd beschouwd als een luxe item, zowel vanwege de hoge kosten als de vermeende functie (voornamelijk het vermijden van het ongemak van een muskietenbeet).

Nadat in het experiment muskietennetten gratis waren verstrekt, bleek het gebruik over het algemeen hoog (ongeveer 76\%).

Echter, het gebruik van een muskietennet bleek meestal seizoens- en leeftijdsgebonden, enerzijds doordat men dacht dat door het gebruik van een net alleen de last ten gevolge van irritante muskietenbeten werd vermeden en men niet wist dat malaria hierdoor werd voorkomen en anderzijds doordat bij een onvoldoende aantal muskietennetten de voorkeur werd gegeven aan volwassenen in plaats van aan kinderen. Toen de gemeenschap eenmaal van voldoende muskietennetten was voorzien, kwamen andere factoren die van invloed waren op het gebruik van muskietennetten door kinderen naar voren, waaronder de tegenzin van verzorgers om dagelijks muskietennetten op te hangen in tijdelijke slaapplaatsen voor kinderen (zoals in keukens en woonkamers) en de neiging om de muskietennetten niet te gebruiken om de kans op beschadiging en slijtage te voorkomen en ze te bewaren voor toekomstig gebruik. Een quasi-experimenteel onderzoek onder kinderen van 6-10 jaar oud resulteerde in verbeteringen in de vaardigheden van kinderen om muskietennetten op te hangen voor zichzelf en hun jongere broers of zusjes, doch de verzorgers (meestal de moeders) bleken terughoudend te zijn in het toestaan aan de kinderen om hun vaardigheden toe te passen. Dit kon zowel toegeschreven worden aan de algemeen geldende sociale norm dat de moeder verantwoordelijk is voor de zorg voor de kinderen en men dus niet als een "slechte moeder" gezien wilde worden en aan de vrees van de verzorgers dat de netten per ongeluk vlam zouden kunnen vatten door nog aanwezig vuur in de keuken.

Onze studies wijzen er op dat, ondanks de voordelen die werden ervaren tijdens het experimenteel gebruik van muskietennetten, aan de aanschaf van netten en de daarbij nodige insecticide, door de huishoudens in deze arme plattelandsgemeenschap geen hoge prioriteit wordt gegeven, terwijl bij een onvoldoende aantal netten de voorkeur wordt gegeven aan het gebruik door volwassenen. Behalve het probleem dat men niet beschikt over voldoende middelen voor de aanschaf van netten is er het probleem van het niet correct gebruiken van netten. Het correct gebruiken van een muskietennet wordt bepaald door het besef van de noodzaak om een muskietennet te gebruiken als belangrijkste middel om malaria te voorkomen. Dit onderstreept het belang dat in programma's waarbij muskietennetten worden verstrekt, de public health functionarissen en de leiding zich ervan bewust moeten zijn dat de ziektepercepties in de gemeenschap en het daaruit voortvloeiend gedrag mogelijk niet overeenkomen met hun eigen verwachtingen. 
Om het gebruik van met insecticide behandelde muskietennetten te maximaliseren, is het op de eerste plaats van essentieel belang dat inzicht wordt verkregen in de sociale context van het gezondheidsprobleem en de factoren die relevant zijn voor het gebruiken van een voorgestelde interventie. Op basis van dit inzicht kan dan een voorlichtingsprogramma worden ontwikkeld. Een behoefteonderzoek dient in het bijzonder gericht te zijn op het verkrijgen van inzicht in de motieven en barrières van verzorgers en of men ook maar enig voordeel ziet in het gebruiken van muskietennetten voor kinderen. Bovendien, als men wil dat kinderen voordeel hebben van gebruik van muskietennetten, dan moet men er in programma's voor zorgen dat alle slaapplaatsen in het huishouden worden voorzien van een muskietennet, terwijl tegelijkertijd gewerkt moet worden aan het beter leren begrijpen waarom in het bijzonder de kinderen daarvan gebruik moeten maken. Tot slot, het ter beschikking hebben van een muskietennet betekent niet noodzakelijk dat er ook consistent gebruik van wordt gemaakt. Het tegelijkertijd geven van goed afgestemde voorlichting is vereist om de mensen voortdurend te herinneren aan het belang van het consistent en iedere nacht blijven gebruiken om de maximale effectiviteit van bednetten te realiseren. 


\section{APPENDICES}

Appendix 3.I Likely Use of traditional medicine to treat common childhood illnesses: Factor pattern, variance, and component correlation matrices

Descriptive Statistics

\begin{tabular}{lllll}
\hline Uses traditional therapy for list of illnesses & Mean & SD & Analysis N & Missing N \\
\hline & .79 & .409 & 1189 & 0 \\
Malaria & .39 & .489 & 1189 & 0 \\
Midhusi & .34 & .473 & 1189 & 0 \\
Liet (high fever) & .14 & .351 & 1189 & 0 \\
Delmaore (fever) & .19 & .391 & 1189 & 0 \\
Diep mar remo (bloody diarrhea) & .72 & .448 & 1189 & 0 \\
Diep (diarrhea) & .52 & .500 & 1189 & 0 \\
Stomach ache & .36 & .481 & 1189 & 0 \\
Orianyanja (yellow diarrhea) & .59 & .491 & 1189 & 0 \\
Fudha (illness stage before anemia) & .47 & .499 & 1189 & 0 \\
Ndulume (serious convulsions) & .86 & .348 & 1189 \\
Talarieya (mild convulsions) & & & 0 \\
\hline
\end{tabular}

Pattern Matrix ${ }^{a}$

\begin{tabular}{|c|c|c|c|}
\hline \multirow{2}{*}{$\begin{array}{l}\text { Uses traditional therapy } \\
\text { for list of illnesses }\end{array}$} & \multicolumn{3}{|c|}{ Component } \\
\hline & I & 2 & 3 \\
\hline Malaria & .821 & & \\
\hline Midhusi & .790 & & \\
\hline Liet (high fever) & .697 & & \\
\hline Delmaore (fever) & .631 & & \\
\hline Diep mar remo (bloody diarrhea) & .587 & & \\
\hline Diep (diarrhea) & .438 & .429 & \\
\hline Stomach ache & & .757 & \\
\hline Orianyanja (yellow diarrhea) & & .727 & \\
\hline Fudha (illness stage before anemia) & & .715 & \\
\hline Ndulume (serious convulsions & & & .831 \\
\hline Talarieya (mild convulsions) & & & .794 \\
\hline
\end{tabular}

Extraction Method: Principal Component Analysis.

Rotation Method: Oblimin with Kaiser Normalization.

a Rotation converged in 14 iterations. 
Total Variance Explained

\begin{tabular}{cc}
\hline \multirow{2}{*}{ Component } & \multicolumn{2}{c}{ Rotation sums of squared loadings a } \\
\cline { 2 - 2 } & Total \\
\hline & \\
2 & 31.71 \\
3 & 27.37 \\
& 18.64
\end{tabular}

Extraction Method: Principal Component Analysis

a When components are correlated. sums of squared loadings cannot be added to obtain a total variance.

Component Correlation Matrix

\begin{tabular}{crrr}
\hline Component & 1 & \multicolumn{1}{c}{2} & \multicolumn{1}{c}{3} \\
\hline 1 & 1.000 & .275 & .112 \\
2 & .275 & 1.000 & .175 \\
3 & .112 & .175 & 1.000 \\
\hline
\end{tabular}

Extraction Method: Principal Component Analysis.

Rotation Method: Oblimin with Kaiser Normalization. 
Appendix 3. I a Likely Use of traditional medicine to treat common childhood illnesses: Reliability scale for items clustering in factor $I$

\begin{tabular}{|c|c|c|c|c|}
\hline Item statistics & Mean & SD & Cases & \\
\hline Del maore (fever) & .3944 & .4889 & 1189.0 & \\
\hline Liet (high fever) & .3381 & .4733 & 1189.0 & \\
\hline Malaria & .1438 & .3511 & 1189.0 & \\
\hline Midhusi & .1884 & .3912 & 1189.0 & \\
\hline Diarrhea & .5181 & .4999 & 1189.0 & \\
\hline Bloody diarrhea & .3633 & .4812 & 1189.0 & \\
\hline \multirow[t]{2}{*}{ Statistics for SCALE } & Mean & Variance & SD & $\mathrm{N}$ of variables \\
\hline & 1.9462 & 3.6857 & 1.9198 & 6 \\
\hline Item-total statistics & $\begin{array}{l}\text { Scale mean if } \\
\text { item deleted }\end{array}$ & $\begin{array}{c}\text { Scale variance if item } \\
\text { deleted }\end{array}$ & $\begin{array}{c}\text { Corrected item-total } \\
\text { correlation }\end{array}$ & $\begin{array}{l}\text { Alpha if } \\
\text { item deleted }\end{array}$ \\
\hline Del maore & 1.5517 & 2.4900 & .6200 & .7572 \\
\hline Liet & 1.6081 & 2.5129 & .6323 & .7542 \\
\hline Malaria & 1.8024 & 2.9062 & .5483 & .7780 \\
\hline Midhusi & 1.7578 & 2.8723 & .4980 & .7854 \\
\hline Diarrhea & 1.4281 & 2.5868 & .5280 & .7809 \\
\hline Bloody diarrhea & 1.5828 & 2.5952 & .5541 & .7735 \\
\hline \multirow[t]{2}{*}{ Reliability coefficients } & $\mathrm{N}$ of cases & $\mathrm{N}$ of items & Alpha & \\
\hline & $=1189.0$ & $=6$ & $=.8026$ & \\
\hline
\end{tabular}


Appendix 3.Ib Likely Use of traditional medicine to treat common childhood illnesses: Reliability scale for items clustering in factor 2

\begin{tabular}{|c|c|c|c|c|}
\hline Item statistics & Mean & SD & Cases & \\
\hline Stomach ache & .7872 & .4094 & 1189.0 & \\
\hline Fudha & .7233 & .4476 & 1189.0 & \\
\hline Diarrhea & .5181 & .4999 & 1189.0 & \\
\hline Orianyanja & .8587 & .3485 & 1189.0 & \\
\hline \multirow[t]{2}{*}{ Statistics for SCALE } & Mean & Variance & SD & $\mathrm{N}$ of variables \\
\hline & 2.8873 & 1.5546 & 1.2468 & 4 \\
\hline Item-total statistics & $\begin{array}{l}\text { Scale mean if } \\
\text { item deleted }\end{array}$ & $\begin{array}{c}\text { Scale variance if item } \\
\text { deleted }\end{array}$ & $\begin{array}{c}\text { Corrected item-total } \\
\text { correlation }\end{array}$ & $\begin{array}{c}\text { Alpha if } \\
\text { item deleted }\end{array}$ \\
\hline Stomach-ache & 2.1001 & .9622 & .5288 & .6089 \\
\hline Fudha & 2.1640 & .9184 & .5082 & .6197 \\
\hline Diarrhea & 2.3692 & .9099 & $.4|4|$ & .6932 \\
\hline Orianyanja & 2.0286 & 1.0581 & .5232 & .6241 \\
\hline \multirow[t]{2}{*}{ Reliability coefficients } & $\mathrm{N}$ of cases & $\mathrm{N}$ of items & Alpha & \\
\hline & $=1189.0$ & $=4$ & $=.6993$ & \\
\hline
\end{tabular}

Appendix 3.Ic Likely Uses of traditional medicine to treat common childhood illnesses: Reliability scale for items clustering in factor 3

\begin{tabular}{|c|c|c|c|c|}
\hline Item statistics & Mean & SD & Cases & \\
\hline Talarieya (mild convulsions) & .5938 & .4913 & 1189.0 & \\
\hline Ndulume (serious convulsions) & .4727 & .4995 & 1189.0 & \\
\hline \multirow[t]{2}{*}{ Statistics for SCALE } & Mean & Variance & SD & $\mathrm{N}$ of variables \\
\hline & 1.0664 & .8247 & .9081 & 2 \\
\hline Item-total statistics & $\begin{array}{l}\text { Scale mean if } \\
\text { item deleted }\end{array}$ & $\begin{array}{c}\text { Scale variance if item } \\
\text { deleted }\end{array}$ & $\begin{array}{c}\text { Corrected item-total } \\
\text { correlation }\end{array}$ & $\begin{array}{c}\text { Alpha if } \\
\text { item deleted }\end{array}$ \\
\hline Talarieya & .4727 & .2495 & .6802 & . \\
\hline Ndulume & .5938 & .2414 & .6802 & . \\
\hline \multirow[t]{2}{*}{ Reliability coefficients } & $\mathrm{N}$ of cases & $\mathrm{N}$ of items & Alpha & \\
\hline & $=1189.0$ & $=2$ & $=.8096$ & \\
\hline
\end{tabular}


Appendix 3.2 Likely Use of medicine purchased over the counter to treat common childhood illnesses: Factor pattern, variance, and component correlation matrices

Descriptive Statistics

\begin{tabular}{|c|c|c|c|c|}
\hline Uses medicines purchased from shops for list of illness & Mean & SD. & Analysis N & Missing $\mathrm{N}$ \\
\hline Ichkach (stomach ache) & .78 & .414 & 1189 & 0 \\
\hline Delmaore (fever) & .91 & .291 & 1189 & 0 \\
\hline Liet (high fever) & .88 & .327 & 1189 & 0 \\
\hline Malaria & .89 & .310 & 1189 & 0 \\
\hline Midhusi & .78 & .416 & 1189 & 0 \\
\hline Fudha (stage before anemia) & .29 & .455 & 1189 & 0 \\
\hline Diep (diarrhea) & .77 & .421 & 1189 & 0 \\
\hline Diep mar remo (bloody diarrhea) & .65 & .478 & 1189 & 0 \\
\hline Talarieya (mild convulsions) & .14 & .351 & 1189 & 0 \\
\hline Ndulume (strong convulsions) & .09 & .284 & 1189 & 0 \\
\hline Orianyanja (yellow diarrhea) & .24 & .428 & 1189 & 0 \\
\hline
\end{tabular}

Pattern Matrix ${ }^{a}$

\begin{tabular}{lll}
\hline & \multicolumn{2}{c}{ Component } \\
\cline { 2 - 2 } Uses medicines purchased from shops & & 2 \\
for list of illness & & \\
\hline Ichkach (stomach ache) & .884 \\
Delmaore (fever) & .878 & \\
Liet (high fever) & .866 & \\
Malaria & .739 & \\
Midhusi & .727 & .646 \\
Fudha (stage before anemia) & .607 & .829 \\
Diep (diarrhea) & & .802 \\
Diep mar remo (bloody diarrhea) & & .612 \\
Talarieya (mild convulsions) & .609 \\
Ndulume (strong convulsions) & &. \\
Orianyanja (yellow diarrhea) &
\end{tabular}

Extraction Method: Principal Component Analysis.

Rotation Method: Oblimin with Kaiser Normalization.

a Rotation converged in 3 iterations. 
Total Variance Explained

\begin{tabular}{cc}
\hline \multirow{2}{*}{ Component } & \multicolumn{2}{c}{ Rotation sums of squared loadings a } \\
\cline { 2 - 2 } & Total \\
\hline 1 & 43.19 \\
2 & 23.97 \\
\hline
\end{tabular}

Extraction Method: Principal Component Analysis

a When components are correlated sums of squared loadings cannot be added to obtain a total variance.

\section{Component Correlation Matrix}

\begin{tabular}{crr}
\hline Component & 1 & \multicolumn{1}{c}{2} \\
\hline 1 & 1.000 & .270 \\
2 & .270 & 1.000 \\
\hline
\end{tabular}

Extraction Method: Principal Component Analysis.

Rotation Method: Oblimin with Kaiser Normalization. 
Appendix 3.2a Likely Uses of medicine purchased over the counter to treat common childhood illnesses: Reliability scale for items clustering in factor I

\begin{tabular}{|c|c|c|c|c|}
\hline Item statistics & Mean & SD & Cases & \\
\hline Stomach ache & .7813 & .4135 & 1189.0 & \\
\hline Del maore (fever) & .9066 & .2911 & 1189.0 & \\
\hline Liet (high fever) & .8780 & .3274 & 1189.0 & \\
\hline Malaria & .8923 & .3101 & 1189.0 & \\
\hline Midhusi & .7780 & .4158 & 1189.0 & \\
\hline Diarrhea & .7696 & .4213 & 1189.0 & \\
\hline Bloody diarrhea & .6476 & .4779 & 1189.0 & \\
\hline \multirow[t]{2}{*}{ Statistics for SCALE } & Mean & Variance & SD & $\mathrm{N}$ of variables \\
\hline & 5.6535 & 4.0583 & 2.0145 & 7 \\
\hline Item-total statistics & $\begin{array}{l}\text { Scale mean if } \\
\text { item deleted }\end{array}$ & $\begin{array}{c}\text { Scale variance if item } \\
\text { deleted }\end{array}$ & $\begin{array}{c}\text { Corrected item-total } \\
\text { correlation }\end{array}$ & $\begin{array}{c}\text { Alpha if } \\
\text { item deleted }\end{array}$ \\
\hline Stomach ache & 4.8722 & 3.0712 & .5631 & .8613 \\
\hline Del maore & 4.7468 & 3.1993 & .7436 & .8425 \\
\hline Liet & 4.7754 & 3.1103 & .7282 & .8409 \\
\hline Malaria & 4.7611 & 3.1365 & .7517 & .8397 \\
\hline Midhusi & 4.8755 & 2.9912 & .6217 & .8530 \\
\hline Diarrhea & 4.8839 & 2.9158 & .6707 & .8459 \\
\hline Bloody diarrhea & 5.0059 & 2.9048 & .5678 & .8656 \\
\hline \multirow[t]{2}{*}{ Reliability coefficients } & $\mathrm{N}$ of cases & $\mathrm{N}$ of items & Alpha & \\
\hline & $=1189.0$ & $=7$ & $=.8683$ & \\
\hline
\end{tabular}


Appendix 3.2b Likely Uses of medicine purchased over the counter to treat common childhood illnesses: Reliability scale for items clustering in factor 2

\begin{tabular}{|c|c|c|c|c|}
\hline Item statistics & Mean & SD & Cases & \\
\hline Fudha & .2918 & .4548 & 1189.0 & \\
\hline Talarieya & .1438 & .3511 & 1189.0 & \\
\hline Ndulume & .0883 & .2839 & 1189.0 & \\
\hline Orianyanja & .2414 & .4281 & 1189.0 & \\
\hline \multirow[t]{2}{*}{ Statistics for SCALE } & Mean & Variance & SD & $\mathrm{N}$ of variables \\
\hline & .7653 & 1.1882 & 1.0900 & 4 \\
\hline Item-total statistics & $\begin{array}{l}\text { Scale mean if } \\
\text { item deleted }\end{array}$ & $\begin{array}{c}\text { Scale variance if item } \\
\text { deleted }\end{array}$ & $\begin{array}{c}\text { Corrected item-total } \\
\text { correlation }\end{array}$ & $\begin{array}{c}\text { Alpha if } \\
\text { item deleted }\end{array}$ \\
\hline Fudha & .4735 & .6704 & .4175 & .6339 \\
\hline Talarieya & .6215 & .7354 & .5472 & .5400 \\
\hline Ndulume & .6770 & .8502 & .4918 & .5942 \\
\hline Orianyanja & .5240 & .7143 & .4016 & .6376 \\
\hline Reliability coefficients & $\begin{aligned} & \mathrm{N} \text { of cases } \\
= & 1189.0\end{aligned}$ & $\begin{array}{l}N \text { of items } \\
=4\end{array}$ & $\begin{array}{c}\text { Alpha } \\
=.6668\end{array}$ & \\
\hline
\end{tabular}


Appendix 8.I Pre-elicitation motivational interview staging guide** (author acknowledges resourcefulness of Bobby Person)

How often has your child slept under

ITN since the beginning of the year?

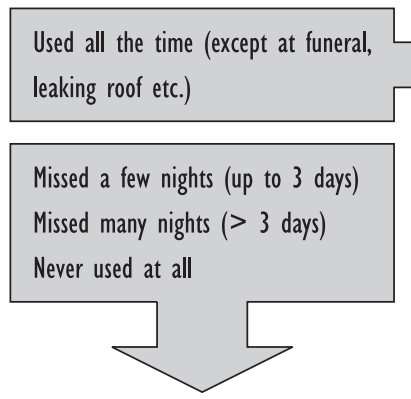

What are your intentions for having child sleep under ITNs more often in the next I-3 months?

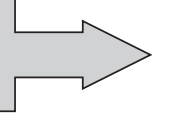

How long has your child been sleeping under ITN all of the time?

\begin{tabular}{|l|l}
\hline $\begin{array}{l}\text { Not thinking at about it at all } \\
\text { May consider it, but cannot tell when }\end{array}$ & $\longrightarrow$ Pre-contemplation \\
May consider it in I-3 months time & $\longrightarrow$ Pre-contemplation \\
\hline
\end{tabular}
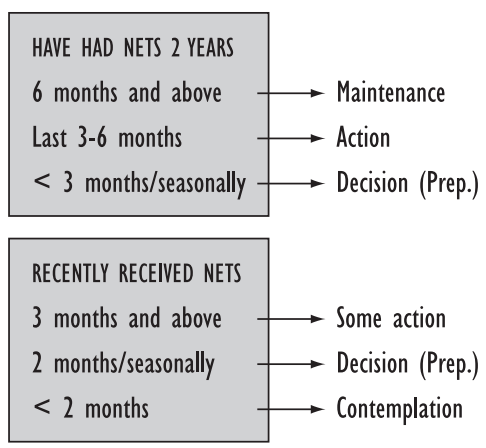

Pre-contemplation

Children have never used bednets or used for sometime and stopped. I) These caregivers are not even thinking about children using bednets, or 2) have no intention of starting to use bednets in the next one month from the day of interviewing.

\section{Contemplation}

Children use nets once in a while, e.g.I) Children use bednets for a few days and stop, then use again for a few days and stop, 2) Children sleep under bednets only if someone remembers to hang bednets, 3) Children sleep under nets only when someone is not too tired to hang nets, 4) Children sleep under bednets only when someone is reminded to hang their net.

\section{Ready-for-Action}

Child bednet use appears consistent, but only under specific circumstances, e.g. I) when it is rainy/cold, 2) when people think mosquitoes are many. In the absence of these conditions they do not use bednets, i.e. I) when they feel it is too hot, 2) when they feel there are no mosquitoes.

\section{Action}

These people have been ensuring their children sleep under ITNs every night for the last 3-6 months regardless of whether or not it is hot, or whether or not they see mosquitoes. The only time children do not use bednets is when they travel elsewhere, when a funeral interrupts sleeping arrangements, or when their house is under repair.

\section{Maintenance}

These people have the same characteristics of ITN use as those in ACTION, but they have used bednets for an extended (longer) period without fail (6 months and above). ITN use has become part and parcel of their daily bedtime arrangements. 


\section{ACRONYMS AND ABBREVIATIONS}

\section{General}

$\begin{array}{ll}\text { CDC } & - \text { Centers for Disease Control and Prevention } \\ \text { DDT } & - \text { dichlorodiphenyltrichorethane } \\ \text { GoK } & - \text { Government of Kenya } \\ \text { ITN(s) } & \text { - Insecticide-treated bednet(s) } \\ \text { KEMRI } & - \text { Kenya Medical Research Institute } \\ \text { KES } & - \text { Kenya Shillings } \\ \mathrm{km}^{2} & - \text { square kilometres } \\ \text { KMO } & - \text { Kaiser-Meyer-Olkin } \\ \text { MI } & - \text { Motivational Interviews } \\ \text { PSI } & - \text { Population Services International } \\ \text { SD } & - \text { Standard Deviation } \\ \text { US\$ } & - \text { United States of America dollar } \\ \text { WHO/RBM } & - \text { World Health Organization/Roll Back Malaria }\end{array}$

\section{Figure I. I}

$\begin{array}{ll}\text { GPS/GIS } & - \text { Global Positioning System } \\ \text { Gov. } & - \text { Government } \\ \text { V. Registration } & - \text { Vital registration }\end{array}$

\section{In Tables}
NS
- not significant

\section{Appendix 8.I}

Prep. - Preparation or Ready-for-Action (in stages of change) 


\section{ACKNOWLEDGEMENTS}

I am grateful to the bednet project staff for their dedication to the research, especially the field supervisors for successfully completing the fieldwork, the research assistants to the social science section for ensuring consistency of completed research tools, and to the data staff for data handling and cleaning. I thank the Asembo community for their time and cooperation. I appreciate the immense support of office and scientific staff both at the Kenya Field station, and at Maastricht University in ensuring smooth transitions between fieldwork, data analysis, and writing up.

I am especially indebted to Marja Slangen, Ria Westenberg, Josee Trottement, and Helga Happaerts for overseeing logistical arrangements in the Netherlands, to Marga Sunnen for homely accommodation during my visits to the Netherlands, to Prof. HW van den Borne, Dr. Penelope Phillips-Howard, Dr. Sjaak van der Geest, and Dr. Patrick Kachur for their unwavering professional and personal support during data analysis and writing up, to Bobbie Person for her resourcefulness in conceptualising theory, to Mieke van den Borne-Hoeks for translating the summary into Dutch, and to my two paranimfen, Janneke Harting, and Leon Kolenburg for wholeheartedly facilitating the final processes from submitting the thesis through to the defence. I was privileged to have the friendly support and encouragement of Prof. dr. Nanne de Vries, Dr. William Hawley, Dr. Bernard Nahlen, Dr. Feiko ter Kuile, Dr. Halima Mwenesi, George B. Olang, Dr. Lawrence Slutsker, and Dr. John Vulule.

I thank the management at the Kenya Medical Research Institute for the opportunity to enhance my career, and for study leave as appropriate, and to the management at Maastricht University for providing an atmosphere conducive for the attainment of training/career goals. Last but not least, I appreciate the support and encouragement of family, friends, and colleagues who, together with the Unseen-Yet-Ever-so-Faithful-Companion walked me through to yet another life phase - let's walk on. 


\section{RESUME}

Jane A. Alaii was born in Kisumu, Kenya, and grew up in Nairobi, where she attended school. She pursued a Bachelors' degree majoring in Sociology at Kenyatta University, Nairobi, graduating in 1991, after which she worked as a Research Assistant at the Kenya Medical Research Institute. In 1994 she was deployed to the institutes' Centre for Public Health Research, Nairobi, as a research scientist, where she provided social science support to community based research projects in Schistosimiasis control, and Bacterial Diarrhea control in coastal Kenya, among others. Since 1996 she has worked as chief social scientist on a recently concluded large-scale community-based research project on insecticide-treated bednets (ITNs) undertaken at the institutes' Centre for Vector Biology and Control Research, Kisumu, in collaboration with the Centers for Disease Control and Prevention, CDC, Atlanta, Georgia. During this time she showed great diligence, pursuing academic studies while taking her responsibilities on the project, setting up field activities, and supervising graduate students. In 1997 she earned, by distance learning, a Master of Science degree in Public Policy and Development from South Bank University, London. In 1999 she obtained a WOTRO grant to pursue a doctorate degree in Health Behaviour and Health Promotion research linked with Maastricht University, the Netherlands. Jane Alaii is a constant resource person to national and regional malaria task forces, collaborating with non-governmental organizations and government officials to maximize linkages between research and policy. Her research interests include studies into social, behavioral and cultural factors affecting disease etiology, and design of health education and promotion programmes to prevent, detect, and reduce the severity of disease. The utility of theories of behaviour change in developing, implementing, and sustaining disease control interventions, particularly in the tropics, is of particular interest. 